\title{
AVOIDED WATER COST OF ELECTRICITY GENERATION BY SOLAR PV AND WIND TECHNOLOGIES IN SOUTHERN CALIFORNIA
}

\author{
A Thesis \\ Presented to \\ The Faculty of California Polytechnic State University, \\ San Luis Obispo
}

\author{
In Partial Fulfillment \\ of the Requirements for the Degree \\ Master of Science in \\ Civil and Environmental Engineering
}

\author{
By \\ Matthew Cohen
}

August 2014 
(C) 2014

Matthew Cohen

ALL RIGHTS RESERVED 
TITLE:

Avoided Water Cost of Electricity Generation by Solar PV and Wind Technologies in Southern California

AUTHOR: $\quad$ Matthew Cohen

DATE SUBMITTED: August, 2014

COMMITTEE CHAIR: Yarrow Nelson, PhD

Professor of Environmental Engineering

COMMITTEE MEMBER: Steve Hamilton, PhD

Area Chair Professor of Economics

COMMITTEE MEMBER: Andrew Kean, PhD

Professor of Mechanical Engineering

COMMITTEE MEMBER: Samuel A. Vigil, PhD

Professor of Environmental Engineering 


\begin{abstract}
Avoided Water Cost of Electricity Generation by Solar PV and Wind Technologies in Southern California

Matthew Cohen
\end{abstract}

The objective of this thesis is to provide a foundation for evaluating the water costs associated with electricity production to calculate the avoided water cost of energy for solar PV and wind technologies relative to coal, natural gas, nuclear, geothermal, concentrated solar thermal, and biomass. Water consumption is estimated for energy production (fuel extraction and preparation) and electricity generation (power plant operation) using the best available information from published articles. The quantity of water consumed for electricity production is monetized for a Southern California case study based on the water rates of Metropolitan Water District of Southern California (MET), which is the largest wholesale supplier of surface water in the United States. Water withdrawals are addressed but not included in the monetization of water consumption. Case studies of specific power plant's water costs are used for comparison and demonstrate variation in water costs due to variations in water consumption.

Water costs are estimated in terms of water cost $(\$)$ per unit energy generated (MWh). Since solar PV and wind energy are shown to have negligible water consumption relative to the other technologies, the water costs for each of the other electrical generation methods are equivalent to the water savings potential of solar PV and wind generated electricity. Compared to other evaluated electricity sources that could provide electricity to Southern California, solar PV and wind energy can save water worth $\$ 0.76 / \mathrm{MWh}$ for natural gas combined-cycle plants, $\$ 0.94 / \mathrm{MWh}$ for geothermal power 
plants, $\$ 1.01 / \mathrm{MWh}$ for biomass power plants, between $\$ 1.14$ and $\$ 1.82$ per $\mathrm{MWh}$ for concentrated solar thermal plants, $\$ 1.43 / \mathrm{MWh}$ for nuclear power plants, and $\$ 1.49 / \mathrm{MWh}$ for coal power plants. Results indicate that there are three processes that use substantial amounts of water: fuel extraction (for coal, natural gas, and nuclear), thermoelectric cooling of power plants and emissions controls such as carbon capture and sequestration. Carbon capture and sequestration are estimated to almost double the water consumption costs of coal and natural gas power plants. Of the evaluated technologies, only solar PV and wind do not require any of those three steps. Solar PV and wind energy can thus save the greatest value of water when displacing power plants that utilize (or may someday be required to utilize) all three of the major culprits of water consumption. Even the use of one of these processes (particularly thermoelectric cooling) results in substantial water consumption.

Total water costs for each technology were normalized to the total expected electrical output of a typical capacity natural gas combined-cycle power plant to demonstrate the economies of scale of power production. Over a forty year lifespan of a typical natural gas power plant, total water consumption would result in \$67 million worth of water (southern CA wholesale prices). To generate the same amount of electricity the total value of water consumption is estimated to be $\$ 83$ million for geothermal plants, $\$ 89$ million for biomass plants, $\$ 100$ million to $\$ 160$ million for concentrated solar thermal plants, \$126 million for nuclear plants, and \$131 million for coal power plants. The use of carbon capture and sequestration is expected to nearly double these total water costs. 
Compliance with environmental regulations can cause expenses much greater than water consumption. For example, mitigation costs for impingement and entrainment (a consequence of cooling water withdrawals) as well as the cost to convert to closedloop cooling for environmental compliance can be considered costs associated with water usage. This is demonstrated by a case study about the Los Angeles Department of Water and Power regarding the elimination of once through cooling. The conversion to closedloop cooling for units 5 and 6 of the Haynes natural gas power plant is expected to cost $\$ 782$ million, resulting in an estimated unit cost of $\$ 10.66 / \mathrm{MWh}$.

Finally, the economic benefits of the California Renewables Portfolio Standard are calculated with respect to water consumption. By holding hydroelectricity, geothermal, biomass and CST production constant and utilizing solar PV and wind to meet the 33\% renewables target by 2020 , a water value of $\$ 28.5$ million/year can be conserved relative to meeting rising electricity demand with only natural gas combinedcycle generation. MET water rates increased 70\% from 2008 to 2014. If water rates increase at the same rate over the next six years, the water savings of the Renewable Portfolio Standard would be $70 \%$ higher in 2020 dollars, equating to water savings of \$48.4 million per year. 


\section{ACKNOWLEDGMENTS}

I would like to thank my thesis advisor, Dr. Yarrow Nelson for all his support throughout the years. The many classes I have taken from him are the foundation of my environmental engineering knowledge. Our numerous office hour discussions have continuously inspired me to believe in myself and accomplish extensive projects that at times seem out of reach. I would also like to thank the rest of my thesis committee, Dr. Stephen Hamilton for his invaluable economic perspective and understanding of water and electricity markets, Dr. Sam Vigil for his almost obsessive passion for technology and his longstanding desire to teach and inspire the younger generation for which it will serve, and Dr. Andrew Kean for his interest in renewable energy technologies and assistance in my literature review.

I would also like to thank my General Engineering undergraduate advisor, Dr. Robert Crockett, for his inspiration and advice throughout the years. Without him, I would not have been able to obtain such expansive engineering knowledge, much of which came together in this report.

This study would not have been possible without the funding and support of SolarCity, an altruistic company that will hopefully continue its righteous path of environmental benefits and reduction of electricity rates for its customers for many many years to come. A special thanks to John Stanton whose work ethic, poise, and accomplishments have inspired me to shape the world and continue my pursuit of establishing a sustainable future for energy and water consumption. I'd also like to thank Sanjay Ranchod and Andy Schwartz for teaching me about the political obstacles that seek to threaten the sustainable future we wish to facilitate. Additional thanks go to Marc Kolb and Nancy Pfund for their interest in the thesis and willingness to talk through the complex issue with me.

I must also thank the researchers that paved the way for me. Many people have spent countless hours studying the energy water nexus. A few of them took the time to indulge my curiosity and provide me with their reports and information that contributed to this thesis. Thank you Dr. Raimondi of UC Santa Cruz and Gregg Morris of the Green Power Institute, amongst others.

Finally, a big thank you to my parents whose interest in my life is a constant motivation. Your love, support, and concern have been invaluable. 


\section{TABLE OF CONTENTS}

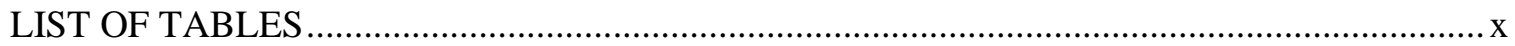

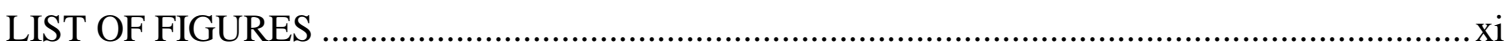

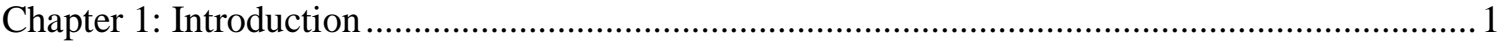

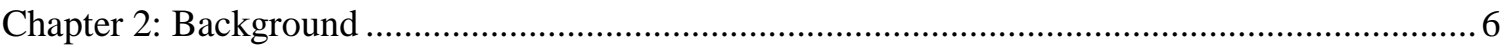

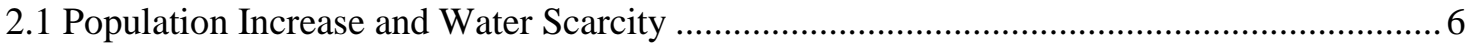

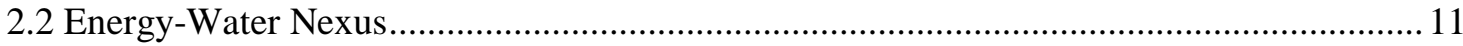

2.2.1 Water Withdrawals vs. Water Consumption................................................................. 13

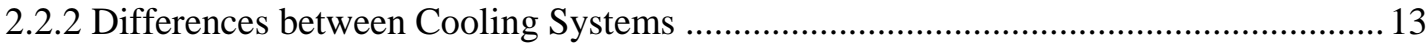

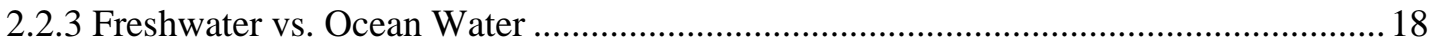

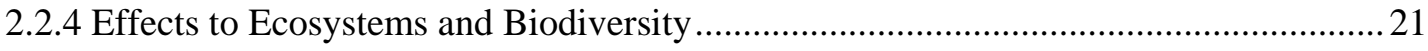

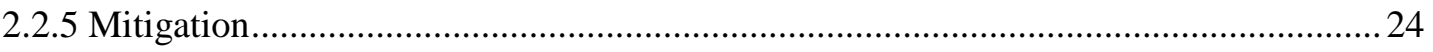

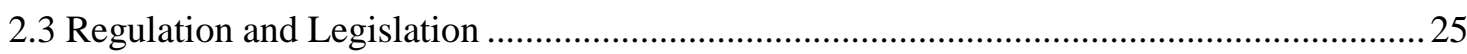

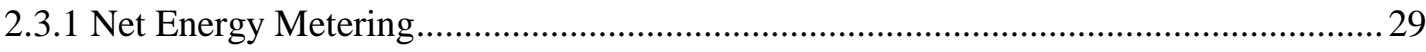

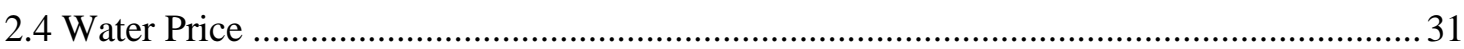

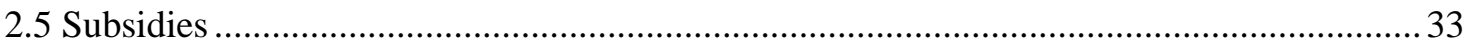

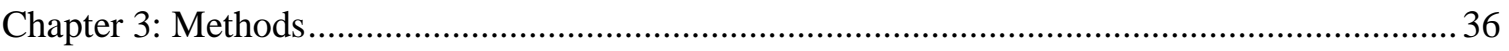

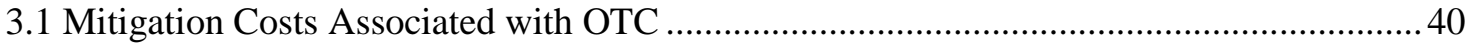

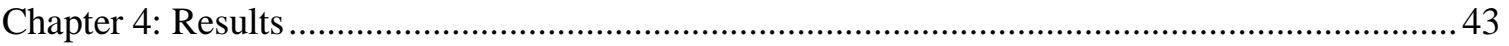

4.1 Consumptive Water Use for Energy Production and Electricity Generation.......................43

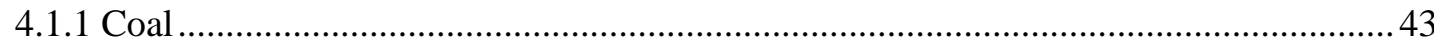

4.1.1.1 Water Consumption of Energy Production for Coal............................................ 44

4.1.1.2 Operational Water Cost for Electricity Generation from Coal ..............................47

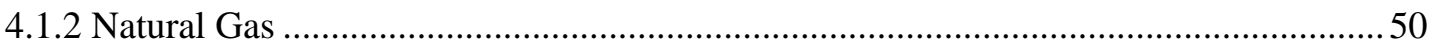

4.1.2.1 Water Consumption of Energy Production for Natural Gas .................................50

4.1.2.2 Operational Water Cost for Electricity Generation from Natural Gas ....................52

4.1.2.3 Natural Gas Case Study: Blythe Energy Project, Phase II ......................................54

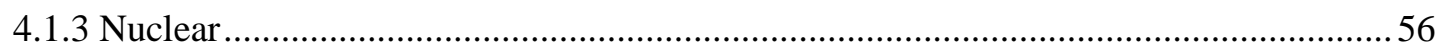

4.1.3.1 Water Consumption of Energy Production for Nuclear.........................................56

4.1.3.2 Operational Water Cost for Electricity Generation from Nuclear ..........................59

4.1.3.3 Nuclear Case Study: Diablo Canyon Power Plant .................................................. 60 


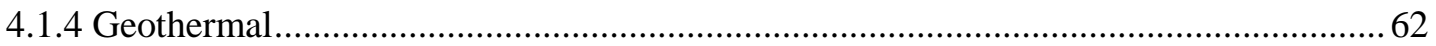

4.1.4.1 Operational Water Cost for Electricity Generation from Geothermal ....................63

4.1.4.2 Geothermal Case Study: Calpine Corporation ..................................................... 65

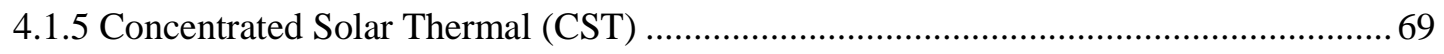

4.1.5.1 Operational Water Cost for Electricity Generation from CST .............................. 70

4.1.5.2 CST Case Study: Abengoa Movaje Solar Energy Project .................................... 71

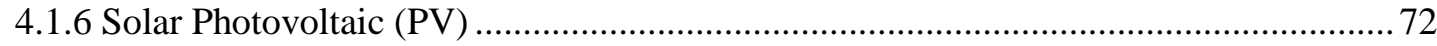

4.1.6.1 Operational Water Cost for Electricity Generation from Solar PV ...................... 72

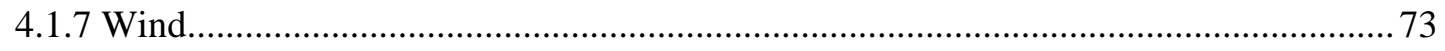

4.1.7.1 Operational Water Consumption for Electricity Generation from Wind ............... 74

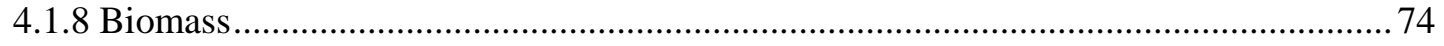

4.1.8.1 Water Consumption of Energy Production for Biomass....................................... 76

4.1.8.2 Operational Water Cost for Electricity Generation from Biomass ........................ 77

4.2 Water Costs Associated with Environmental Compliance ............................................... 78

4.2.1 Environmental Compliance Case Study: LADWP ……............................................. 79

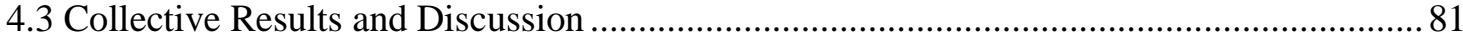

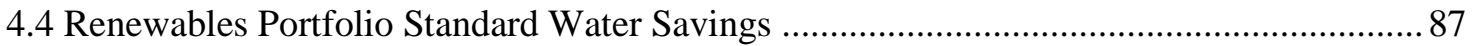

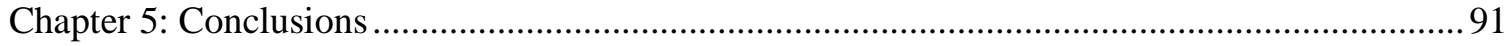

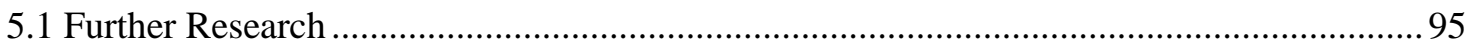

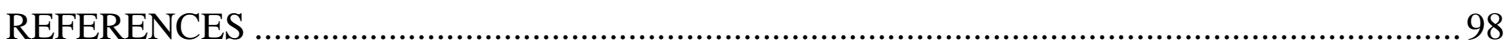




\section{LIST OF TABLES}

Table 4.1 Consumptive Water Use for Coal Fuel Cycle............................................................45

Table 4.2 Coal Operational Water Withdrawals and Consumption by Coal Type ........................ 48

Table 4.3 Coal Operational Water Cost by Coal Type ............................................................. 48

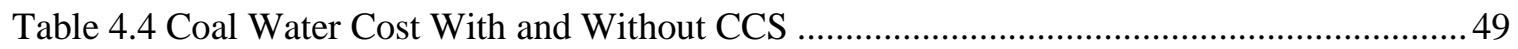

Table 4.5 Consumptive Water Use for Conventional Natural Gas Fuel Cycle.............................51

Table 4.6 Combined Cycle Water Withdrawals and Consumption by Cooling Method ................53

Table 4.7 Natural Gas Cooling Water Cost by Cooling Type ...................................................53

Table 4.8 Natural Gas Water Withdrawals and Consumption with and without CCS ..................54

Table 4.9 Natural Gas Combined Cycle Water Cost with and without CCS ..................................54

Table 4.10 Consumptive Water Use for Nuclear Fuel Cycle.....................................................57

Table 4.11 Nuclear Operational Water Withdrawal and Consumption by Cooling Method.........59

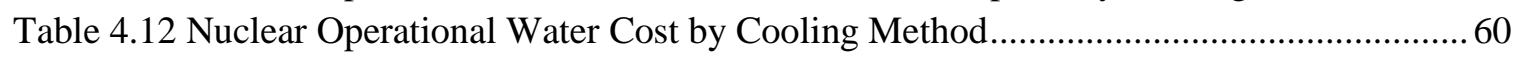

Table 4.13 Lifecycle Water Consumption for Geothermal Scenarios ............................................ 64

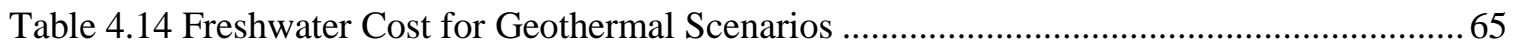

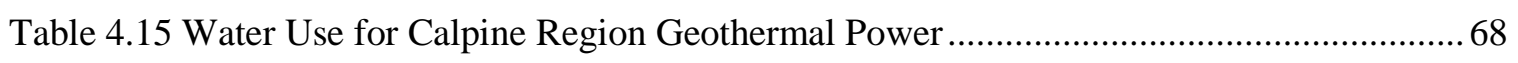

Table 4.16 Water Consumption Cost for CST Technologies ...................................................... 71

Table 4.17 Water Cost for the Abengoa Mojave Solar Energy Project ........................................ 71

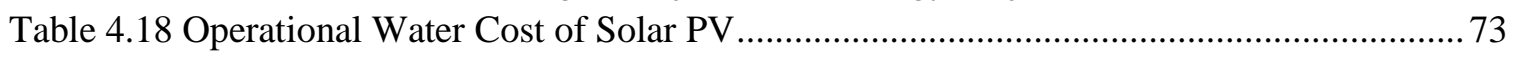

Table 4.19 Operational Water Cost of Wind Energy ................................................................... 74

Table 4.20 Operational Water Withdrawals and Consumption for Biomass Power Plants ........... 77

Table 4.21 Operational Water Cost for Biomass Power Plants ................................................... 78

Table 4.22 Freshwater Cost per MWh by Electricity Generation Type........................................ 82

Table 4.23 Freshwater Costs Normalized to NGCC Plant Electricity Production.......................... 85

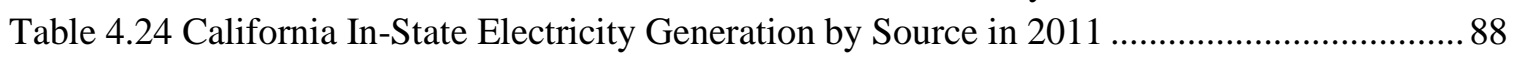

Table 4.25 Total Water Costs for Electricity Production for the Year of 2020 Using the

Non-RPS and RPS Scenario 89 


\section{LIST OF FIGURES}

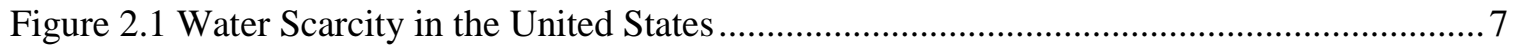

Figure 2.2 Historical Water Supply and Use / Projected Future Supply and Demand of the

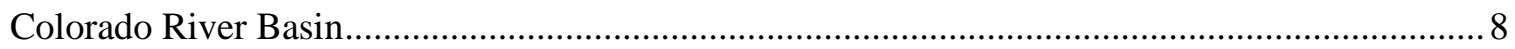

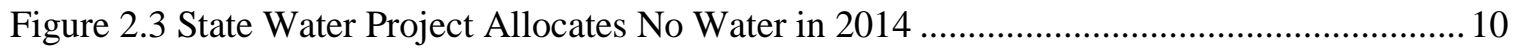

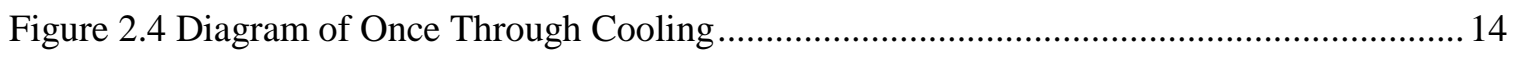

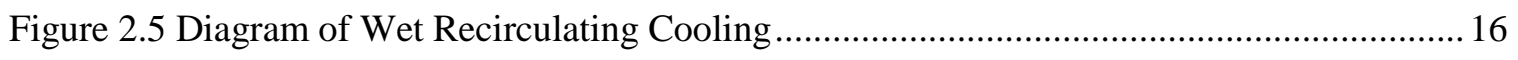

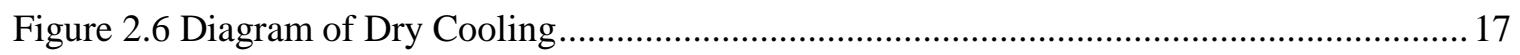

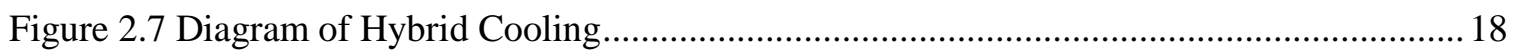

Figure 2.8 Fresh Water versus Saline Water by Cooling Type in the U.S.................................. 19

Figure 2.9 Water Source for Power Plant Withdrawals by U.S. Region ....................................... 20

Figure 2.10 Water Source for Power Plant Consumption by U.S. Region ................................. 21

Figure 2.11 California Nuclear Subsidies vs Solar Subsidies in First Five Years ........................ 34

Figure 2.12 Cumulative Nuclear Subsidies vs Solar Subsidies ................................................. 35

Figure 4.1 Transportation Rates for Coal Delivery Basins ...................................................... 46

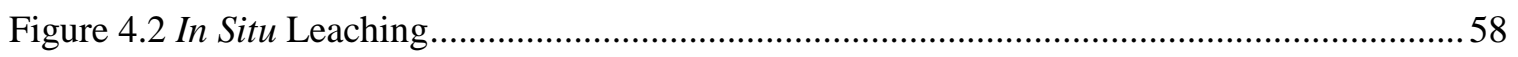

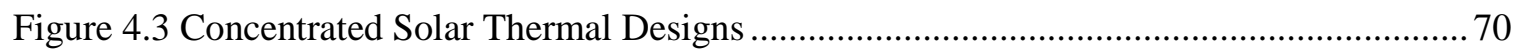

Figure 4.4 Total Potential Biomass Map of Continental United States ....................................... 75

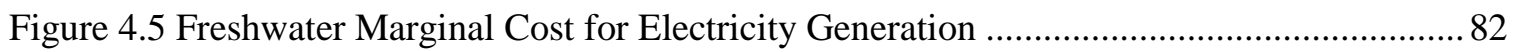




\section{Chapter 1: Introduction}

The energy crisis of the 1970s sparked the first wave of interest in renewable energy technologies in the United States and this interest has been greatly renewed by the more recent climate change concern. Now an emphasis is placed on greenhouse gas emissions as a measure of sustainability. With climate change looming, it is important for energy policy decisions to consider sustainability with respect to atmospheric emissions. However, other environmental considerations such as water scarcity may also be important in guiding decisions on the adoption of renewable energy sources. Energy technologies such as solar photovoltaic (PV) and wind are particularly promising because they have the potential to be sustainable both in terms of atmospheric greenhouse gas emissions and water consumption.

In January, 2014 California Governor Edmund G. Brown Jr. declared a statewide drought emergency, elucidating the severity of the situation by asking all Californians to reduce their water consumption by $20 \%$. Now seven months later, it seems that Californians did not heed the message. A survey released in July 2014 showed that the state used 1\% more water in May than the previous three-year average for the same month (Pickert, 2014). California, which is home to an estimated 38.3 million people (GAO, 2009) and is the nation's top farming state, only averages 21.4 inches of rain annually (GAO, 2009), yet supplies over half the U.S. fruits, nuts, vegetables, and over $90 \%$ of the nation's avocados, broccoli, and processing tomatoes (Reuters, 2009). According to studies by the University of Davis, over the course of the $21^{\text {st }}$ century, 
climate models show California's water supply dropping 24 - 30\% (Reuters, 2009). Beyond the scope of California, water conservation is an important environmental consideration that deserves increasing attention nationally and worldwide.

This thesis addresses the water consumption aspect of energy sustainability by monetizing the water consumption savings that can be generated by the implementation of solar PV and wind technologies. Other water-related costs, such as mitigation costs to compensate for affected aquatic species afflicted by once through cooling (OTC) and water pollution from fuel extraction are also considered in this thesis.

This study takes an in-depth look at the water cost for electricity production in Southern California for two main reasons. Southern California is one of the most impacted areas by drought in the U.S. and it tends to be on the forefront of innovative policy adoption. California is a trendsetter; policies adopted by California have a way of trickling down to other states. The California Renewables Portfolio Standard (RPS) is evaluated with respect to water consumption by comparing two energy mix scenarios developed for 2020, the year in which $33 \%$ of total energy procurement is required to come from eligible renewable energy resources. Case studies explore other regions when Southern California does not offer the best frame of reference.

Water consumption is monetized for the following methods of power production: coal, natural gas, nuclear, geothermal, concentrated solar thermal, distributed generation (DG) solar PV, wind, and biomass. While the highest water consumption factors for power production come from cooling towers during the operational phase (Mays, 2011), 
the scope of this report also considers water consumption for energy production, which encompasses fuel extraction, processing, and transportation. Additionally, the water cost of environmental controls such as scrubbers and carbon capture and sequestration (CCS) is accounted for.

Water withdrawals used for once through cooling (OTC) are evaluated separately from consumption. The most up to date USGS (United States Geological Survey) report on water withdrawals indicate that electricity generation is responsible for the majority of surface freshwater withdrawals $(53 \%)$ in the United States but power plants only consume $7 \%$ of the withdrawn water while the rest is returned to the environment, albeit altered (Water in the West, 2013). Since not all of the water is being consumed, the cost cannot be calculated in the same way as consumption. To account for the environmental cost associated with such cooling-water withdrawals, mitigation costs are considered. Power plants may be mandated to mitigate their environmental impacts or change their process in order to alleviate the negative effects of cooling water withdrawals. The cost of mitigation and environmental compliance are calculated for power plants in California through specific case studies to account for the harmful consequences of water withdrawals associated with OTC of thermoelectric power plants.

This thesis relies on reported water usage associated with power production. Though these data are readily available for some lifecycle stages, they are lacking for others. Operational water consumption is easily discernible for most technologies studied here, but data gaps are prevalent for other stages of the power generation lifecycle such as 
component manufacturing, power plant construction, and power plant decommissioning. A complete lifecycle analysis of water consumption for electricity production is limited by such data gaps, but because nonoperational water consumption tends to be orders of magnitude less than for operational water consumption, reasonable estimates for total lifecycle water cost can still be developed and used for meaningful discussion on water related concerns of the electricity sector.

Regardless, this thesis is limited to the data that is available. If all power plants reported accurate data, the values presented in this thesis would be more accurate. Unfortunately, many power plants do not report their water consumption and water withdrawal data at all. According to a 2011 study that references 2008 data, power plants that did not report their water use to the Energy Information Administration (EIA) accounted for 28 to 30 percent of the freshwater withdrawals by the electricity sector and at least 24 to 31 percent of freshwater consumption by the sector (Avery et al, 2011). Nuclear power plant water use has been exempt from reporting to the EIA since 2002.

Water cost for power production is monetized based on water consumption statistics from textbooks and published review studies for each of the considered technologies. Water consumption data for energy production of coal, natural gas, and uranium come from an environmental engineering textbook and are supplemented with statistics from a variety of sources for practices that are likely to develop, such as hydraulic fracturing. Water consumption data for electricity production come from a number of review studies that present mean and median data. 
Since a water market does not exist, water consumption for electricity generation is monetized using the tier 1 full service untreated volumetric rate from the Metropolitan Water District of Southern California (MET), the largest wholesale supplier of surface water in the United States. Though some agencies may purchase a portion of their water at the tier 2 rate, the tier 1 rate is used instead as a conservative estimate of water value in Southern California. To evaluate future power plants that purchase groundwater rights to avoid purchasing freshwater from MET, the MET tier 1 rate is still used. This is because whatever agency owned the groundwater rights before the purchase will now need to supplement their water needs from a new source, which is likely to be MET.

The scope is focused around power plants in Southern California. Marginal water costs are created in terms of $\$ / \mathrm{MWh}$ and are relevant for existing power plants as well as future power plants that could provide electricity in Southern California. Total water costs for each evaluated technology are normalized to the electricity generating potential of a $540 \mathrm{MW}$ natural gas combined-cycle (NGCC) power plant and are displayed in annual cost and total costs for a NGCC lifespan of 40 years. Water savings are calculated for the Renewables Portfolio Standard (RPS) and consider the entirety of California. Savings are determined by comparing the total water cost of electricity generation in 2020 between two scenarios, one that meets the 2020 RPS standard of 33\% renewable energy and one that does not. The former scenario is based on solar PV and wind displacing some coal and natural gas electricity and the latter is based on an aggressive natural gas policy. 


\section{Chapter 2: Background}

This section discusses topics relevant to the modern energy-water paradigm. It addresses population increase and water scarcity, terminology related to the energy-water nexus and the effects of electricity production on aquatic species. It also describes legislation and regulatory measures that affect electricity generation with respect to water, in addition to policies regarding renewable energy. The philosophy behind water pricing is discussed and finally, subsidies for solar PV are compared to government subsidies for nuclear energy.

\subsection{Population Increase and Water Scarcity}

In 1999, the world's population was at 6 billion people. In 2011, the world's population exceeded 7 billion for the first time. According to the U.S. Census Bureau, the world's population is expected to breach 9 billion people by 2044, a $50 \%$ increase from 1999. Increasing population will be met with rising energy demand and greater competition for water.

An MIT paper on water withdrawals and consumption for electricity generation in the United States (Strzepek, 2012) models the water scarce regions in the United States as shown in red in the Figure 2.1 below. A region is considered water scarce if the mean water withdrawal rate exceeds $60 \%$ of the mean annual runoff. 


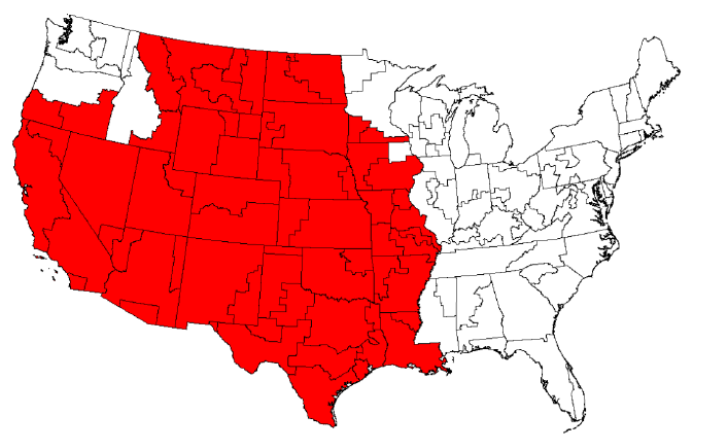

Figure 2.1 Water Scarcity in the United States (accessed from Strzepek, 2012)

The Bureau of Reclamation for the U.S. Department of the Interior put together a comprehensive study of water supply and demand of the Colorado River Basin projecting future water scarcity. Using forecasts of water supply and demand from a scenario development and qualification process, a range of water supply and demand was developed and is shown in Figure 2.2 below. Using the median values, the study predicts a water deficit of 3.2 million acre-feet (equivalent to over $10^{12}$ gallons) for the year of 2060. Each year leading up to 2060 also shows water imbalance. 


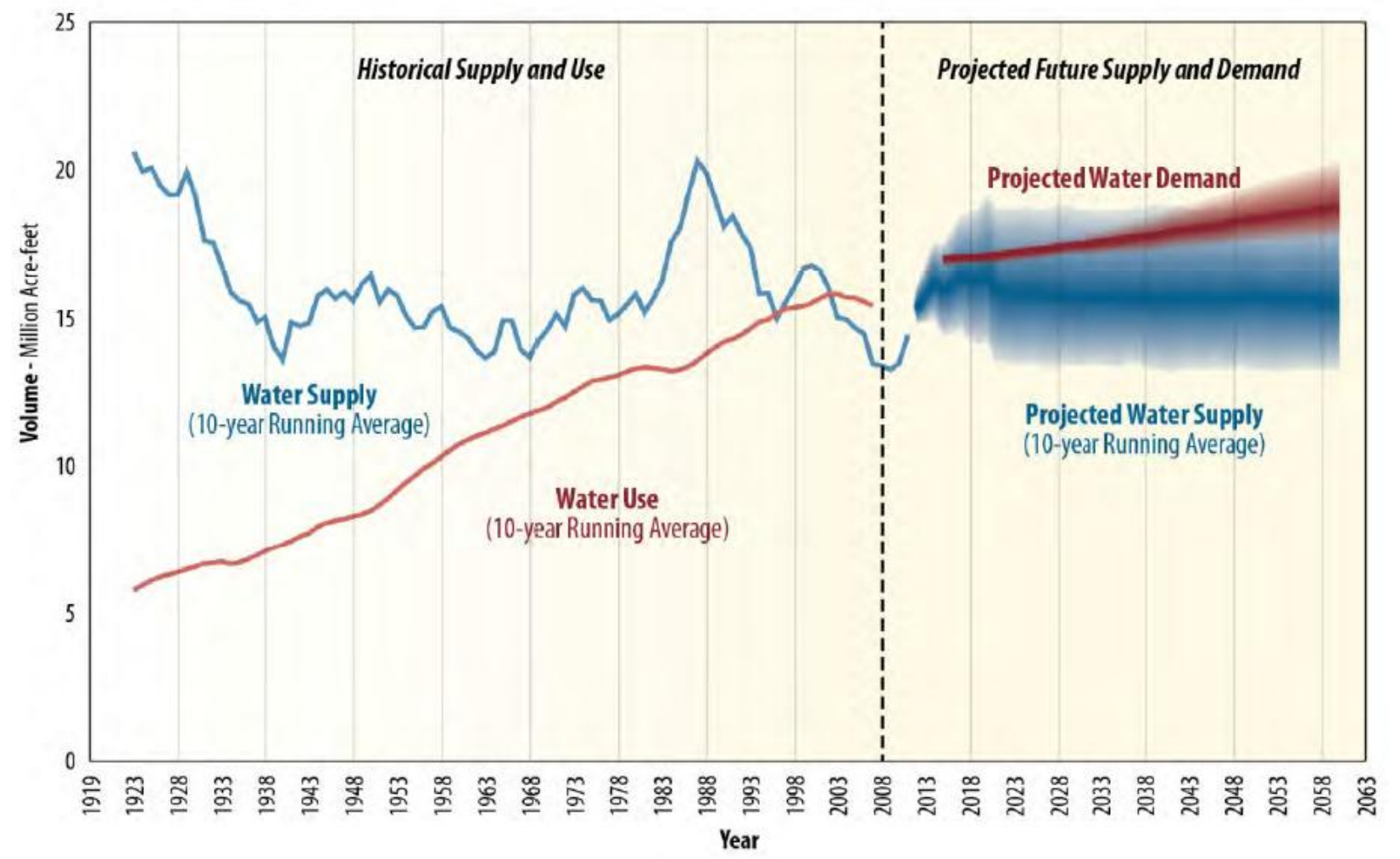

Figure 2.2 Historical Water Supply and Use / Projected Future Supply and Demand of the Colorado River Basin (accessed from U.S. Department of the Interior, Bureau of Reclamation (2012))

Agricultural losses in California due to lack of sufficient water supply resulted in severe economic losses in 2014. A web article from The Fiscal Times (Groman, S. \& Reuters, 2014) reported three quarters through the rainy season in California that farmers faced drastic cutbacks in water for irrigation expecting to top 500,000 acres of idle cropland (about one twelfth of the Central Valley) that would otherwise have been utilized. Most of the reservoirs that collect melted snowfall from the Sierra Nevadas that collectively account for the number one source of freshwater in California - are severely depleted. The article adduced a $\$ 5$ billion hit to California's economy from the 
drought crisis. A Times Magazine article (Pickert, 2014) discusses a UC Davis study elucidating some 17,000 seasonal and part-time agricultural jobs lost.

Climate change can have massive consequences for vital water bodies. Many reservoirs are experiencing drastically depleting water depths, which can have huge implications for power plants, especially in regards to water intakes that draw from a specified depth (Schneider, 2008). Lake Mead, which provides water for over 20 million people in Southern Nevada, Central California, and Arizona has lost 4 trillion gallons of water since 2000 (Tracy, 2014). If the lake drops another 20 feet this year, as expected, it will be below one of the intake elevations, triggering automatic water supply cuts to Nevada and Arizona. Nevada, which receives $90 \%$ of its water from Lake Mead, has been scrambling to create a new intake pipe at a lower elevation. The expected cost of such a project is $\$ 817$ million (Tracy, 2014). A slightly further drop in elevation will result in decreased efficiency of the Hoover Dam as water pressure will be reduced (LADWP, 2010). Las Vegas has had to take drastic measures by paying its homeowners \$200 million to get rid of their thirsty lawns and by reusing 93\% of its water (Tracy, 2014). It's not only lakes in the southwest that are being affected as water levels in Lake Huron and Lake Michigan also recently reached record lows (U.S. Army Corps of Engineers, 2013).

The drought in California has been so severe that many places that rely on the State to provide water did not receive any this year. For the first time in its 54-year history the State Water Project - which operates a system of reservoirs and distribution 
systems delivering water in Northern California, the San Francisco Bay Area, the San Joaquin Valley, the Central Coast, and Southern California - made the decision in January of 2014 to halt deliveries for the year (Rogers, P., 2014). Instead, municipalities were forced to rely more heavily on local reservoirs, aquifers, and water recycling. Figure 2.3 shows the regions affected by this decision. $100 \%$ of California is now experiencing severe, extreme, or exceptional drought conditions, according to the U.S. Drought Monitor (Pickert, 2014).

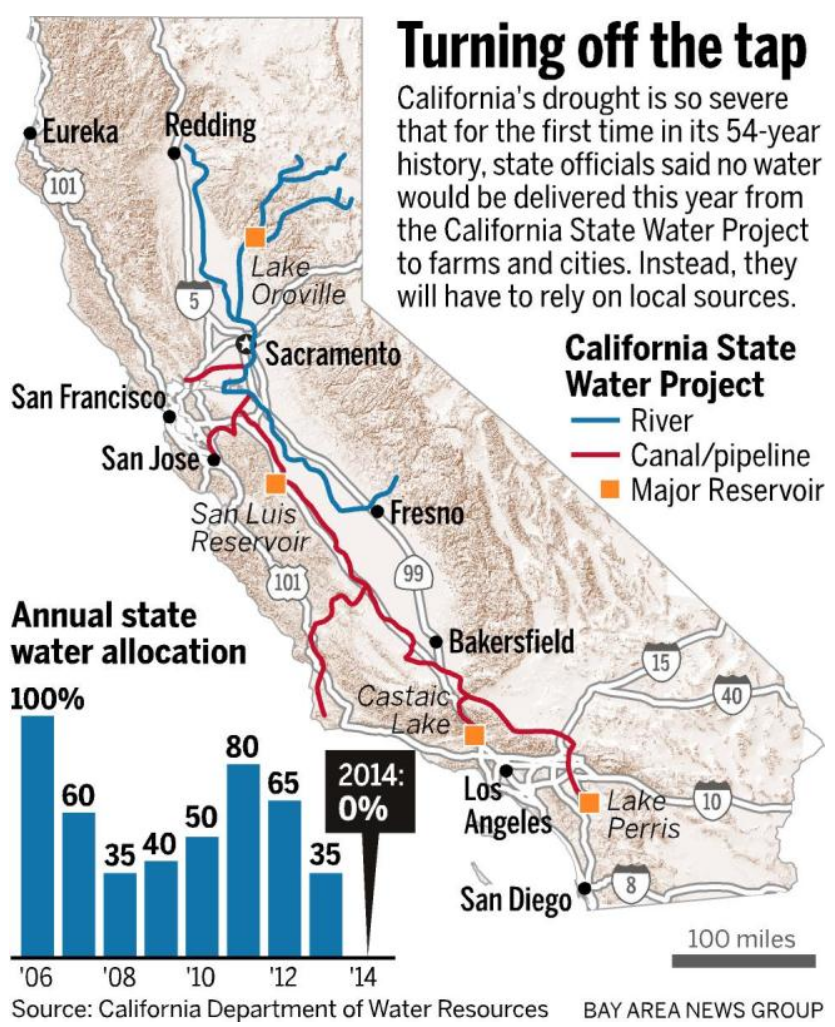

\section{Figure 2.3 State Water Project Allocates No Water in 2014}

Even groundwater aquifers such as the Ogallala Aquifer beneath the Great Plains are diminishing. The Ogallala Aquifer is the largest aquifer in the U.S. and is depleting at a rate of $12 \times 10^{9} \mathrm{~m}^{3} / \mathrm{yr}$, which is roughly equivalent to 18 times the annual flow of the 
Colorado River (Schneider, 2008). Though there is a lack of detailed water consumption data, there are many signs that consumption is outpacing supply and that in general, aquifers are declining (DOE, 2006). With supply limited, groundwater is vulnerable to price spikes. While some groundwater gets used for the public domestic supply, in the United States about two-thirds of the groundwater pumped is used for irrigation (Water in the West, 2013). The value of farmland is only as good as its water supply allows, so when groundwater aquifers become depleted the agriculture sector will be more dependent on freshwater. Since thermoelectric cooling and urban needs also rely on freshwater, growing competition for the dwindling resource may create conflict.

\subsection{Energy-Water Nexus}

Energy and water are inexorably linked since the production of freshwater requires electricity and the production of electricity requires water. Therefore, it is often said that anything that saves water or electricity saves both water and electricity. This thesis addresses only the water used for power production and not electricity requirements for water production.

The production of energy requires water at several different stages of production. First, water is required for fuel extraction. Mining activities affect water (qualitatively and quantitatively) for fossil fuel and uranium extraction. Shale gas requires water for hydraulic fracturing (fracking), a process in which water is mixed with other chemicals and is pressurized to fracture rock so that gas underneath can reach the surface and be captured. 
Once the fuels are obtained, water may be involved in transportation and processing. Fuels may be transported in a number of ways. Slurry pipeline, in which the fuel is mixed with water, is the method that directly consumes the most water (Mielke et al, 2010). Other methods such as barge transportation can affect water in more indirect ways, by increasing evaporation rates through the creation of locks to facilitate conveyance. Reports indicate that reservoirs can lose between 2 million and 10 million gallons of water for each operation (DOE, 2006). Accidents such as oil spills can affect water bodies for decades. Once the fuel reaches its intended location, it often needs to be processed to convert it into a usable form. This may involve water for a number of steps such as coal washing or uranium enrichment.

The largest consumer of water for conventional electricity production is thermoelectric cooling (Macknick et al, 2011). Such power plants use coal, natural gas, nuclear fission, geothermal heat, biomass, or the sun's rays (in the case of CST plants) in a process called the Rankine cycle, which boils water into steam to spin turbines. After the steam passes through the turbine, it is cooled so that it condenses and can be reused. Cool water is usually used to absorb heat and condense the steam back to liquid form to be boiled again. This steam-cooling step accounts for the majority of consumed water and even rivals other massive water users in other industries such as agriculture. According to USGS, thermoelectric power plants accounted for approximately $41 \%$ of the total U.S. freshwater withdrawals in 2005 (53\% of fresh surface-water withdrawals), whereas agricultural irrigation accounted for $37 \%$ of the freshwater withdrawals (Kenny, 2009). 
Not all of the withdrawn water gets consumed. Much of the water withdrawn for cooling is returned to original body source, albeit altered.

\subsubsection{Water Withdrawals vs. Water Consumption}

In the analysis of water use for thermoelectric cooling, it is important to differentiate between water withdrawals and water consumption. Water withdrawals are defined as water removed from the ground or diverted from a surface-water source for offstream use (Mays, 2011). For thermoelectric power, the water may be evaporated (consumed), reused, or returned to the water source at a higher temperature.

The amount of water not returned is referred to as the water consumption. Water consumption is defined as the part of water withdrawn that is evaporated, transpired, incorporated into products or crops, consumed by humans or livestock, or otherwise removed from the immediate water environment (Mays, 2011). Consumption is important because the water lost to evaporation cannot be used for other purposes such as agriculture or drinking. Depending on the locale, withdrawals or consumption may be the predominant concern.

\subsubsection{Differences between Cooling Systems}

The amount of water withdrawn and consumed for thermoelectric power depends somewhat on the fuel source but it depends more on the type of cooling system. Cooling systems can be broken down into three categories: wet, dry, and hybrid. Wet cooling systems use water for cooling. Dry systems use air. Hybrid systems can use water or air. 
Wet cooling systems can come in a few different forms: once through, recirculating, and pond.

Once through cooling systems (OTC, also referred to as open loop) withdraw water and use it only once before discharging it. As shown in Figure 2.4, the cooling water passes through condenser tubes. After the steam is used to spin turbines, it passes through the condenser where it comes into contact with the cooling water in the tubes. This contact cools the steam and condenses it back into liquid form for reuse in the boiler. The cooling water is then discharged at a higher temperature. This can facilitate evaporation from the body of water it is being discharged into. These systems withdraw the largest amount of water of the three wet cooling types but they are the most energy and cost efficient. They consume less water than recirculating cooling and pond systems.

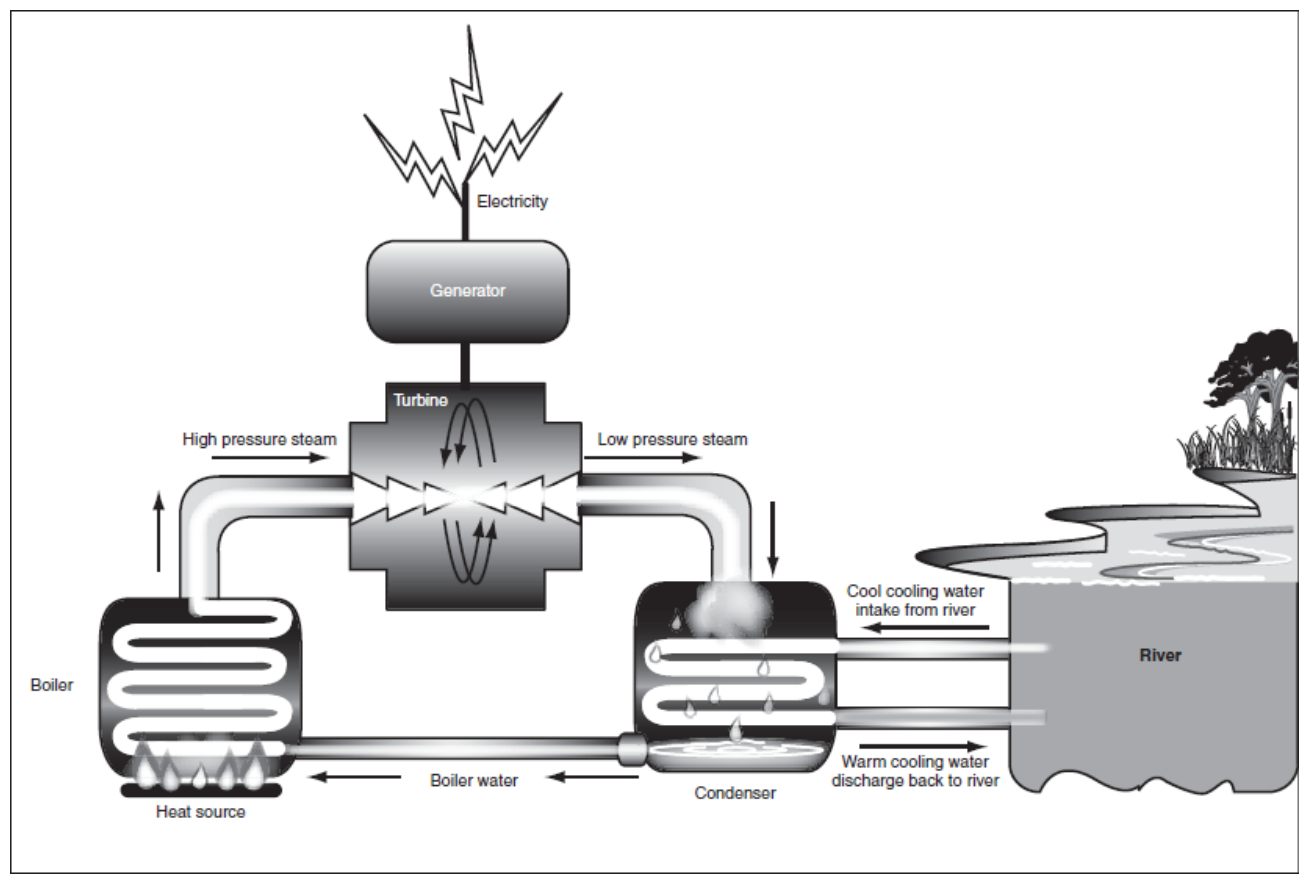

Figure 2.4 Diagram of Once Through Cooling (accessed from GAO, 2009) 
Wet recirculating systems, shown in Figure 2.5, withdraw less by reusing some of the cooling water. Just like for once through cooling, recirculating systems use the cooling water to condense the steam after it has passed through the turbine. Similarly, the steam transfers heat to the cooling water in the condenser. Instead of discharging all the heated water and withdrawing new cool water, however, recirculating systems send the warm cooling water to a cooling tower. There, heat from the now warm water is transferred to air and substantial amounts of water are lost to evaporation. Some new water must be withdrawn to replace the water lost to evaporation but most cooling water is available for reuse. The recirculated cooling water, though cooled by contact with air in the cooling tower, is still generally warmer than fresh cooling water so the thermal efficiency of the condenser is lower. Over time, the quality of the water is diminished as minerals and sediment present in the cooling water become concentrated which happens because water gets evaporated but minerals and sediment do not. The solids can adversely affect the condenser and cooling tower performance so the portion of water containing the suspended solids must periodically be discharged in a process called blowdown. Wet recirculating systems consume $1.5-6.5$ times more water than once through systems (NETL, 2009). 


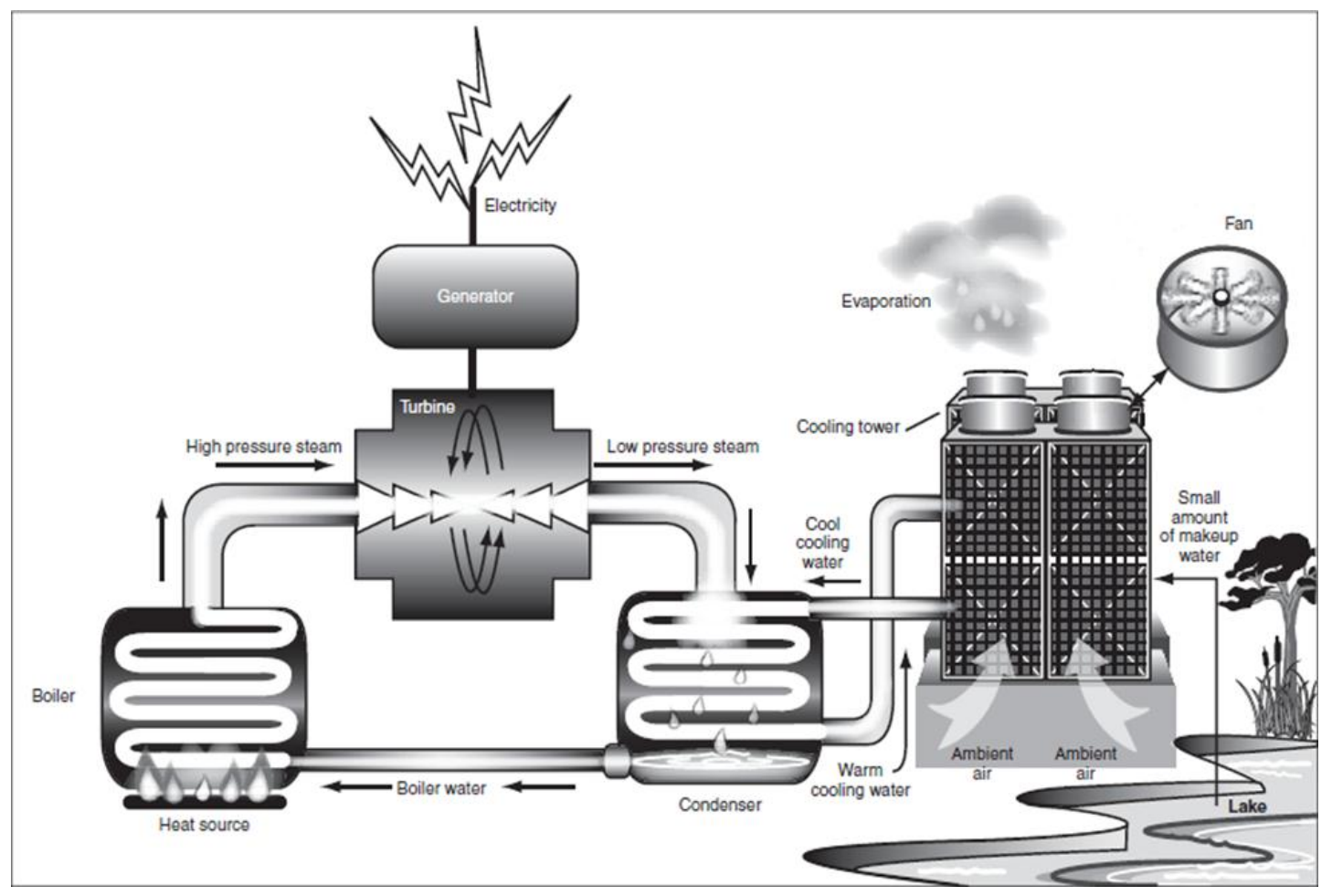

Figure 2.5 Diagram of Wet Recirculating Cooling (accessed from GAO, 2009)

In dry cooling systems, shown in Figure 2.6, minimal cooling water is required.

This is because the fans send air into contact with the condenser tubes to condense the steam back to boiler water instead of using water. These types of systems are best for conserving water but they tend to have higher capital costs and they lose efficiency during hot weather or high winds. In California, the use of dry cooling has the potential to reduce a $250 \mathrm{MW}$ gas-fired combined cycle power plant's water requirement by approximately 2000 to 2500 acre-feet per year, but will increase the plant's total capital cost by 5 to $15 \%$, while reducing its total energy production 1 to $2 \%$ (4 to $6 \%$ on hot days) and potentially reducing the annual revenue of the power plant by $\$ 1.5$ to $\$ 3.0$ million (1 to $2 \%$ of the total) (Maulbetsch and DiFilippo, 2006). 


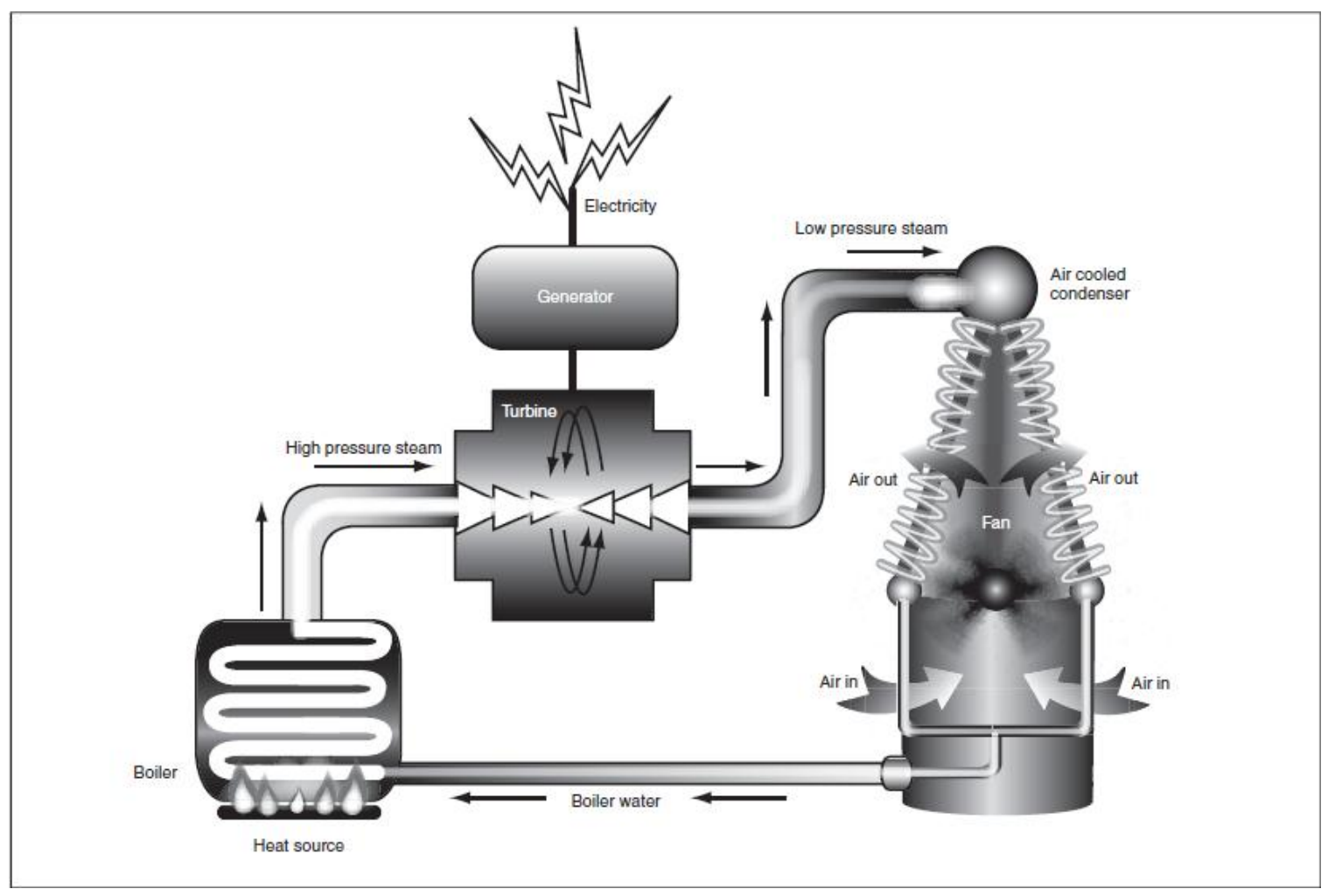

Figure 2.6 Diagram of Dry Cooling (accessed from GAO, 2009)

Sometimes pond systems are used for cooling. Cooling ponds are man-made bodies of water that are formed for the purpose of supplying cooling water to a nearby power plant or other industrial facility that requires cooling water. They work much the same way as once through cooling systems but discharged water can be reused after it is sent back to the pond and is exposed to ambient air. They tend to consume more water than OTC systems but less than recirculating cooling systems. Ponds provide an alternative to building a cooling tower like for recirculating cooling systems or discharging heated water back to a river or lake. Make-up water is added to the pond to account for the water lost to evaporation. 
Hybrid system, as shown in Figure 2.7, can utilize water or air for cooling. The wet system and dry system can operate at the same time to increase cooling efficiency or they can be run separately depending on the situation. If water needs to be conserved, the wet cooling tower can be shut off and the air cooled condenser can be run instead. Hybrid systems incur higher capital costs for construction but give the luxury of choice in cooling method.

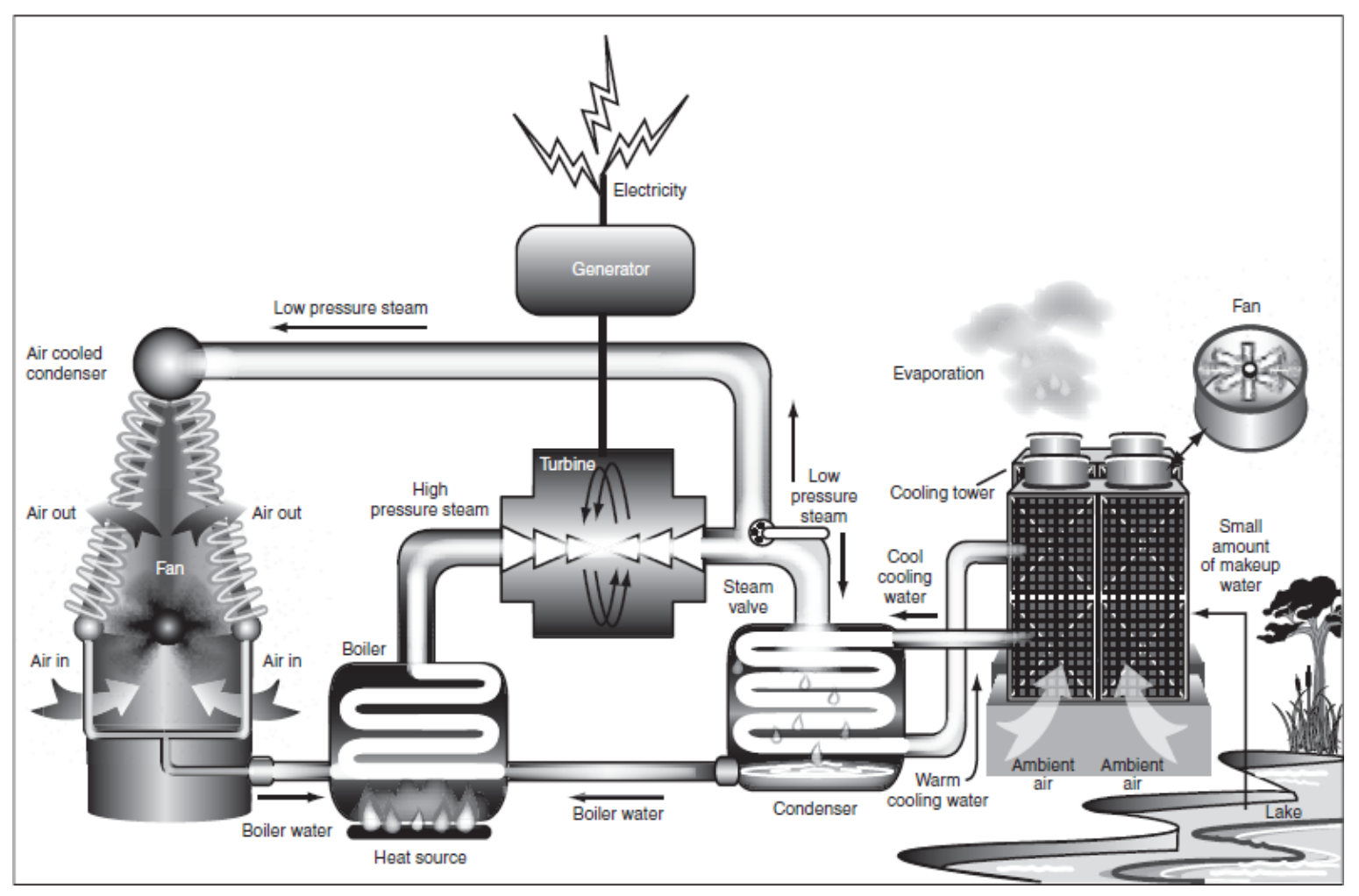

Figure 2.7 Diagram of Hybrid Cooling (accessed from GAO, 2009)

\subsubsection{Freshwater vs. Ocean Water}

Wet cooling towers may use freshwater or ocean water depending on location and availability of water resources. Freshwater is the primary concern since in addition to thermoelectric cooling, it is also used for public water supply, and agriculture whereas 
ocean water is too saline for such purposes. Ocean water withdrawals are still important because they can negatively affect aquatic life (as discussed in Section 2.2.4), consequently affecting biodiversity of ecosystems and human occupations that rely on them, such as the fishing industry.

Figure 2.8 gives a breakdown of freshwater versus ocean water and type of cooling system for thermoelectric power plants over the continental United States. NETL (2010) developed the graphic based on 2000 and 2005 data collected by the EIA. Power plants with a capacity less than $100 \mathrm{MW}$ are not included. Not surprisingly, ocean water is only used along the coasts of the United States; they predominantly use OTC systems. All areas that do not have access to ocean water rely on freshwater from rivers and lakes or municipal groundwater, recycled water, or transported water from nearby regions. The water-scarce southwest uses mostly recirculating towers to cut back on withdrawals.

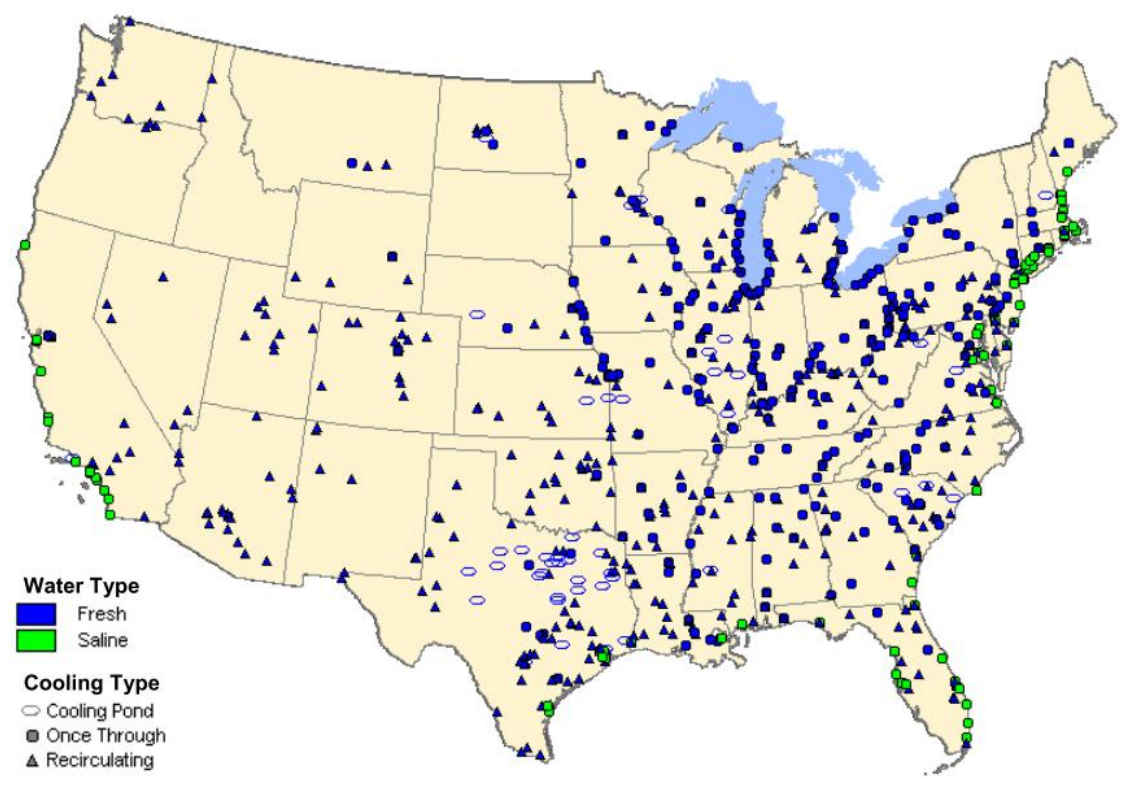

Figure 2.8 Fresh Water versus Saline Water by Cooling Type in the U.S. 
Figures 2.9 and 2.10 present a breakdown of water withdrawals and consumption, respectively, used by power plants for 20 distinct regions in the U.S. as well as the national average based on 2008 data (Avery, 2011). In the East, water withdrawals come primarily from fresh surface water, except for some power plants on the Atlantic Coast, which withdraw ocean water. The Southwest withdraws more water from alternative sources such as groundwater and wastewater than other regions. California and Hawaii withdraw almost entirely ocean water, with many OTC plants right along the coast. In $2008,84 \%$ of the national average for power plant withdrawals was freshwater coming from rivers and lakes. The remainder was primarily ocean water from coastal power plants.

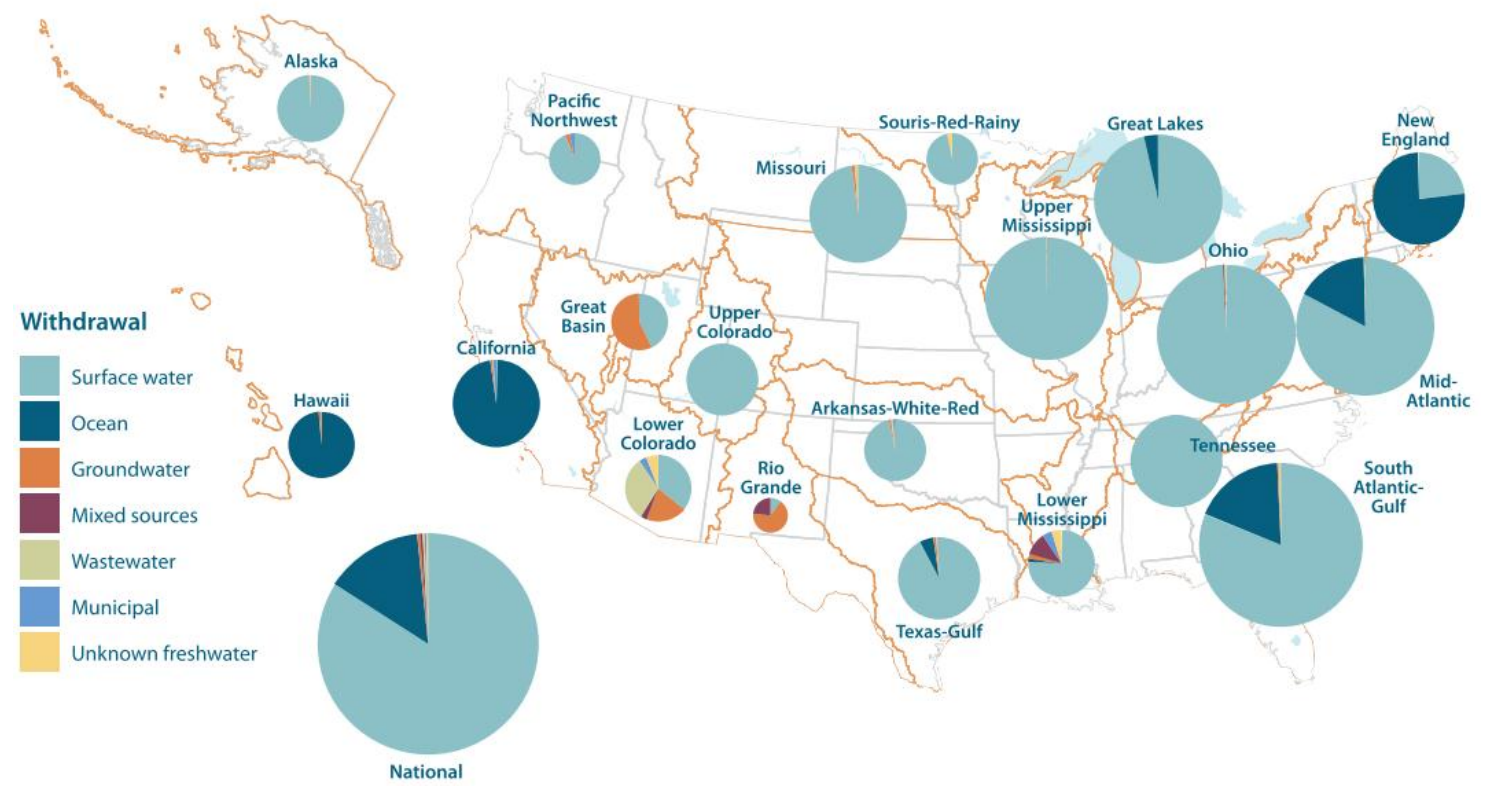

Figure 2.9 Water Source for Power Plant Withdrawals by U.S. Region (accessed from Avery, 2011)

Consumptive water sources are much more variable. The general trend is that most of the water consumption in the eastern half of the U.S. is freshwater. Power plants 
in the western half of the U.S. consume water from a wide variety of sources; freshwater is not always the dominant source. Groundwater makes up significantly higher percentages on the West Coast, the Southwest, and Hawaii. Freshwater is still the predominant water consumed by power plants nationally, although groundwater and other sources make up significant percentages as well.

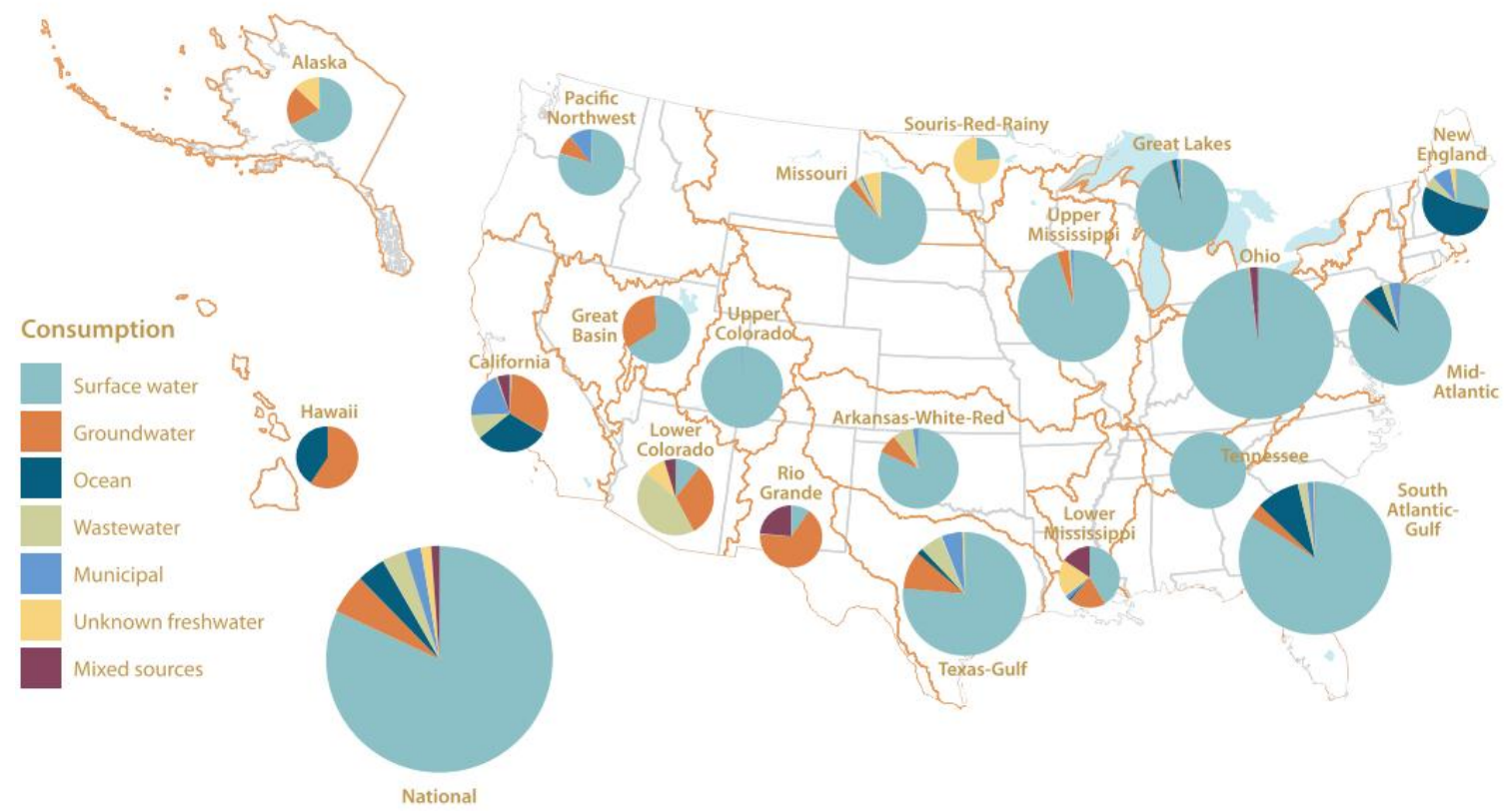

Figure 2.10 Water Source for Power Plant Consumption by U.S. Region (accessed from Avery, 2011)

\subsubsection{Effects to Ecosystems and Biodiversity}

Impingement and entrainment are two negative consequences of once through cooling. Impingement happens when aquatic species become trapped in the screens of a water intake system as water is getting drawn into the facilities' cooling system. Affected fish often lose their gills and die within a few days because they can no longer breathe 
(Rogers et al, 2013). Younger and smaller aquatic organisms are more susceptible to impingement.

Entrainment occurs when aquatic organisms get drawn into the cooling facility itself. Once inside, the organisms are subjected to high pressures and temperatures that kill them (Rogers et al, 2013). Young organisms, typically at the egg or larvae stage, are most affected by entrainment. The resultant damage from impingement and entrainment can result in economic fishing losses (NRDC, 2007).

Power plants that discharge water into a nearby water body cause thermal pollution. Thermal pollution degrades water quality by raising the ambient water temperature, affecting aquatic species in the discharge location zone. The increased ambient water temperature depletes the oxygen supply and affects ecosystem composition. When a power plant begins or terminates operations, the drastic change in temperature can kill fish and other organisms that have adapted to the normal temperature range, in a process called thermal shock. In the United States, about 75 to $82 \%$ of thermal pollution is generated by power plants (Laws, 2000).

Mining can have serious impacts on water resources as well. With mountaintop mining and valley fill (aka mountaintop removal), streams are often covered with mining soil. Palmer et al (2010) documents several other issues with mountaintop removal including: decreased soil infiltration of rainwater, increased frequency and magnitude of flooding, increased rates of total dissolved solids, sulfates and other minerals contaminating surface water, and reduced stream biodiversity. The affected headwater 
streams are biologically important due to the diversity of aquatic species they contain as well as the organic energy they provide to fish and other aquatic life throughout the river. Hydraulic fracturing also raises great concern over surface contamination from the handling and disposal of produced water as well as for accidents and spills. Groundwater contamination is a persistent issue arising from the fuel extraction process step in electricity production for a number of energy sources including coal, gas, and nuclear. A report by the USGS National Water Quality Assessment Program found water in wells near the Appalachian mining region to have "significantly greater" levels of sulfate, iron, manganese, aluminum, hardness, calcium, magnesium, turbidity, and specific conductance than wells in unmined areas (McAuley and Kozar, 2006). Higher levels of contaminants can lead to impacts on human health.

The construction of wind power plants also has environmental consequences, though not with contamination or thermal shock. Construction of off-shore wind projects can disturb ecosystems with noise from boat and barge traffic. The noise from construction can have a significant impact as pile driving operations are able to create extremely high sound pressure levels underwater (Thomsen et al, 2006). Noise and sediment disturbance reduce marine population density during construction but most aquatic life will return after completion (Keith et al, 2012). The impacts of operational use are generally considered minor or negligible, though visual disturbance and bird kills can be seen as potential issues. Visual disturbance can be minimized by locating wind farms away from urban areas. Bird deaths from wind farms and solar energy technologies are small compared to other causes. A study from the Renewable Energy international 
journal estimated that wind farms and nuclear power stations are each responsible for between 0.3 and 0.4 fatalities per GWh of electricity generated while fossil fueled power stations are responsible for about 5.2 fatalities per GWh (Sovacool, 2013). It estimates that throughout 2009, wind farms killed approximately 20,000 birds, nuclear plants killed about 330,000 and fossil fuel power plants killed more than 14 million. To put this into perspective, free-ranging domestic cats are estimated to kill over one billion birds every year in the United States (Dauphine and Cooper, 2009). Some studies actually show that in the long run, off-shore wind farms can have positive environmental effects because aquatic organisms can adapt to the new conditions. Vattenfall, a Swedish power company, monitors its off-shore wind projects and found that the addition of hard surfaces underwater fostered new populations of seaweed, mussels, worms and hydroids (Vattenfall, 2010).

\subsubsection{Mitigation}

Depending on regional regulations, a power plant may be required to mitigate the environmental problems it causes. The cost of mitigation can be determined by the expense of counteracting the negative effects to the surrounding ecosystem. A few possible ways of achieving this is through the implementation of a marine park to protect marine life, construction of an artificial reef to enhance reproduction and sustainability of aquatic organisms, or wetland restoration, depending on the particular power plant's ecological impacts. 


\subsection{Regulation and Legislation}

"Energy policy is primarily regulated by the U.S. Department of Energy (DOE), the Federal Energy Regulatory Commission (FERC) and state Public Utility Commissions (PUCs), while water policies are overseen by fifty state agencies and multiple branches of the federal government - including the U.S. Department of Interior's Geological Survey (USGS), the Army Corps of Engineers (ACE) and the U.S. Environmental Protection Agency (EPA). This makes it difficult to compare data for water use and energy generation, but all the more important that we try" (Wilson et al, 2012).

The Clean Water Act (CWA) contains mandates that may affect power plants that withdraw from already polluted sources of water. Section 303(d) requires states to develop a list documenting all bodies of water that are not meeting water quality standards and establish total maximum daily loads (TMDL). The TMDL specifies the maximum amount of pollutants a body of water can receive without exceeding the water quality standards. If a power plant is discharging polluted water into a water source beyond what the TMDL specifies, they may be required to find an alternative water source for cooling or implement additional water treatment to lower the pollution to acceptable levels.

Another important piece of legislation regarding water and thermoelectric power production in the Clean Water Act (CWA) is Section 316b, which establishes the requirements and standards for cooling water intake structures based on impingement 
mortality and entrainment. It dictates that the EPA must safeguard the nature of location, design, construction, and capacity of cooling water intake structures to ensure up to date technology use to minimize adverse environmental impacts. Impingement mortality and entrainment must be reduced by a minimum level determined by the type of cooling water. Compliance is coordinated through individual NPDES (National Pollution Discharge Elimination System) permitting programs.

The most prominent effect of CWA $316 \mathrm{~b}$ will be the utilization of closed-loop systems instead of OTC for most new power plants and retrofitting of closed-loop systems for existing OTC power plants. Open loop systems are strongly discouraged unless the applicant can demonstrate alternative measures to compensate for the effects of impingement mortality and entrainment. Mitigation measures must have a comparable impact to switching to a closed-loop system to justify maintaining OTC. Corresponding byproducts of increasing closed-loop systems are reduced water withdrawals but increased water consumption.

Air quality legislation also impacts water usage for power generation. Increased attention to air pollution often results in increased water-requiring process steps. The Clean Air Act, for example, has provisions to reduce sulfur emissions amongst other harmful gaseous emissions. Two of the main methods of reducing $\mathrm{SO}_{\mathrm{x}}$ emissions are by requiring sources to install controls such as a scrubber to handle the emissions (postburning of fuel) which uses water to prevent emissions and by washing coal that is high in sulfur content (before burning the fuel) which also requires water. More stringent 
emission requirements on sulfur dioxide have inspired rapid growth in the flue gas desulfurization (FGD) market. FGD and coal washing require only a fraction of the water required for thermoelectric cooling, but the addition of $\mathrm{SO}_{\mathrm{x}}$ scrubbers to coal fired power plants in the coming decades will add additional stress to the water supply. If carbon capture and sequestration (CCS) becomes widely adopted, water requirements for energy production may be substantially increased. Additionally, groundwater near the storage location will be affected in a manner similar to the issues with produced water during drilling for oil and gas extraction.

A multitude of policy decisions have been affected by growing concern over water supply. For example, in 2006 the Idaho House Committee unanimously voted to impose a two-year moratorium on construction of coal-fired power plants (Anderson, 2006). Similarly, Arizona rejected permitting for a local power plant due to concerns about how much water it would withdraw from a local aquifer (Land Letter, 2004).

The Safe Drinking Water Act (SDWA) is the main federal law regulating the quality of drinking water and is relevant for mining activities, hydraulic fracturing, and CCS. It requires many actions to protect drinking water and its sources such as rivers, lakes, reservoirs, and groundwater aquifers. A major component of SDWA is the Underground Injection Control program. This program is responsible for the proper management of injection wells that inject fluids underground for storage or disposal, potentially contaminating groundwater aquifers. 
The Surface Mining Control and Reclamation Act of 1977 (SMCRA) is the primary federal law that regulates coal mining in the United States. It created the Office of Surface Mining, an agency within the Department of Interior to regulate mining and oversee correspondence with state regulations. It regulates mining on both private and federal lands. Many mines have been abandoned and now pose environmental problems. In an effort to ensure reclamation of mined lands and its water resources, state regulations require companies to post bonds for sums equal to the estimated cost of reclamation (Keith et al, 2012).

Currently, gas drilling is not regulated by the CWA or the SDWA. With the recent advent of hydraulic fracturing, the EPA launched a large scale study of the relationship between fracking and drinking water resources. The anticipated study will be released for public comment and peer review in the latter months of 2014. The results of the study may lead to further regulations to safeguard drinking water resources.

State legislation differs from state to state. In California, the use of surface water is subject to both the riparian and appropriative rights doctrines (GAO, 2009). A permit is not necessary to utilize riparian surface water rights, which allow landowners the right to make reasonable use of water bodies adjoined to the owned land. Appropriative rights (to acquire legal possession of the water) are acquired through the State Water Resources Control Board (SWRCB). The California Water Code does not authorize the State to manage groundwater. The legislature has created nine groundwater management agencies 
to manage groundwater on the local level but the majority of groundwater in California is unregulated.

The California Energy Commission (CEC) is the primary organization dealing with energy policy and planning in California. The CEC, in alignment with the SWRCB and CWA, discourages the use of OTC due to the harm it causes to aquatic organisms. The CEC prioritizes the use of dry cooling and discourages the use of freshwater for cooling.

The California Renewables Portfolio Standard (RPS) was established in 2002 under SB1078, made into law in 2006 under SB107, and expanded in 2011 under SB2. The RPS program requires investor-owned utilities, electric service providers, and community choice aggregators to increase procurement of eligible renewable energy resources to $33 \%$ of the total procurement by 2020 .

SB1 enacts Governor Schwarzenegger's Million Solar Roofs initiative and expands upon the California Solar Initiative (CSI) and the CEC's New Solar homes Partnership. The goal of the CSI is to install 3000 MW of net-metered solar energy over a ten year period. Los Angeles Department of Water and Power (LADWP) must account for $280 \mathrm{MW}$ out of the $3000 \mathrm{MW}$ total (over a ten year period) by allocating $\$ 313$ million in expenditures towards customer net metered solar incentives (LADWP, 2013).

\subsubsection{Net Energy Metering}

The Energy Policy Act of 2005 facilitated renewable energy adoption and hindered it at the same time. It helped solar energy by establishing a net energy metering 
(NEM) policy on the federal level and creating the federal investment tax credit (ITC).

NEM is a crucial policy for the development of renewable energy technologies because it allows distributed generation producers of renewable electricity to receive adequate compensation. Under the Energy Policy Act, all public electric utilities must make net metering available to customers upon request. However, the act has been criticized for creating loopholes for the nation's electric utilities by exempting hydraulic fracturing from clean water laws, helping hydropower facilities appeal environmental restrictions, and subsidizing the nuclear and oil industry (Grunwald and Eilperin, 2005).

Forty-three states currently have NEM policies but size caps restrict their full potential. In California, there is a $1 \mathrm{MW}$ capacity limit, meaning renewable energy plants over this size do not qualify for NEM. Furthermore, there is a 5\% cap which means that utilities (LADWP exempted) in California must provide credit for distributed generation (DG) systems up to at least $5 \%$ of customer aggregate peak demand. After the $5 \%$ cap has been reached, it is voluntary for utilities to credit DG producers.

Legislation in California has been extending the cap on net energy metering over time. SB1 (in 2006) increased the aggregate limit of net-energy metered systems within a utility's service territory from $0.5 \%$ to $2.5 \%$ before AB510 (in 2010) further increased it to $5 \%$ where it stands now. AB 327 (which took effect January $1^{\text {st }}, 2014$ ) mandates that that the largest utilities must offer NEM until the cap is reached or until July $1^{\text {st }}, 2017$, whichever comes first. It also establishes NEM grandfathering rules, protecting the 
investments of solar customers by upholding the agreements the customer originally agreed to.

Some electric utilities, such as the Lompoc Electric Division in California, are nearing the cap and no longer wish to offer NEM credit to their customers. While AB 327 ensures that previous solar customers continue to receive credit for their production, future customers will be prevented from receiving credit if they choose to go solar unless the cap is extended.

\subsection{Water Price}

Water is different from most commodities and valuing it properly is not straightforward. Depending on the situation, water can be a public good or a private good. The two distinguishing properties that define a public good are non-rivalry in consumption, and non-excludability (Hoekstra et al, 2011). A good example of a nonmarket public good is national defense which all members of a nation benefit from but cannot directly buy more of. Let's apply this to water now. If an individual farm is purchasing water for irrigation, water may be treated as a private good. There is rivalry in consumption - as the water consumed by the farm is taking away water that could be used elsewhere, and excludability - since the farm could theoretically purchase enough water as to exclude its sale to other private consumers. If it is being left in situ, for recreation or for the benefit of an aquatic habitat, on the other hand, water may be treated as a public good. 
English and American common law are largely based on Roman law, which views flowing water as a common right to everyone. It is not deemed capable of ownership in the same way that land is. Many people object to water being treated as a private good. They do not want it to be bought, sold, and traded for profit. This study indeed seeks to treat water as a private good but does not intend to detract from the collective, sustainable, and fair management of Earth's most precious resource. On the contrary, water is treated as a private good for the purpose of monetizing the avoided water cost of more sustainable and environmentally beneficial sources of electricity so policy makers may recognize the opportunity cost of wasteful water practices in the energy sector.

In economic theory there is a concept of essentialness which refers to values not represented in the price of water. Essentialness of water can relate to an input for production or to a private commodity. As an input for production, water is essential for agriculture because without it the crops would not grow. Water is also an essential input for thermoelectric power plants that use wet cooling. Without water, wet cooling towers cannot run and electricity cannot be generated. It is also essential as a commodity. The price of water in the U.S. does not accurately account for the essentialness of the vital resource. Even though water is as essential as more highly priced commodities such as oil, its cost per gallon value is about one thousandth that of oil.

The price of water is not representative of its essentialness because it is viewed as a fundamental human right; instead, it is based upon the costs of production. As 
mentioned by W.M. Hanemann of the University of California Berkeley, "It is important to emphasize that the price which most users pay for water reflect, at best, its physical supply cost and not its scarcity value" (Hanemann, 2000). Hanemann goes on to explain "In places where water is cheap, this is almost always because the infrastructure is inexpensive, or the water is being subsidized, rather than because the water per se is especially abundant.”

\subsection{Subsidies}

A subsidy involves assistance from a government or public body to an industry or business to allow it to be economically competitive with substitute options. Without government subsidies, many industries that exist today may not have been able to get off their feet in the early stages. Nuclear energy, for example, had a big issue with insurance costs in its early development. In the case of potential disaster, nuclear power plants could not assume the liability and still be economically competitive with conventional energy sources. The Price-Anderson Act of 1957 limited the insurance costs of power plants by shifting a portion of the liability from power plant operators to tax payers, "thus removing a substantial (and possibly insurmountable) barrier to nuclear power plant development" (Komanoff Energy Associates, Greenpeace, 1992). The federal government invested over $\$ 6$ billion (in 2012 dollars) in research and development for nuclear energy in 1953, yet there were still no privately owned nuclear generating facilities prior to 1957 (Pfund and Walker, 2013). By 1965, there were 13 nuclear reactors in operation and by 2012 there were 104 in total (EIA, 2013b). 
The solar energy industry is now in a similar stage of development as the nuclear industry in the 1950s. Figure 2.11 shows federal subsidies for nuclear energy in its first five years of development compared to federal subsidies for solar energy at comparable stages of early development. The solar subsidies, consisting of the Federal Investment Tax Credit (ITC) and 1603 Treasury Grant Program (2009-2011), are inferior to the support from the federal government in the first five years of nuclear development. The ITC, which was passed as part of the Energy Policy Act of 2005 provides a tax credit of $30 \%$ of the installation costs for solar systems is set to end in 2016. It is yet to be seen if it will be renewed. Cumulative subsidies are shown in Figure 2.12.

California's Share of Federal Subsidies: Nuclear (1963-1967) and Solar (2007-2011)

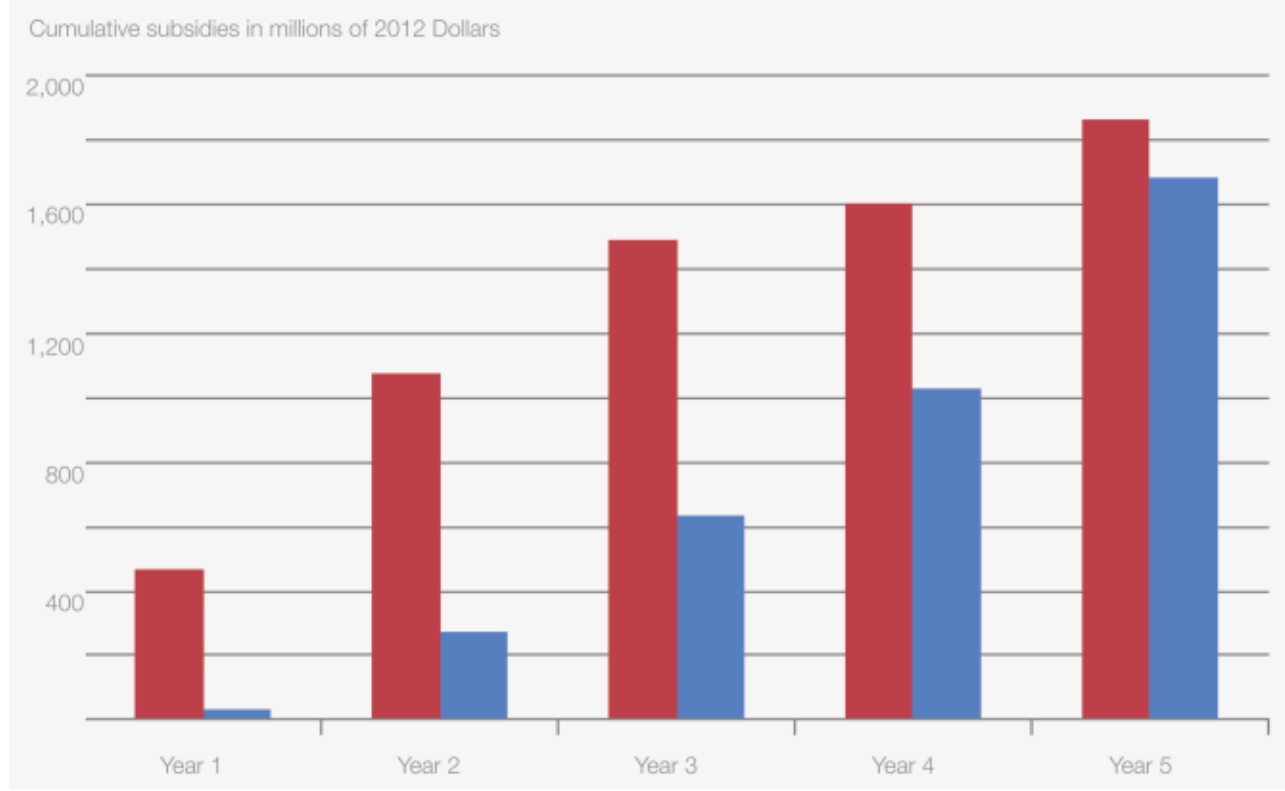

Figure 2.11 California Nuclear Subsidies vs Solar Subsidies in First Five Years (accessed from Pfund and Walker, 2013) 


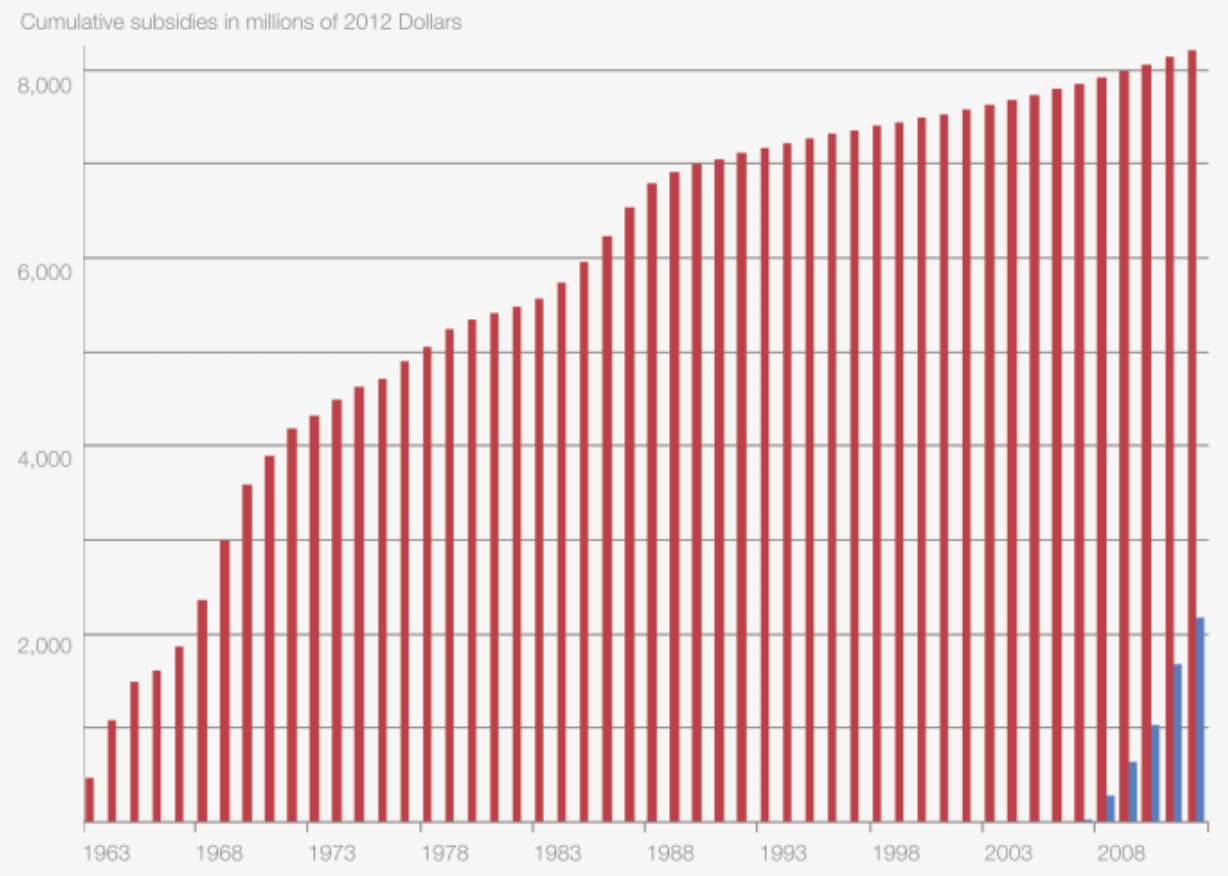

- Nuclear Subsidies

- Solar ITC Subsidies

Figure 2.12 Cumulative Nuclear Subsidies vs Solar Subsidies (accessed from Pfund and Walker, 2013) 


\section{Chapter 3: Methods}

Both water withdrawals (the amount of water removed from its original source) and water consumption (the amount of water that is not returned) for electricity generation are presented but they are treated differently in this analysis. Water consumption is the primary indicator of water cost in this study. It is monetized by multiplying the rate of consumption (gal/MWh) by the appropriate cost of water (\$/gal) to calculate water consumption cost per unit of electricity generated (\$/MWh). Water withdrawals are presented but not monetized except for Diablo Canyon Power Plant, a case study in which consumption is of ocean water so mitigation cost (to compensate for entrainment effects) provides the best estimate for water cost.

Water consumption data for energy production - which encompasses water used for fuel extraction, processing, transportation and other plant operations -was obtained from Water Resources Engineering by Larry Mays (2011), an environmental engineering textbook. Power plant operational water consumption are presented for each technology in the following subsections based on a variety of sources including a Harvard report (Mielke et al, 2010), a Stanford report (Water in the West, 2013), a couple studies from environment related journals (Meldrum et al, 2013; Fthenakis and Kim, 2010), an NREL report (Macknick et al, 2011), a Pacific Institute study (Cooley et al, 2010), and a few DOE sponsored studies (Clark et al, 2010; DOE, 2006; DOE/NETL, 2010) amongst others. 
Water consumption data are monetized using the 2014 tier 1 full service untreated water volumetric cost from the Metropolitan Water District of Southern California (MET) since this rate is a proxy for the value of non-interruptible water in Southern California. MET is the largest wholesale supplier of freshwater in the nation but is focused around Southern California, providing water for 26 cities and member agencies, serving over 19 million people. The district imports water from the Colorado River and Northern California to supplement local supplies. The tier 1 rate is $\$ 593 / \mathrm{AF}$, equivalent to $\$ 0.00182 / \mathrm{gal}$. This number is used to monetize the water consumption of electricity generating technologies that consume freshwater by multiplying it by the gal/MWh water consumption rate. It is also a proxy rate for monetizing the water consumption of power plants that use groundwater in Southern California. This is because the purchase of groundwater rights displace the water requirements of the seller, resulting in equivalent water purchases from MET. Many agency purchases extend past the tier 1 cap and some of the water is purchased at the higher tier 2 rate of $\$ 735 / \mathrm{AF}$ ( $\$ 0.00225 / \mathrm{gal})$. However, to be conservative only the tier 1 water rate is used for monetization in this report.

As discussed in Section 2.4, the costs presented are not representative of the scarcity value of usable water; they are representative of the infrastructure costs to obtain and transport water. There is a strong case to be made that the societal value of usable water is much greater than the price tag.

Multiple case studies are provided to demonstrate how an individual power plant may differ from the water consumption averages and wholesale water prices with respect 
to its water usage and water cost. Some power plants such as Calpine Corporations Geothermal Power Plant (Section 4.1.4.2) receive water from a specific source at a different price than those listed here. Other power plants such as Diablo Canyon Nuclear Power Plant withdraw ocean water and cannot be said to consume any value of freshwater or groundwater. Instead, the Diablo Canyon case study (Section 4.1.3.3) monetizes the environmental impacts of water withdrawals during electricity generation using mitigation costs (the methods of which are discussed in Section 3.1). The total mitigation cost $(\$)$ is divided by the lifetime power production $(\mathrm{MWh})$ to calculate the water cost of mitigation per unit of electricity generation. Such environmental impacts are different for each power plant and therefore must be evaluated on a case by case basis.

To demonstrate economies of scale, lifetime water consumption costs are developed for a $540 \mathrm{MW}$ natural gas combined-cycle (NGCC) power plant by calculating the expected electrical generation of such a facility (total MWh/lifespan) - assuming a forty year lifespan - and multiplying by the water consumption average (gal/MWh) and unit water cost (\$/gal). The lifetime electricity production is calculated by multiplying the capacity (MW) by $\left(24 \frac{\text { hour }}{\text { day }}\right) \times\left(365.25 \frac{\text { day }}{\text { year }}\right) \times(40$ years $)$ and then multiplying by the capacity factor (to account for actual output over a period of time relative to its total potential output) to produce a total MWh value expected over the lifetime of the power plant. The water costs of the other technologies are normalized for the expected electrical output of a 540 MW NGCC power plant and are also multiplied by their respective unit 
water costs to show the total value of water each technology would consume to produce as much electricity as an NGCC power plant throughout the facilities' forty year lifetime.

Water costs of environmental compliance are discussed and a case study is provided to demonstrate the unit cost of complying with environmental regulations such as the Clean Water Act Section 316(b). The Los Angeles Department of Water and Power (LADWP) case study calculates the unit cost of retrofitting two aging units (each $300 \mathrm{MW}$ gas turbines) with six simple cycle gas turbines with dry cooling at the Haynes natural gas power plant to mitigate the environmental impacts of once through cooling. The total expected cost to convert the units is divided by the expected electricity production for thirty years of operational use for the units.

Finally, the water savings of the Renewables Portfolio Standard are monetized for the year 2020 by calculating the annual water cost for two scenarios and contrasting the two numbers. The first scenario, referred to as the "Non-RPS Scenario," assumes constant electricity generation from all sources except natural gas. All additional electricity necessary to meet the expected 2020 California electricity demand is assumed to come from NGCC power plants. The second scenario, referred to as the "RPS Scenario," assumes constant electricity generation from nuclear, geothermal, CST, hydroelectricity, and biomass from 2011 levels and assumes that all new renewable electricity to meet RPS 2020 standards comes from solar PV and Wind, while the rest of the electricity to meet 2020 demand comes from NGCC power plants. Total annual water costs for each scenario are calculated by multiplying the expected yearly MWh electricity 
production for each technology by its respective marginal water cost. The economic water savings is calculated by subtracting the total 2020 water cost for electricity generation under the RPS scenario from the total 2020 water cost for electricity generation under the non-RPS scenario.

\subsection{Mitigation Costs Associated with OTC}

Impingement and entrainment effects (see Section 2.2.4) of thermoelectric cooling have ecological impacts to the surrounding ecosystems that may represent additional economic consequences for a power plant through mitigation costs, pursuant to the Clean Water Act Section 316b and State Water Resources Control Board (SWRCB). Mitigation costs are based on the cost of replacing the production lost ('forgone') to entrainment by producing new, equivalent habitat, restoration that replaces the lost production, or other projects deemed equivalent (Foster et al, 2013). This may take the form of wetland restoration, creation of a marine park reserve, or creation of an artificial reef, etc. to compensate for the habitat forgone due to the existence of a power plant. The estimated cost of mitigation may be calculated by independent scientists, but the responsibility for implementation of mitigation costs and measures is the responsibility of the group with permitting authority (such as the SWRCB or California Energy Commission, etc.).

The Area of Production Forgone (APF) model is used in this report to estimate the scale of ecological loss from OTC cooling. The use of APF allows for the estimation of both the direct and indirect consequences of an impact and provides a currency (i.e., 
habitat acreage) that may be useful for estimating the extent of compensation required to offset an impact (Raimondi, 2013). The loss rate of APF is based on population mortality as calculated using empirical transport modeling (ETM) according to the following equations:

where:

$$
P_{m}=1-\sum_{1}^{n} f_{i}\left(1-P E_{i}\right)^{d}
$$

$P_{m}=$ proportional mortality rate

$f_{i}=$ the proportion of total larvae entrained in a year, entrained in period $\mathrm{i}$

$P E_{i}=$ the estimate of proportional entrainment (proportion of vulnerable population lost per day) for period i

$d=$ the number of days that larvae are exposed to entrainment

The proportional mortality represents the percentage of the aquatic organism of interest at risk that is entrained and killed. To calculate the APF, the proportional mortality rate is multiplied by the Source Water Body (SWB) as shown in equation (2). SWB (in units of acres) is representative of the total acreage of water for which the organism of interest is vulnerable. To determine SWB for a species of interest, samples are taken once per month at the intake structure and nearby areas to determine the age of the organisms. If, for example, a species of larvae are 1 to 24 days old at the intake structure, then larvae from the surrounding area that could travel to the intake structure in 24 days are considered vulnerable and their location is included in their SWB. For power plants that withdraw from an estuary, the entire estuary is considered to be in the SWB. 


$$
A P F=P_{m} \times S W B
$$

To account for multiple species, APF is individually calculated for each species and the average APF for all species of interest is taken. APF represents the total area of new habitat (estuarine, artificial reef, etc. based on the source water body affected) that would need to be created to fully compensate for the losses due to entrainment. The final APF can be used to calculate mitigation costs by determining the total cost required to construct the appropriate habitat of the deemed size (including the cost of assessment). This methodology was applied by Raimondi (2013) in calculating the APF and mitigation cost for Diablo Canyon Power Plant, a case study discussed in Section 4.1.3.3. The Diablo Canyon case study is the only section in this thesis where mitigation costs are taken into account. Mitigation costs are not included in the operational costs of power plants calculated in Chapter 4 but may be an additional cost to such power plants when evaluated on a specific case-by-case basis. Therefore, they are not included in the cost per unit energy calculations. 


\section{Chapter 4: Results}

A distinction is made here between energy production and electricity generation. Energy production refers to the fuel extraction, transportation, and processing. Renewable energy sources do not require water for energy production since they do not need to extract, transport, or process their energy source. Therefore only coal, natural gas, and nuclear energy require water for energy production. Other forms of nonoperational water use such as withdrawals for solar PV are discussed in their respective energy production subsections. Electricity generation refers to the operational use of a power plant to convert the energy source into usable electricity.

\subsection{Consumptive Water Use for Energy Production and Electricity Generation}

\subsubsection{Coal}

Making up over $37 \%$ of the net electricity generation in the United States in 2012, coal remains the most commonly used source for electricity generation in the United States although it has decreased from the $44 \%$ of net electricity generation it provided in 2009 (EIA, 2013b). In 2008, more than twice as much electricity was generated from coal fired power plants than any other source (EIA, 2013b) but it has been steadily declining since then. The use of coal powered electricity is particularly low in California, making up just $1 \%$ of the total generation, not including imported coal generated electricity (EIA, 2013b). Due to concern over greenhouse gas emissions, retirements of almost 5.4 gigawatts of coal fired electric generation has been announced since November of 2013, all of which is in the eastern half of the U.S. (EIA, 2014). Carbon capture and 
sequestration (CCS) can reduce carbon dioxide emissions by $80 \%$ - $90 \%$ compared to coal fired power plants without CCS (IPCC, 2005) but is met with additional water consumption and decreased power plant efficiency. The application of CCS is still in its infancy.

\subsubsection{Water Consumption of Energy Production for Coal}

The consumptive water use for extraction, transportation, and processing of coal is shown in Table 4.1 in units of $\mathrm{m}^{3} /$ terajoule from Water Resource Engineering (Mays, 2011) and converted to gal/MWh for consistency. A conversion heat rate of 10,498 BTU/kWh (EIA 2012 annual average for coal power plants) was used to convert between thermal energy and electricity production so that water consumption could be calculated per MWh of electrical generation. The maximum value for underground mining is representative of mining without recycling water. Beneficiation is a purification processing step whereby the extracted ore is separated from gangue to make it more suitable for combustion. "Other plant operations" consist of plant service, potable water requirements, boiler makeup water, ash handling and flue gas desulfurization process makeup water. 
Table 4.1 Consumptive Water Use for Coal Fuel Cycle (accessed from Mays, 2011)

\begin{tabular}{|ccc|}
\hline \multirow{2}{*}{ Coal Fuel Cycle } & \multicolumn{2}{c|}{ Water Consumption } \\
\hline Surface mining: no revegetation & $\mathbf{( m}^{\mathbf{3}} / \mathbf{1 0} \mathbf{1 2} \mathbf{J}(\mathbf{t h}) \mathbf{)}$ & $\mathbf{( g a l / M W h )}$ \\
\hline Surface mining: revegetation & 2 & 6 \\
\hline Underground mining minimum & 5 & 15 \\
\hline Underground mining maximum & 3 & 9 \\
\hline Beneficiation & 20 & 58 \\
\hline Slurry pipeline min & 4 & 12 \\
\hline Slurry pipeline max & 40 & 117 \\
\hline Other plant operations & 85 & 249 \\
\hline
\end{tabular}

Water needed for coal mining varies depending on method and the predominant method varies by region. The different coal basins and delivery locations are shown in Figure 4.1. In the West, approximately $90 \%$ of the coal is mined using surface mining. In the Appalachia region (which encompasses Kentucky, West Virginia, Virginia, and Tennessee), approximately $65 \%$ of the coal is mined using underground mining (EIA, 2003). Mountaintop mining with valley fills, in which forests are cleared and soil and rock are removed to access coal seams, is also commonly used in Appalachia and can have negative impacts on watersheds (Wilson et al, 2012). Streams nearby mountaintop removal sites show increases in minerals - such as zinc, sodium, selenium, and sulfate and a corresponding decrease in diversity of fish species (Wilson et al, 2012). Although this is equivalent to water consumption in terms of environmental services of water, these environmental effects are not considered in the cost estimate provided in this thesis. 


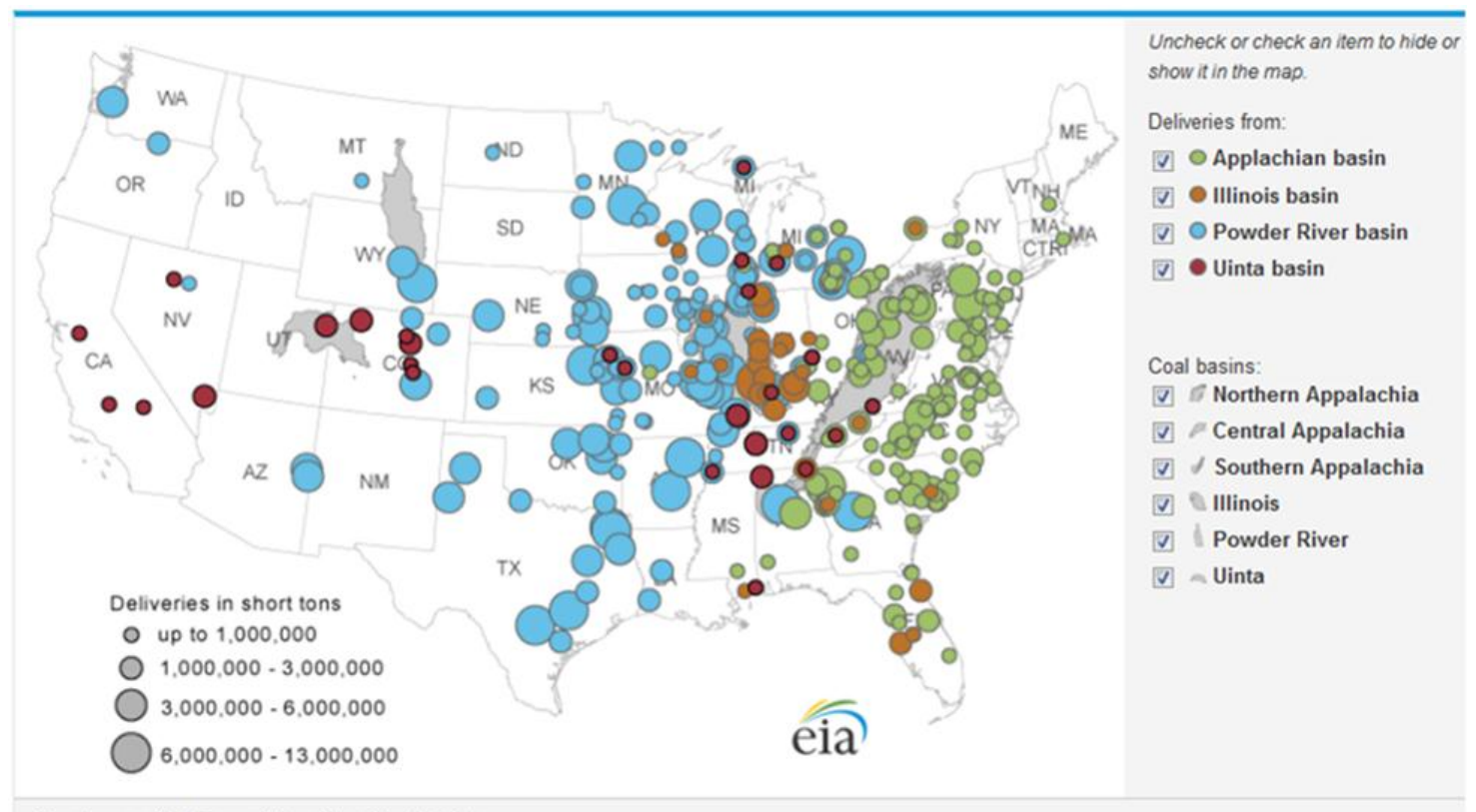

Map Source: U. S. Energy Information Administration

Figure 4.1 Transportation Rates for Coal Delivery Basins (accessed from EIA, 2012)

Transportation of coal can use substantial amounts of water for the slurry pipeline method, but other transportation methods are less considerable. In 2012, $69.6 \%$ of the domestic coal used for power production was transported using rail, while $11.6 \%$ was delivered using barge transportation via the nations rivers, $11.6 \%$ by truck, while slurry pipeline accounted for only $7.1 \%$ and Great Lakes and Tidewater pier transport accounted for less than $0.2 \%$ of the total coal transportation (EIA, 2012). While slurry pipeline can use up to $250 \mathrm{gal} / \mathrm{MWh}$, the majority of coal is transported using the other methods for which water usage is considered negligible. Despite having negligible water usage, barge transportation may still have important impacts on water quality from spills or accidents. However, the latter water expense is not considered here.

Another major issue with coal mining is acid mining drainage, potentially occurring from any type of coal mining. Acid mining drainage occurs when coal mining 
exposes sulfur-containing rocks to surface or ground water, introducing sulfuric acid and dissolving heavy metals from rocks into the stream. The impacts to water streams can range from a moderate loss in biodiversity to completely dead streams (Keith, 2012). The extent of the damage has been estimated by the NRDC to have affected between 9,000 and 22,000 miles of streams in the U.S. (NRDC, 2007). The Hidden Cost of Electricity (Keith, 2012) study addresses more specific issues with acid mining drainage in the heavily mined mid-Atlantic region, citing estimates from the Office of Surface Mining of at least $\$ 3.8$ billion as the expected cost to remediate the impacts of acid mining drainage to an EPA estimated 4,785 miles of affected stream. This remediation cost is not included in water consumption cost estimates in this thesis.

\subsubsection{Operational Water Cost for Electricity Generation from Coal}

The quantities of water withdrawn and consumed for cooling depend on the method of coal generation (pulverized coal, subcritical or supercritical, fluidized bed, or integrated gasification combined cycle) and the cooling system employed, whether it is once through cooling, wet recirculating cooling, pond cooling, dry cooling, or hybrid cooling. According to a joint report by the Department of Energy and the National Energy Technology Laboratory (2010), about $48 \%$ of coal fired power plants in the United States use wet recirculating cooling systems, 39\% use once through cooling, and 13\% use cooling ponds (Table 4.2). Dry cooling systems are almost never employed in the United States for coal fired power plants. 
Fthenakis and Kim (2010) report water withdrawal and consumption values for coal power plants with OTC, cooling ponds, and wet cooling towers (for subcritical, supercritical and fluidized-bed) and integrated gasification combined cycle (IGCC), which is evaluated separately. In Table 4.2, the average water withdrawal and consumption for the coal technologies (IGCC separately) is presented with respect to cooling type, along with a weighted average for the collective coal power plants based on U.S. prevalence data. Applying the default value for untreated MET water, the cost per unit energy is calculated and shown in Table 4.3.

Table 4.2 Coal Operational Water Withdrawals and Consumption by Coal Type

\begin{tabular}{|c|ccc|}
\hline Coal Type & $\begin{array}{c}\text { Withdrawals } \\
\text { (gal/MWh) }\end{array}$ & $\begin{array}{c}\text { Consumption } \\
\text { (gal/MWh) }\end{array}$ & U.S. Prevalence \\
\hline $\begin{array}{c}\text { Average Once- } \\
\text { Through }\end{array}$ & 35135 & 301 & $39 \%$ \\
\hline $\begin{array}{c}\text { Average Cooling } \\
\text { Pond }\end{array}$ & 749 & 700 & $48 \%$ \\
\hline $\begin{array}{c}\text { Average Wet } \\
\text { Recirculating }\end{array}$ & 11157 & 416 & $13 \%$ \\
\hline $\begin{array}{c}\text { Average Coal } \\
\text { (Weighted) }\end{array}$ & 15513 & 507 & \\
\hline IGCC & 423 & 369 & \\
\hline
\end{tabular}

Table 4.3 Coal Operational Water Cost by Coal Type

\begin{tabular}{|ccc|}
\hline Coal Type & Water Consumption (gal/MWh) & Water Cost (\$MWh) \\
\hline Avg Once-Through & 301 & 0.55 \\
\hline Avg Cooling Pond & 700 & 1.27 \\
\hline $\begin{array}{c}\text { Avg Wet } \\
\text { Recirculating }\end{array}$ & 416 & 0.76 \\
\hline Avg Coal (Weighted) & 507 & 0.92 \\
\hline IGCC & 370 & 0.67 \\
\hline
\end{tabular}


Efforts to reduce greenhouse gas emissions from coal plants using carbon capture and sequestration would require significant additional water usage if this technology was adopted. The water increase comes partly from water needed for the capture process but also from the parasitic effect of CCS, a reduction in overall plant efficiency (Mielke, 2010).

Table 4.4 Coal Water Cost With and Without CCS

\begin{tabular}{|ccccc|}
\hline $\begin{array}{c}\text { Coal Power } \\
\text { Plant Type }\end{array}$ & $\begin{array}{c}\text { Water } \\
\text { Consumption } \\
\text { with CCS } \\
\text { (gal/MWh) }\end{array}$ & $\begin{array}{c}\text { Water Cost } \\
\text { with CCS } \\
\text { (\$/MWh) }\end{array}$ & $\begin{array}{c}\text { Water } \\
\text { Consumption } \\
\text { without CCS } \\
\text { (gal/MWh) }\end{array}$ & $\begin{array}{c}\text { Water Cost } \\
\text { without CCS } \\
\text { (\$/MWh) }\end{array}$ \\
\hline $\begin{array}{c}\text { Wet tower, } \\
\text { subcritical }\end{array}$ & 1330 & 2.42 & 680 & 1.24 \\
\hline $\begin{array}{c}\text { Wet tower, } \\
\text { supercritical }\end{array}$ & 1150 & 2.09 & 590 & 1.07 \\
\hline $\begin{array}{c}\text { Wet tower, } \\
\text { retrofit }\end{array}$ & 343 & 0.62 & & \\
\hline IGCC & 502 & 0.91 & 370 & 0.67 \\
\hline
\end{tabular}

Table 4.4 uses values from the Fthenakis and Kim (2010) study and the MET untreated water price to compare water costs for power plants with and without CCS. The CCS studies reviewed by Fthenakis and Kim (2010) assumed that carbon dioxide is captured through absorption with amine solvents that are the most commonly used in modeling for advanced coal power plants (GCEP, 2005). CCS can almost double the water cost for a power plant (Table 4.4), however, this analysis for CCS additional water is unverified as CCS technologies are not yet in service (Fthenakis and Kim, 2010). 


\subsubsection{Natural Gas}

For many years, natural gas provided a small percentage of electricity in the United States. However, gas-fired power plants have increased substantially in recent years due in part to the advent of combined cycle combustion turbines (CCCT). Since 2008, natural gas electricity generation has increased by almost 40\% (EIA, 2013b). Using CCCT, excess heat from the turbine can be used to drive a steam cycle and generate additional electricity (Keith et al, 2012). Combined Cycle power plants operate at a higher thermal efficiency and thus produce less waste heat per unit electricity produced (Cooley et al, 2011). Since they are more thermally efficient than coal and nuclear plants, they have lower cooling water use rates than before. According to AOE2000 projections, over 90\% of gas-fired electricity will come from CCCT in 2020 (EPRI, 2002). Section 4.1.2 analyzes water use for natural gas CCCT systems only since it has become the dominant form of natural gas generated electricity and is predicted to further increase relative to conventional turbines as time progresses.

\subsubsection{Water Consumption of Energy Production for Natural Gas}

Water usage of natural gas production depends on whether conventional or unconventional natural gas is being utilized. Conventional natural gas was the primary gas energy used in the past. The conventional natural gas is much easier to extract as it exists in highly permeable surfaces, whereas unconventional gas is found in deeper, less permeable rock formations. More than $96 \%$ of all oil and gas has been depleted from its source rocks (Engelder and Ingraffea, 2011), and consequently the use of unconventional natural gas is expected to increase relative to conventional gas. Shale gas, tight sands, and 
coal bed methane are examples of unconventional natural gas. Shale gas extraction is viable with the use of hydraulic fracturing which uses water to fracture the shale rock, allowing the shale gas to escape and be captured. Shale gas rose from $1 \%$ of domestic gas production in 2000 to $20 \%$ in 2010 and the EIA estimates that $46 \%$ of U.S. gas supply will come from shale gas by 2035 (Stevens, 2012).

Table 4.5 Consumptive Water Use for Conventional Natural Gas Fuel Cycle (accessed from Mays, 2011)

\begin{tabular}{|ccc|}
\hline Natural Gas Fuel Cycle & \multicolumn{2}{c|}{ Water Consumption } \\
& $\left.\mathbf{( m}^{\mathbf{3}} / \mathbf{1 0} \mathbf{1 0}^{\mathbf{1 2}} \mathbf{J}(\mathbf{t h})\right)$ & (gal/MWh) \\
\hline Onshore gas extraction & negligible & negligible \\
\hline Natural gas processing & 6 & 13 \\
\hline Gas pipeline operation & 3 & 7 \\
\hline Other plant operations & 100 & 224 \\
\hline
\end{tabular}

Table 4.5 shows the water consumption associated with conventional natural gas extraction, transportation, processing, and other plant operations. The values are presented in units of $\mathrm{m}^{3} /$ terajoule from Water Resource Engineering textbook (Mays, 2011) and converted to gal/MWh for consistency. A power plant heat rate of 8,039 BTU/kWh was used to convert between thermal energy and electricity production. This conversion rate is the EPA cited average operating heat rate for natural gas power plants in 2012. The "other plant operations" includes plant service, potable water requirements and boiler makeup water.

Due to diminishing natural gas reserves and the recent advent of hydraulic fracturing, the water impact of natural gas is likely now different from the assumptions depicted in Table 4.5. Though the extent of water intensity and environmental impacts 
associated with hydraulic fracturing will not be fully elucidated until the EPA publishes its report on the matter (it has not yet been published), other sources can give us a glimpse. Meldrum et al (2013) looks at 49 sources ranging from 1 gal/MWh to 186 gal/MWh and reports a median value of $12 \mathrm{gal} / \mathrm{MWh}$ as the water consumption for hydraulic fracturing of shale gas. The $12 \mathrm{gal} / \mathrm{MWh}$ would replace the negligible water use for onshore gas extraction, but would still require water for the other steps included in Table 4.5. Other operational concerns of hydraulic fracturing such as fugitive methane emissions, blowouts, and contamination of drinking water from poorly treated flowback water are other important issues with indirect effects on water consumption.

\subsubsection{Operational Water Cost for Electricity Generation from Natural Gas}

Table 4.6 shows estimates of U.S. average amounts of water withdrawals and consumption for natural gas combined cycle electricity generation based on cooling method prevalence. The withdrawals and consumption data are taken from the source listed in the same row. The U.S. prevalence data is from Water in the West (2013), which references EIA 2012 data. EIA reports hybrid cooling prevalence of $0.6 \%$ but in Table 4.6, which does not include hybrid cooling, $0.3 \%$ was added to both wet recirculating and dry system percentages to compensate. 
Table 4.6 Combined Cycle Water Withdrawals and Consumption by Cooling Method

\begin{tabular}{|ccccc|}
$\begin{array}{c}\text { Combined- } \\
\text { Cycle } \\
\text { Combustion }\end{array}$ & $\begin{array}{c}\text { Withdrawals } \\
\text { (gal/MWh) }\end{array}$ & $\begin{array}{c}\text { Consumption } \\
\text { (gal/MWh) }\end{array}$ & Source & $\begin{array}{c}\text { U.S. } \\
\text { Prevalence }\end{array}$ \\
\hline Once-Through & 11860 & 80 & $\begin{array}{c}\text { Water in the } \\
\text { West, 2013 }\end{array}$ & $13.5 \%$ \\
\hline $\begin{array}{c}\text { Wet } \\
\text { Recirculating }\end{array}$ & 253 & 198 & $\begin{array}{c}\text { Macknick, } \\
2011\end{array}$ & $71.6 \%$ \\
\hline Dry & 10 & 10 & $\begin{array}{c}\text { Water in the } \\
\text { West, 2013 }\end{array}$ & $12.0 \%$ \\
\hline Cooling Pond & 5950 & 240 & Macknick, \\
2011 & $2.9 \%$ \\
\hline $\begin{array}{c}\text { Weighted } \\
\text { Average }\end{array}$ & 1956 & 161 & & $100.0 \%$ \\
\hline
\end{tabular}

Table 4.7 monetizes the water cost of consumption using the $\$ 0.00182 /$ gal default MET price for surface water. Since some OTC systems use seawater, the $\$ / M W h$ values do not apply to them. For NGCC systems in Southern California, \$0.29 is the average value of water consumed per MWh of electricity generated.

Table 4.7 Natural Gas Cooling Water Cost by Cooling Type

\begin{tabular}{|ccc|}
\hline $\begin{array}{c}\text { Combined-Cycle } \\
\text { Combustion }\end{array}$ & $\begin{array}{c}\text { Water Consumption } \\
\text { (gal/MWh) }\end{array}$ & $\begin{array}{c}\text { Water Cost } \\
\text { (\$/MWh) }\end{array}$ \\
\hline Once-Through & 80 & 0.15 \\
\hline Wet Recirculating & 198 & 0.36 \\
\hline Dry & 10 & 0.02 \\
\hline Cooling Pond & 240 & 0.44 \\
\hline Weighted Average & 161 & 0.29 \\
\hline
\end{tabular}

As described for coal, use of CCS could greatly increase water consumption for natural gas powered generation. Table 4.8 shows the water withdrawals and consumption for natural gas CCCT systems that employ carbon capture and sequestration compared to 
those that don't. Note, the non-CCS values for Table 4.8 come from Fthenakis and Kim (2010) and are higher than the values for natural gas CCCT listed in Table 4.6 and 4.7, which drew from different sources. The Fthenakis and Kim (2010) non-CCS values are congruent with the values they present for CCCT with wet towers but they overestimate the water consumption of natural gas power plants relative to the sources used in Tables 4.6 and 4.7, which use more recent data.

Table 4.8 Natural Gas Water Withdrawals and Consumption with and without CCS

\begin{tabular}{|c|cc|}
\hline $\begin{array}{c}\text { Natural Gas Combine } \\
\text { Cycle }\end{array}$ & Withdrawals (gal/MWh) & $\begin{array}{c}\text { Consumption (gal/MWh) } \\
\text { with carbon capture }\end{array}$ \\
\hline without carbon capture & 555 & 502 \\
\hline
\end{tabular}

Applying the default $\$ 0.00182 /$ gal MET price for untreated freshwater produces the cost estimates shown in Table 4.9, which indicate that if CCS is implemented for natural gas fired power plants, water costs may almost double. It is also worth noting that NGCC plants with CCS experience a thermal efficiency of $43.9 \%$ compared to $51 \%$ for those without CCS (Meldrum et al, 2013).

Table 4.9 Natural Gas Combined Cycle Water Cost with and without CCS

\begin{tabular}{|ccc|}
\hline NGCC & Water Consumption (gal/MWh) & Water Cost (\$/gal) \\
\hline With CCS & 502 & 0.91 \\
\hline Without CCS & 264 & 0.48 \\
\hline
\end{tabular}

\subsubsection{Natural Gas Case Study: Blythe Energy Project, Phase II}

The Blythe natural gas power plant provides an interesting case study because its use of groundwater was contested throughout its application process. The California 
Energy Commission approved the Blythe Energy Project, Phase II (BEPII), a proposed 520 MW combined-cycle facility in Blythe California (Riverside County) in 2005 (California Energy Commission, 2005). The commission decision document specifies the use of well water from the Palo Verde Mesa Aquifer for cooling system makeup water, the steam production system, and potable water for domestic uses. It also adduces a dialogue that occurred between the applicant and the commission staff over whether the groundwater was applicable for use by the power plant. The groundwater beneath the Palo Verde Mesa Aquifer near the BEPII site has a total dissolved solids (TDS) content of $920-1100 \mathrm{ppm}$, which the applicant argued is greater than $1000 \mathrm{ppm}$, thus characterizing it as brackish water and making it eligible to be used for the cooling tower in accordance with resolution 75-58 (California Energy Commission, 2005). The commission staff contended that project groundwater is actually drinking water quality and thus, highly disfavored as cooling water under the same resolution. After the commission staff explored alternative options (such as reclaimed water from the City of Blythe's Wastewater Treatment Plant and dry cooling) and found them to not be suitable for the power plant, the proposal to use groundwater was approved but with a mitigation contingency of a voluntary Water Conservation Offset Program.

The plant is expected to use 3,300 acre-feet/year of groundwater for the aforementioned purposes. Using an EIA-cited capacity factor for natural gas power plants of 0.465 , a $520 \mathrm{MW}$ power plant such as this can be expected to produce 2.1 million MWh/year. Converting 3,300 acre-feet/year to gal/year and dividing the expected energy production by this number yields a water use rate of approximately 510 gal/MWh. Since 
the purchase of groundwater rights requires the seller to obtain water from a new source, presumably MET, the MET price is used as a proxy for the Blythe water consumption. Using $\$ 0.00182 / \mathrm{gal}$ as the proxy price for water and multiplying it by $510 \mathrm{gal} / \mathrm{MWh}$ produces an estimate of $\$ 0.93 / \mathrm{MWh}$ of water use. This means that $\$ 2$ million worth of water is withdrawn from the Palo Verde Mesa Aquifer each year.

\subsubsection{Nuclear}

Nuclear energy provides $19 \%$ of the total U.S. electrical energy supply (EIA, 2013b). In California it provides less than half this amount, at only 9\% (EIA, 2013b). Nuclear energy production in California has decreased since the decommissioning of Humboldt Bay Power Plant in 1976, Rancho Seco Nuclear Generating Station in 2009, and the San Onofre Nuclear Generating Station in 2013. Currently, the only operating nuclear generating station in California is Diablo Canyon Power Plant situated on the Central Coast in San Luis Obispo County.

\subsubsection{Water Consumption of Energy Production for Nuclear}

Table 4.10 shows the water consumption associated with uranium extraction, transportation, processing, and other plant operations. The values are presented in units of $\mathrm{m}^{3} /$ terajoule from Water Resource Engineering textbook (Mays, 2011) and converted to gal/MWh for consistency. A range of 8 to $10 \mathrm{~m}^{3} /$ terajoule was in the textbook for uranium milling but the average of 9 is reported in Table 4.10. A power plant heat rate of 10,479 BTU/kWh was used to convert between thermal energy and electricity 
production. This conversion rate is the EPA-cited average operating heat rate for nuclear power plants in 2012 .

Table 4.10 Consumptive Water Use for Nuclear Fuel Cycle

\begin{tabular}{|ccc|}
\hline Nuclear Fuel Cycle & \multicolumn{2}{c|}{ Water Consumption } \\
\hline Open pit uranium mining & $\mathbf{( m}^{\mathbf{3}} \mathbf{/ 1 0} \mathbf{1 2} \mathbf{~}($ th $)$ ) & (gal/MWh) \\
\hline $\begin{array}{c}\text { Underground uranium } \\
\text { mining }\end{array}$ & 20 & 58 \\
\hline Uranium milling & 0.2 & 1 \\
\hline $\begin{array}{c}\text { Uranium hexafluoride } \\
\text { conversion }\end{array}$ & 9 & 12 \\
\hline $\begin{array}{c}\text { Uranium enrichment: } \\
\text { diffusion }\end{array}$ & 4 & 35 \\
\hline $\begin{array}{c}\text { Uranium enrichment: } \\
\text { centrifuge }\end{array}$ & 12 & 6 \\
\hline Fuel fabrication & 2 & 3 \\
\hline Nuclear fuel reprocessing & 1 & 146 \\
\hline
\end{tabular}

Uranium has been mined for over 100 years in the United States but mining methods have changed considerably over time. The EIA has documented up to 4,000 uranium mines in the United States, but the vast majority of these mines have been abandoned. The majority of uranium mining has taken place in Wyoming, Texas, and Nebraska though uranium reserves also exist in Arizona, New Mexico, Utah, and Colorado. There are currently four underground mines in operation in the U.S and four in situ leaching (ISL) mines, with $90 \%$ of the uranium coming from the in situ leaching mines (EIA, 2011). A diagram of in situ leaching is shown in Figure 4.2. 


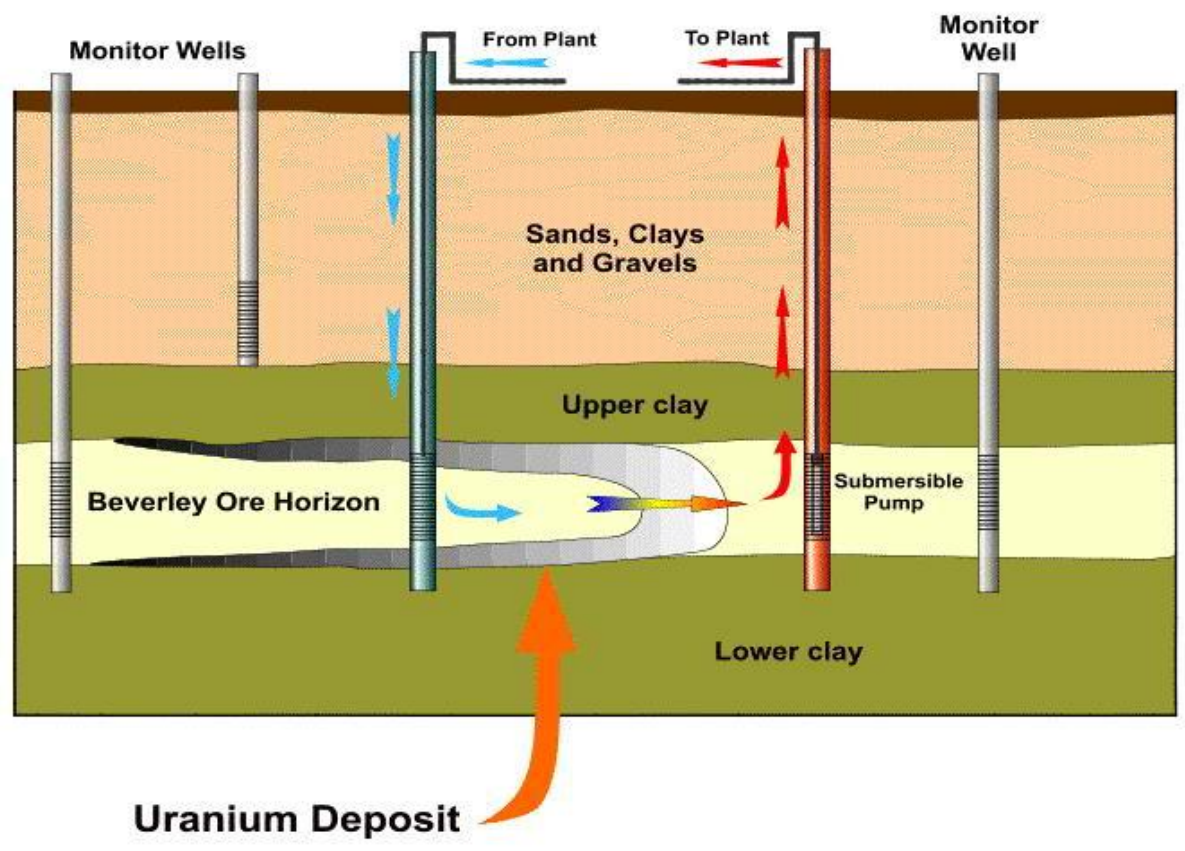

Figure 4.2 In Situ Leaching (accessed from Healthgate Resources, 1998)

The reporting of ISL water requirements has enormous variation, primarily distinguished by how the water is classified. A common case study referenced for ISL mining is Mudd and Diesendorff (2008). Looking at an ISL site for 6 years, the average water consumption was listed at 8,207 $\mathrm{L} /$ ton $\mathrm{U}_{3} \mathrm{O}_{8}$. Cooley et al (2011) extrapolated these data and reported $1.1 \mathrm{gal} / \mathrm{kWh}$ of electricity produced. Equivalent to $1,100 \mathrm{gal} / \mathrm{MWh}$, this is an extremely large rate of water usage, yet the vast majority is likely produced water. Meldrum et al (2013) reports a value of $18 \mathrm{gal} / \mathrm{MWh}$ as the water consumption for in situ leaching. The Meldrum et al (2013) study recognizes the higher values reported elsewhere - stating that the inclusion of produced water in the water consumption can lead to values up to 70 times greater - but does not seek to quantify the use of produced water as external water consumption. 


\subsubsection{Operational Water Cost for Electricity Generation from Nuclear}

As for all thermoelectric power plants, the bulk of lifecycle water consumption for nuclear power comes from water used for cooling. Since the only nuclear power plant in California uses OTC with seawater, there are no actual nuclear power plants in California that use freshwater. CWA section 316(b) discourages the construction of new power plants with seawater OTC, so a nuclear power plant built in Southern California would very likely use freshwater from MET or purchase groundwater rights that result in equivalent purchases from MET (since the seller of the groundwater rights will need to compensate with purchases from MET). Therefore the water costs for nuclear cooling are represented by the MET tier 1 rate of $\$ 0.00182 / \mathrm{gal}$ and are applied in Table 4.12 to estimate the operational water cost of nuclear power plants that use freshwater. However, these costs will not be used for the California case study. Statistics for water withdrawals and consumption in Table 4.11 come from Meldrum et al (2013) and U.S. prevalence data comes from DOE/NETL (2010).

Table 4.11 Nuclear Operational Water Withdrawal and Consumption by Cooling Method

\begin{tabular}{|ccccc|}
\hline $\begin{array}{c}\text { Operational } \\
\text { Cooling Method }\end{array}$ & $\begin{array}{c}\text { Withdrawals } \\
\text { (gal/MWh) }\end{array}$ & $\begin{array}{c}\text { Consumption } \\
\text { (gal/MWh) }\end{array}$ & Source & $\begin{array}{c}\text { U.S. } \\
\text { Prevalence }\end{array}$ \\
\hline Once-Through & 47000 & 400 & $\begin{array}{c}\text { Meldrum et al, } \\
2013\end{array}$ & $38 \%$ \\
\hline Cooling Pond & 1100 & 610 & $\begin{array}{c}\text { Meldrum et al, } \\
2013\end{array}$ & $18 \%$ \\
\hline $\begin{array}{c}\text { Wet } \\
\text { Recirculating } \\
\text { Tower }\end{array}$ & 1100 & 720 & $\begin{array}{c}\text { Meldrum et al, } \\
2013\end{array}$ & $44 \%$ \\
\hline Weighted Avg & 18542 & 577 & & \\
\hline
\end{tabular}


Table 4.12 Nuclear Operational Water Cost by Cooling Method

\begin{tabular}{|ccc|}
\hline $\begin{array}{c}\text { Operational Cooling } \\
\text { Method }\end{array}$ & $\begin{array}{c}\text { Water Consumption } \\
\text { (gal/MWh) }\end{array}$ & Water Cost (\$/MWh) \\
\hline Once-Through & 400 & 0.73 \\
\hline Cooling Pond & 610 & 1.11 \\
\hline Wet Recirculating & 720 & 1.31 \\
\hline Weighted Average & 577 & 1.05 \\
\hline
\end{tabular}

Average water consumption for nuclear power plants in the United States are higher than for coal and natural gas power plants (for operational use). The average operational water cost for nuclear power plants that use freshwater for cooling is $\$ 1.05 / \mathrm{MWh}$ compared to $\$ 0.92 / \mathrm{MWh}$ and $\$ 0.29 / \mathrm{MWh}$ for coal and natural gas respectively. Power plants that use seawater instead of freshwater for cooling, such as Diablo Canyon Power Plant, cannot be said to incur this cost for water. Instead, the value of its environmental impact due to cooling water use is incurred in another fashion, through mitigation costs, as demonstrated by the case study in Section 4.1.3.3 below.

\subsubsection{Nuclear Case Study: Diablo Canyon Power Plant}

Diablo Canyon Nuclear Power Plant in San Luis Obispo County, California uses OTC with seawater. Therefore, the water withdrawals cannot be represented by the default price of MET. Instead of freshwater evaporation, the water cost can be represented by estimating the mitigation cost to remedy the ecological impacts that ocean water OTC causes.

In calculating the environmental mitigation cost, the goal is to determine the cost to compensate the effects of entrainment caused by the OTC system. Peter Raimondi, 
Chair and Professor for the Department of Ecology and Evolutionary Biology at UC Santa Cruz, worked as an independent scientist to determine the mitigation cost of Diablo Canyon using the APF method based on ETM (see Section 3.1). A couple of compensatory options were considered, including establishment of a marine reserve and construction of an artificial reef. After some deliberation, the artificial reef option was decided to be best to compensate for the rocky reef type mitigation project. Raimondi determined the area of production forgone to be 543 acres (Raimondi, 2013). Using a value of $\$ 125,000 /$ acre - which represents the real cost per unit area to construct the artificial reef that compensated for San Onofre Nuclear Generating Station's ecological impact and continues to serve as the best estimate for the cost of building an artificial reef - Raimondi calculated the mitigation cost of Diablo Canyon's ecological effects to be $\frac{\$ 125,000}{\text { acre }} \times 543$ acres, for a total of $\$ 67,875,000$.

Diablo Canyon is a $2240 \mathrm{MW}$ plant and produces about $18,000 \mathrm{GWh}$ of electricity annually (Mayeda, Riener, PG\&E, 2013). Taking the lifespan of a nuclear power plant to be 40 years, this means that Diablo Canyon will produce a total of 720,000 GWh. Dividing the total mitigation cost, $\$ 67.875$ million, by the total MWh produced in its lifespan, 720 million MWh, yields a unit mitigation cost of $\$ 0.094 / \mathrm{MWh}$. This is a relatively small unit cost compared to the water costs of thermoelectric cooling due to the large quantity of electricity produced by nuclear power plants. The total mitigation cost however, is comparable to the total water consumption costs of a standard sized NGCC power plant, as demonstrated in Section 4.3. 
Though the compensatory cost of mitigation has been estimated for Diablo Canyon, no such action has been taken on the part of PG\&E (the electric utility responsible for Diablo Canyon) to construct an artificial reef. Whereas most seawater OTC power plants have been held accountable and do actually implement the compensatory mitigation strategy, PG\&E declared bankruptcy around the time that the artificial reef was being proposed. This is a unique situation, which resulted in no mitigation formally being done. If Diablo Canyon, which is responsible for $80 \%$ of the damage done to the marine environment from all California coastal power plants, is exempted from minimizing its environmental damage, the OTC policy will be effectively gutted and a major state marine protection initiative will be dead (World Business Academy, N.D.)

\subsubsection{Geothermal}

Geothermal energy makes up a very small percentage of the overall energy production in the United States, making up less than 1\% of the net generation in 2012 (EIA, 2013b) but California is the number one producer of geothermal electricity of any state. In 2010, geothermal energy provided $42 \%$ of California's commercial in-state renewable electricity generation (California Energy Commission, 2011). Most of California's geothermal electricity is produced in the Geyser Region of Northern California, but Southern California provides enough geothermal capacity in Coso and Imperial Valley to meet the demands of an estimated 1 million California households (Jannejohn et al, 2011). Geothermal electricity is expected to experience lesser growth than solar PV in California en route to meeting RPS standards (Reyes, 2014) however, a 
variety of sources estimate untapped longer term geothermal potential ranging from 3,186 $-24,750 \mathrm{MW}$ with an average of 10,917 MW in California (Jannejohn et al, 2011).

\subsubsection{Operational Water Cost for Electricity Generation from Geothermal}

There are three main forms for geothermal energy: dry steam (colloquially called steam), binary, and flash steam (colloquially called flash). A fourth type of geothermal plant has been developing in recent years and is called Enhanced Geothermal System (EGS). Dry steam power plants receive only steam from underground whereas flash power plants receive hot water in addition to steam and must separate the liquid from the gas before electricity generation. Binary power plants can economically generate electricity from lower temperature reservoirs. In the binary process, geothermal water is used to heat a "working fluid" (also called binary liquid) such as isobutane in a heat exchanger. The working fluid then vaporizes into gaseous form and is driven through a turbine to generate electricity. EGS systems can expand existing subsurface fractures or create new ones by injecting water to improve circulation of the geofluid (the subsurface fluid used to transfer the heat energy from the Earth); this is referred to as hydraulic stimulation. Enhanced systems can operate at higher temperatures, $175^{\circ} \mathrm{C}$ to $225^{\circ} \mathrm{C}$, as opposed to binary plants that operate at more moderate temperatures of $74^{\circ} \mathrm{C}$ to $182^{\circ} \mathrm{C}$ (Clark, 2010). Cooling towers are included in geothermal power plant design and are necessary for cooling the turbines and prolonging the longevity of the plant. These cooling towers require a continuous supply of cooling water and consume much of it as it escapes in large vapor plumes. 
A study of lifecycle water consumption was conducted by Argonne National Laboratory and is documented in the paper by Clark et al (2010) called Water Use in the Development and Operation of Geothermal Power Plants. This report develops lifecycle water use analysis for four different geothermal scenarios: 20-MW EGS, 50-MW EGS, 10-MW Binary, and 50-MW Flash. Makeup water - any additional water that must be added to the system to compensate for water lost to evaporation - is used to replenish lost cooling water when surface and groundwater are not available from nearby sources. Makeup water for use during the operational phase was the largest water consumer for all scenarios, the results of which are shown in Table 4.13.

Table 4.13 Lifecycle Water Consumption for Geothermal Scenarios (Clark et al, 2010)

\begin{tabular}{|cccc|}
\hline Scenario & $\begin{array}{c}\text { Construction \& EGS } \\
\text { Stimulation } \\
\text { (gal/MWh) }\end{array}$ & Water Consumption (gal/MWh) & Total \\
\hline 20 MW EGS & 10 & $290-720$ & $300-730$ \\
\hline 50 MW EGS & 10 & $290-720$ & $300-730$ \\
\hline 10 MW Binary & 1 & 270 & 271 \\
\hline $\mathbf{5 0}$ MW Flash & 1 & 10 & 11 \\
\hline
\end{tabular}

Clark et al (2010) provided a range of values for the EGS systems because not all the geofluid lost to evaporation must be replaced with makeup water to maintain the reservoir pressure. The lower end of the range represents a minimum amount of makeup water replacement and the upper range represents $100 \%$ replacement. Since most geothermal power plants replace between $40 \%$ and $50 \%$ of the consumed water (Reyes, 2014), the average of the range is taken and then multiplied by the $\$ 0.00182 /$ gal MET default price for surface water from a wholesale supplier to produce the water cost per 
unit electricity for geothermal power plants that use freshwater for makeup water, shown below in Table 4.14 .

Table 4.14 Freshwater Cost for Geothermal Scenarios

\begin{tabular}{|ccc|}
\hline Scenario & Water Consumption (gal/MWh) & Water Cost (\$/MWh) \\
\hline 20 MW EGS & 515 & 0.94 \\
\hline 50 MW EGS & 515 & 0.94 \\
\hline 10 MW Binary & 271 & 0.49 \\
\hline 50 MW Flash & 11 & 0.02 \\
\hline
\end{tabular}

Though the water cost for full replacement of withdrawn groundwater can reach as high as $\$ 1.33 / \mathrm{MWh}$ (corresponding to $730 \mathrm{gal} / \mathrm{MWh}$ ), the $50 \%$ makeup water costs of \$0.94/MWh is chosen as the representative value for calculations in Chapter 5 because it is reflective of most geothermal operations.

\subsubsection{Geothermal Case Study: Calpine Corporation}

The Calpine Corporation's geothermal production in California was chosen as a case study for two reasons. One reason is that it is located in the most productive region for geothermal energy in the world. The other reason is that it demonstrates the complexities of deducing a comprehensive water cost for a site-specific power plant. The following paragraphs describe the operation, showing the intricacies of detail in water supply and cost, and then make assumptions to estimate the value of water consumed though the actual water cost to Calpine per MWh of electricity produced is much more difficult to discern. 
There are only two geothermal plant locations in the world right now that produce over 500MW, one in the Geyser region in California and the other in Italy (Water in the West, 2013). Out of 17 total power plants in the area, Calpine Corporation owns 15 of them. In 2013, the Calpine Geysers provided about 15\% of California's renewable electricity and $36 \%$ of the U.S. geothermal generation; the region is the single largest geothermal operation in the world (Calpine Corporation, 2014.) The Calpine power plants use minimal water for burner units, scrubbers, and dry cooling systems; the vast majority of the water usage for power production is for water reinjection through wells to replenish the steam that gets used to spin the turbines. Over the past decade, about 6 million MWh of electricity was generated per year by the Calpine geothermal power plants (Calpine Corporation, 2014). Currently, a total of 20 million gallons per day - 11 million gallons of tertiary treated wastewater from Santa Rosa (Kagel et. al, 2007) and 9 million gallons of secondary treated wastewater from Clear Lake (Calpine Corporation, 2012) - get pumped daily for injection into the geothermal reservoir. Using these data, a calculated 1217.5 gallons of wastewater are used per MWh of electricity produced.

Calculating the actual water usage for this geothermal case study is not as straightforward as the aforementioned statistics make it seem. The power plants actually utilize a number of sources for water and the amounts are variable depending on multiple factors. From personal communication with Calpine's Production Engineer Supervisor at the Geysers, Santa Rosa pumps lower rates of their tertiary treated water in the summer, usually between 7.5 - 12 MGD, but in the winter it goes up to 20 MGD (Reyes, 2014). The 9 MGD from Clear Lake is likely representative of non-drought winter months but is 
closer to 2 MGD in the summer time (Reyes, 2014). The Clear Lake water comes from multiple treatment plants (Solar Powered NE Treatment Plant, Clearlake Oaks Treatment Plant, Solar Powered SE Treatment Plant, and Middleton) and is used by both Calpine Corporation and another power agency NCPA (NCPA operates one of the other geothermal plants in The Geysers; Clear Lake water is split about 2/3 Calpine and 1/3 NCPA according to Reyes). Wastewater is sometimes supplemented with freshwater from Clearlake and Lower Lake but due to the recent drought, no water from the lakes has been used this year. Calpine also has a permit to extract groundwater from Big Sulfur Creek, regulated by the USGS, but cannot draw from it if the water table gets too low (Reyes, 2014). For policy decisions that look at a specific situation, this sort of detail is critical to proper evaluation but makes estimating the marginal water cost of electricity much more difficult.

Due to the aforementioned level of detail, exact water costs are indiscernible. To estimate water cost for Calpine geothermal power plants, water usage was simplified according to the following assumptions: (1) 20 MGD recycled water coming from Santa Rosa only (2) all of the water used for reinjection is used by Calpine Corporation's power plants (3) the value of Santa Rosa's recycled wastewater is $\$ 5.01 / 1000$ gallons (which is what the City of Santa Rosa charges other customers for their recycled water). With these assumptions, the wastewater cost shown in Table 4.15 was calculated. The value of water consumed if an equivalent operation were to be commissioned in Southern California is also shown as the MET water reinjection type. The costs for both are reflective of the rate that alternative agencies would pay for the water. Also note the water consumption 
shown in Table 4.15 is significantly higher than those expected from Table 4.14 since the statistics used for Calpine water consumption don't account for lesser water consumption in the summer time and because Calpine replaces a greater percentage of lost water than most geothermal power plants.

Table 4.15 Water Use for Calpine Region Geothermal Power

\begin{tabular}{|cccc|}
\hline Water Use Type & Water Consumption (gal/MWh) & \$/gal & \$/MWh \\
\hline Wastewater reinjection & 1217.5 & 0.00501 & 6.10 \\
\hline MET water reinjection & 1217.5 & 0.00182 & 2.22 \\
\hline
\end{tabular}

The city of Santa Rosa sells 1000 gallons of recycled wastewater for a marginal cost of \$5.01 (Santa Rosa, 2014); hence the cost for recycled wastewater reinjection is $\$ 0.00501 / \mathrm{gal}$. The cost of producing this water is based on EPA standards rather than scarcity of freshwater and the cost is relatively high because Santa Rosa provides tertiary treatment. It is important to note that Calpine Corporation does not actually pay $\$ 0.00501 /$ gal for the water from Santa Rosa. Instead, they have an individual agreement to pay the city of Santa Rosa $\$ 300,000 /$ year for the recycled water. This equates to $\$ 0.05 / \mathrm{MWh}$ but this rate is not all inclusive. Calpine also provides the electricity to pump to the water up approximately 3,000 feet in elevation to the Geyser location site, the energy requirements of which are estimated to be between 4-6 MW (Reyes, 2014). Since the City of Santa Rosa charges \$5.01 for 1000 gallons of wastewater however, the $\$ 0.00501 /$ gal represents the marginal value of the water to the City of Santa Rosa. In actuality though, they may not be able to sell all that recycled water without Calpine's business. Additionally, if Calpine's geyser operation were to be decommissioned, other 
expenses such as the construction of new pipelines would be incurred to transport the water to other agencies. This case study demonstrates that the water costs would not necessarily be conserved in their entirety in realistic and more complicated situations.

\subsubsection{Concentrated Solar Thermal (CST)}

The use of solar thermal has expanded in California in the past decade, yet is still small in the overall energy picture in the United States, making up less than $1 \%$ of the net generation (EIA, 2013b). CST systems harness the energy of the sun using large arrays of reflective materials to concentrate the light and heat a fluid to create steam that then spins a turbine to generate electricity. Since utility-sized solar thermal technologies use heat to boil a fluid and operate using the Rankine cycle just like thermoelectric power plants, they require cooling towers and have water requirements comparable to conventional thermoelectric power producing systems. There are four main kinds of CST systems: parabolic trough, linear Fresnel, power tower (aka central receiver), and dish/engine as shown in Figure 4.3. Each type of concentrator has different water requirements for cooling and cleaning, which are presented in Section 4.1.5.1. 


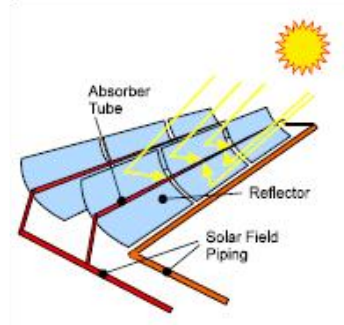

Parabolic troughs

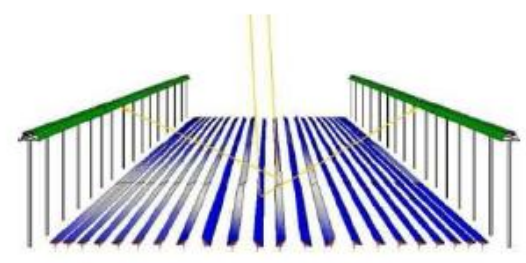

Linear Fresnel Reflectors

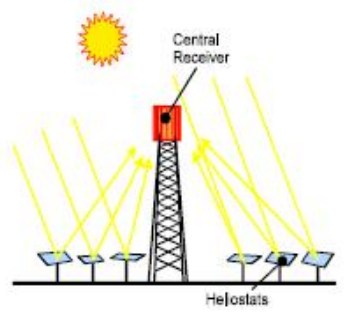

Central Receiver / Heliostats

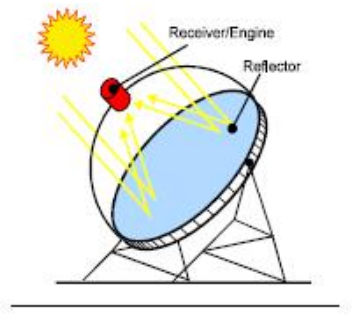

Parabolic dishes

Figure 4.3 Concentrated Solar Thermal Designs

\subsubsection{Operational Water Cost for Electricity Generation from CST}

Operational water consumption for CST is primarily related to cooling with a much lesser amount of water use (about 10\%) related to the washing of mirrors (Mielke, 2010). Operational water requirements differ for each type of concentrator. Average water usage has been reported for each type of concentrator and is shown in Table 4.16 using water consumption statistics from Mielke (2010) with one exception. Operational water consumption for the Power Tower is the average of $500 \mathrm{gal} / \mathrm{MWh}$ reported by Mielke (2010) and 750 gal/MWh reported by the U.S. Department of Energy (2006). Dish/engine systems use significantly less water because they do not boil water to create steam and thus do not require a cooling tower. They tend to be for personal use, as in the case of a solar cooker, but are not used for utility-scale solar thermal. The water cost is 
monetized for freshwater using the $\$ 0.00182 /$ gal default MET price. The average of the three utility scale CST designs is $\$ 1.47 / \mathrm{MWh}$.

Table 4.16 Water Consumption Cost for CST Technologies

\begin{tabular}{|ccc|}
\hline Technology & Water Consumption (gal/MWh) & Water Cost (\$/MWh) \\
\hline Parabolic Trough & 800 & 1.46 \\
\hline Linear Fresnel & 1000 & 1.82 \\
\hline Power Tower & 625 & 1.14 \\
\hline Utility Scale Avg & 808.3 & 1.47 \\
\hline Dish/Engine & 20 & 0.04 \\
\hline
\end{tabular}

\subsubsection{CST Case Study: Abengoa Movaje Solar Energy Project}

The Abengoa Mojave Solar (AMS) Energy Project at Harper Lake in San Bernardino California is a parabolic trough CST design licensed by the CEC on September $9^{\text {th }}, 2010$. It will have a net turbine capacity of $250 \mathrm{MW}$ and is expected to produce $600,000 \mathrm{MWh}$ per year. It will utilize wet cooling towers. The AMS project is expected to draw a maximum of 2154 acre-feet per year of groundwater from Harper Valley Ground Basin for plant operations. However, if AMS used hybrid cooling, the expected water use would instead be 426 acre-feet per year, an $80 \%$ reduction (Douglas, 2010). A water rate of $\$ 0.00182 / \mathrm{gal}$ is applied as a proxy for water value in Table 4.17 below. The annual value of the water used by the AMS project is approximately $\$ 1.28$ million for the wet cooling tower design and \$253 thousand for hybrid cooling.

Table 4.17 Water Cost for the Abengoa Mojave Solar Energy Project

\begin{tabular}{|cccc|} 
Cooling Type & $\begin{array}{c}\text { Cooling Rate } \\
\text { (gal/MWh) }\end{array}$ & Annual Cost $\mathbf{( \$ )}$ & $\begin{array}{c}\text { Marginal Cost } \\
\text { (\$/MWh) }\end{array}$ \\
\hline Wet & 1170 & $1,280,000$ & 2.13 \\
\hline Hybrid & 231 & 253,000 & 0.42 \\
\hline
\end{tabular}




\subsubsection{Solar Photovoltaic (PV)}

Solar PV has grown rapidly in the past few years (EIA, 2014b). The resource has yet to comprise $1 \%$ of the net electricity generation in the United States, however almost twenty times more electricity was generated from photovoltaic sources in 2013 than 2008 (EIA, 2014b). Regardless of the recent expansion of solar electricity, solar PV made up less than $2 \%$ of the net generation from renewable sources in 2013 and still less than $1 \%$ of the total electricity generation of all energy sources (EIA, 2014b).

\subsubsection{Operational Water Cost for Electricity Generation from Solar PV}

Solar PV technologies require virtually no water during operation. After installation, the only water used for the production of solar photovoltaic electricity is for washing the solar panels (Keith et al, 2012). However, not all solar panels get washed; some owners may be content with the production regardless of a minor drop in efficiency due to dust accumulation. If the panels are installed in a rainy area, the rain may provide all the washing necessary. Even when solar panel washing is taken into account, the quantity of water use is minimal. In some instances water use during operation can actually be zero. For example, a technology called electro-dynamic dust shield is capable of removing dust without any water consumption by sending an electronic pulse through the transparent layer on the surface of the solar panel. This technology is currently being employed in the aerospace industry where water is not available to clean solar panels generating electricity on space crafts. Future solar panel production may possibly employ such technologies and further lower water consumption associated with solar photovoltaic electrical generation. 
Studies regarding water consumption of electricity generating technologies either cite no water consumption or very minimal water consumption. Fthenakis and Kim (2010) cite two sources, one of which was personal communication with First Solar Inc. and the other from a 2002 NREL study about solar power's potential for western energy supply. First Solar Inc. cited 0 gal/MWh whereas NREL cited 4 gal/MWh. The difference has to do with whether or not the panels are being washed, but either way the consumption is negligible relative to thermoelectric power production. The average of the two values is taken as the operational water consumption in this report, as shown in Table 4.18. Using the MET tier 1 for freshwater ( $\$ 0.00182 /$ gal) produces a water cost of $\$ 0.004$ per MWh produced.

Table 4.18 Operational Water Cost of Solar PV

\section{Lifecycle Stage Water Consumption (gal/MWh) Water Cost (\$/MWh)} Power Generation 2 0.004

\subsubsection{Wind}

Wind energy, like other sources of renewable electricity, makes up only a small fraction of the overall energy picture in the United States but has been increasing rapidly in recent years (EIA, 2013b). In 2013, wind accounted for 32\% of the total electricity generated from renewable energy sources and $4 \%$ of the total electricity generation from all sources (EIA, 2014b). Wind technologies produced three times as much electricity in 2013 than it did in 2008 (EIA, 2014b). 


\subsubsection{Operational Water Consumption for Electricity Generation from Wind}

Water consumption for plant operation of wind energy technologies can be considered negligible (Keith et al, 2012). Once the device has been created and installed, almost no water is required to sustain operations. Water may occasionally be used for cleaning, hence the water consumption is greater than zero (Table 4.19) but cleaning is not as vital for power production as in the case of solar PV technologies. Thus, operational water consumption per MWh is less than for solar PV. Fthenakis and Kim (2010) cite two sources for water consumption of wind power during operational use. The first one is the U.S. Department of Energy's Report to Congress (2006) which says no water gets used. The other source, NREL (2002) reported 1 gal/MWh for cleaning. Taking the average of these two values produces $0.5 \mathrm{gal} / \mathrm{MWh}$ as the operational water consumption for wind (Table 4.19). The cost is $\$ 0.001 / \mathrm{MWh}$, representing a massive avoided water cost relative to conventional methods of electricity production.

\section{Table 4.19 Operational Water Cost of Wind Energy}

\section{Lifecycle Stage $\quad$ Water Consumption (gal/MWh) $\quad$ Water Cost (\$/MWh) Power Generation 0.5 0.001}

\subsubsection{Biomass}

Biomass power plants accounted for between 1 and 2 percent of the net electricity generation in the United States in 2012 (EIA, 2013b). Thirty-eight million MWh were generated from "wood and wood derived fuels" in that year while an additional 20 million MWh were generated from "other biomass" (EIA, 2013b). Biomass power plants can use a variety of sources for fuel. Typically, they use fuel sources such as forest slash, 
urban wood waste, lumber wastes, and agricultural wastes, but dedicated energy crops are an energy source that provides a possibility of expansion for biomass electricity. Figure 4.4 shows the total potential biomass availability across the continental United States, encompassing potential for energy crops, agricultural residues, waste materials, and forest biomass. Potential for dedicated energy crops makes up 400 million of the 677 million dry tons (Union of Concerned Scientists, 2012). According to Oak Ridge National Laboratory (2011) energy crops are likely to be grown primarily in Kansas, Missouri, Oklahoma, Texas, and to a lesser extent Arkansas, Kentucky, North Carolina, and Virginia. Biomass potential in California is predominately from waste materials.

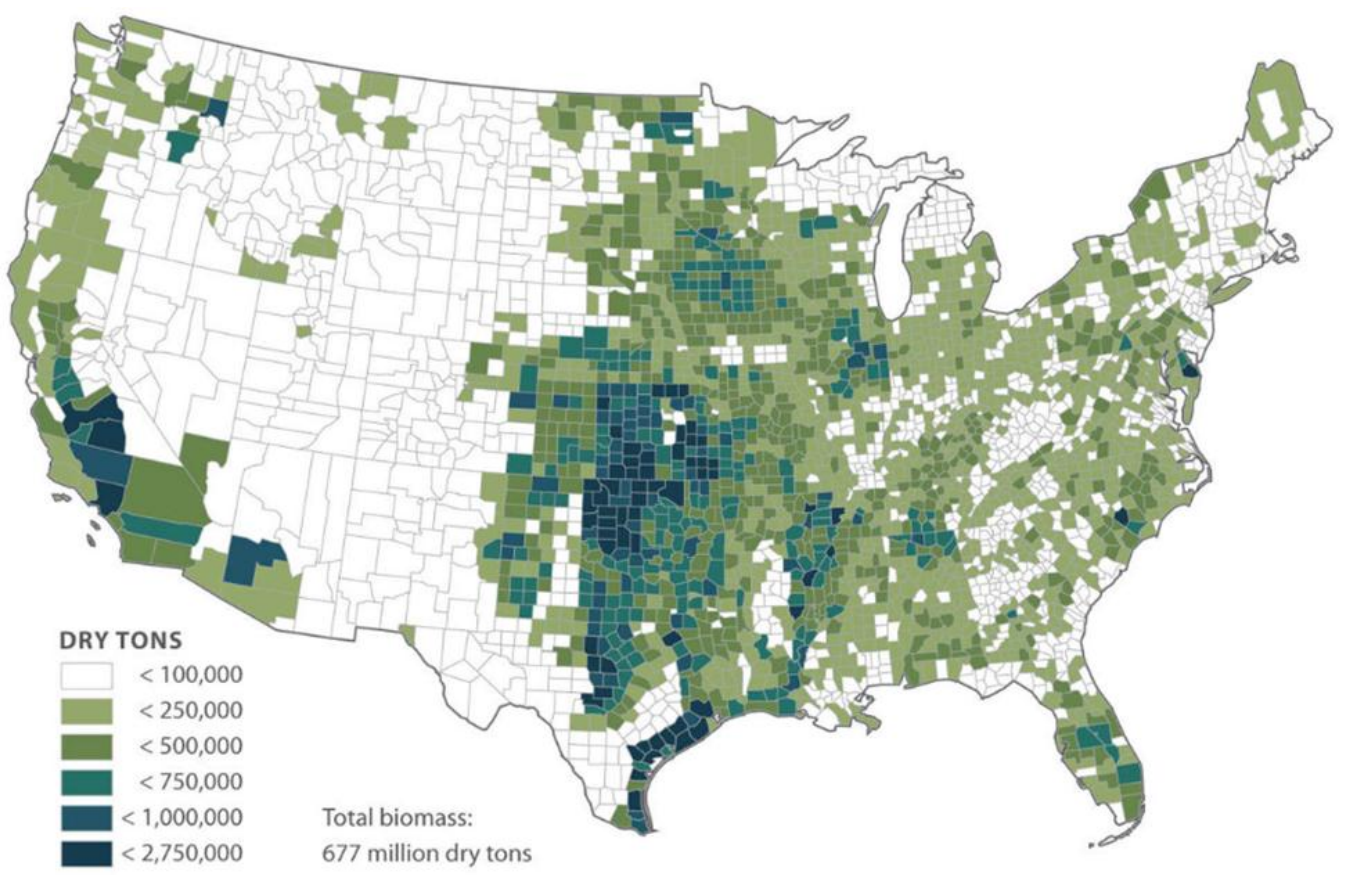

Total potential biomass availability across the continental United States Though biomass production is generally widespread, it is most concentrated in the southern plains, California, the Corn Belt, and along the Mississippi River. Counties that are not shaded may have biomass available, but in comparatively small amounts.

(c) Union of Concerned Scientists 2012; www.ucsusa.org/biomassresources

Figure 4.4 Total Potential Biomass Map of Continental United States 


\subsubsection{Water Consumption of Energy Production for Biomass}

According to the California Energy Commission, biomass power plants in California typically use biomass residues - such as forest slash, urban wood waste, lumber wastes, agricultural wastes, etc. - as fuels. Utilization of waste biomass from such processes does not require additional water for energy production because the water either came naturally (in the case of forest waste) or would have been used anyway for the intended purpose (as is the case for agricultural wastes). Transportation requirements are minimal as biomass power plants tend to be built near the energy source. Additional biomass power generation from dedicated energy crops provide an opportunity to expand the use of biomass for electricity but currently, energy crops are not being grown commercially in the United States; however, this situation could change if they could be sold at prices that ensure producers a profit comparable to using the land for alternative processes (Energy and Environmental Analysis Inc. \& Eastern Research Group Inc., 2007). The Bioenergy Feedstock Development Program at Oak Ridge National Laboratory (ORNL) has identified hybrid poplars, hybrid willows, and switchgrass as having the greatest potential for dedicated energy use over a wide geographic range (ORNL, 2011). The water requirements for energy crops depend on too many factors (such as geography, precipitation, cropland potential, economics and subsidies, etc.) to accurately estimate and are therefore outside the scope of this thesis. Due to the nature of agriculture and water requirements, however, such a strategy could be very water intensive. 


\subsubsection{Operational Water Cost for Electricity Generation from Biomass}

Some biomass power is generated from cofiring, which involves substituting biomass for a portion of the coal used in an existing power plant boiler, however most of today's biomass power plants are direct-fired - combusting biomass to produce highpressure steam used to spin a turbine and generate electricity (Energy and Environmental Analysis Inc., \& Eastern Research Group Inc., 2007). Only direct-fired steam systems are considered in the cost estimation in this study.

Water consumption and prevalence of cooling system are difficult to discern for biomass power plants. This is because biomass power systems are typically below 50 MW in size compared to coal power plants which are in the $100 \mathrm{MW}$ to $1000 \mathrm{MW}$ range (Energy and Environmental Analysis Inc. \& Eastern Research Group Inc., 2007) and plants under $100 \mathrm{MW}$ capacity are exempt from reporting their water use to the EIA (Averyt et al, 2011). Even so, there are reports such as Macknick et al (2011) that conglomerate data from the California Energy Commission, Electric Power Research Institute, and the U.S. Department of Energy to estimate water consumption from biomass power plants, as shown in Table 4.20 below. For statistics with more than one estimate, the median value was chosen.

Table 4.20 Operational Water Withdrawals and Consumption for Biomass Power Plants

\begin{tabular}{|ccc|}
$\begin{array}{c}\text { Operational Cooling } \\
\text { Method }\end{array}$ & Withdrawals (gal/MWh) & Consumption (gal/MWh) \\
\hline Once-Through & 35000 & 300 \\
\hline Wet Recirculating & 878 & 553 \\
\hline Pond & 450 & 390 \\
\hline
\end{tabular}


In Table 4.21, the water consumption has been monetized according to the MET default rate for freshwater. According to Dr. Gregg Morris, director of the Green Power Institute, the majority of biomass power plants use wet recirculating cooling towers (Morris, 2014). Therefore $\$ 1.01 / \mathrm{MWh}$ is most representative of operational biomass water cost.

Table 4.21 Operational Water Cost for Biomass Power Plants

\begin{tabular}{|ccc|} 
Cooling Method & Water Consumption (gal/MWh) & Water Cost (\$/MWh) \\
\hline Once-Through & 300 & 0.55 \\
\hline Wet Recirculating & 553 & 1.01 \\
\hline Pond & 390 & 0.71 \\
\hline
\end{tabular}

\subsection{Water Costs Associated with Environmental Compliance}

Environmental degradation from electricity generation can occur through accidents in addition to routine operations. The responsible party, ratepayers, or relevant government agency may incur costs in the form of mitigation or they may simply be mandated to alter their processes at an additional expense to them. Such degradation may or may not involve water directly, but there are many aspects that deal specifically with water.

One example of an additional cost for environmental compliance is the cost of bioremediation of superfund sites. Abandoned coal mines create contamination that must be remedied. In situations where mining is a threat to water contamination, water may need to be pumped and treated. Nuclear fuel extraction has been implicated in surface 
and groundwater contamination, resulting in over 500 abandoned uranium mines awaiting remediation in the Navajo Nation area alone (Cooley, 2010).

Other mitigation costs may be incurred from an accident resulting from energy operations, such as the BP oil spill in the Gulf of Mexico in 2010. Cost for such disasters can be immense. Remediation of the BP oil spill has been reported to cost over $\$ 40$ billion (Bergin, 2010). Environmental consequences such as loss of biodiversity and destruction of fisheries will persist well into the future. However, an extrapolation to

obtain a cost per unit energy ( $\$ / \mathrm{MWh})$ is more abstract for accidental mitigation costs and difficult to quantify and is therefore outside the scope of this report.

An example that is quantifiable on a cost per unit energy basis is the environmental compliance cost of retrofitting power plants, such as converting a power plant's cooling system from open loop cooling to closed-loop cooling. In Section 4.2.1, the mitigation cost per MWh is discussed as it relates to a specific LADWP project - in compliance with environmental regulations - converting from OTC to closed-loop cooling.

\subsubsection{Environmental Compliance Case Study: LADWP}

The Federal Environmental Protection Agency Clean Water Act Section 316(b) requires minimizing or reducing the impacts of power plant intake structures to marine life. In order to reduce these impacts, the Los Angeles Department of Water and Power (LADWP) has committed to completely eliminating once through cooling (LADWP, 2013). The policy decision to eliminate OTC in California results in added costs that will 
ultimately be passed on to ratepayers. The amount of generation to be converted from OTC is approximately 2,839 MW of LADWP's total in-basin plant capacity of 3,415 MW, the total expenditures of which are expected to total $\$ 2.2$ billion (LADWP, 2013). According to LADWP's Power Integrated Resource Plan, the entire project is expected to take through 2029 and involve three natural gas power plants: Haynes, Harbor, and Scattergood. A total of ten units amongst the three power plants will be converted to closed-loop cooling. In this section, we will look in depth at one particular project, the repowering of Haynes Units 5 \& 6 (each 300 MW gas turbines) into six simple cycle gas turbines with dry cooling, and break down the projected cost into $\$ / \mathrm{MWh}$ values. This can be used as an estimate of the water cost of OTC.

Conversion of the two units was projected to cost a total of $\$ 782$ million (LADWP, 2013c). Taking the capacity factor of 0.465 for natural gas steam plants reported by the EIA and assuming a useful lifespan of 30 years for the turbines after converting, the repowered units can generate a total of 73.37 million MWh based on the calculation below.

$$
(600 \mathrm{MW})\left(\frac{365.25 \text { day }}{\text { year }}\right)\left(24 \frac{\text { hours }}{\text { day }}\right)(30 \text { years })(0.465)=73,370,000 \mathrm{MWh} / 30 \text { years }
$$

Dividing the conversion cost (\$782 million) by the expected electricity production over 30 years (73.37 million MWh) yields a unit cost of \$10.66/MWh. Compared to the weighted average operational water consumption cost of $\$ 0.29 / \mathrm{MWh}$ for NGCC without CCS (Table 4.7), the expense for environmental compliance is extremely expensive. It is 
important to note that environmental compliance with CWA Section 316(b) dictates the conversion from OTC but proponents of natural gas may rightly argue that this full cost is not directly attributable to only the purpose of reducing impacts of impingement and entrainment. Repowering the two units also provides other benefits. The implementation of six simple cycle units also removes two aging generating units from service, provides six "peakers" to ramp full capacity and meets fluctuating energy demands, and increases fuel efficiency (LADWP, 2013c). Regardless of the additional benefits of repowering, the conversion from OTC was required by CWA Section 316(b) and the associated costs are a result of environmental compliance. Though the collective benefits exceed reductions in impingement and entrainment, the relatively high cost per MWh of environmental compliance compared to operational water use demonstrate that power plant retrofits to mitigate environmental degradation can have very high economic consequences.

\subsection{Collective Results and Discussion}

The total cost for energy production and electricity generation for selected technologies that result in MET water purchases are calculated and displayed in Table 4.22. A graphical representation is shown in Figure 4.5. The $310 \mathrm{gal} / \mathrm{MWh}$ for coal energy production represents the average of all the mining methods (Table 4.1) plus beneficiation plus the average of the slurry pipeline minimum and maximum times 0.071 (since only $7.1 \%$ of coal is transported this way) plus other plant operations. The natural gas energy production value of $256 \mathrm{gal} / \mathrm{MWh}$ is the summation of all natural gas fuel cycle steps (Table 4.5) plus $12 \mathrm{gal} / \mathrm{MWh}$ for hydraulic fracturing. The $209 \mathrm{gal} / \mathrm{MWh}$ for nuclear fuel cycle is the summation of values for underground mining (but doesn't 
include open pit mining), milling, uranium hexafluoride conversion, the average of enrichment methods (diffusion and centrifuge), fuel fabrication, and fuel reprocessing (found in Table 4.10).

Table 4.22 Freshwater Cost per MWh by Electricity Generation Type

\begin{tabular}{|ccccc|}
\hline Electric Fuel & $\begin{array}{c}\text { Water Consumption (gal/MWh) } \\
\text { Production }\end{array}$ & $\begin{array}{c}\text { Electricity } \\
\text { Generation }\end{array}$ & Total & $\begin{array}{c}\text { Water Cost } \\
\text { (\$/MWh) }\end{array}$ \\
\hline Coal & 310 & 507 & 817 & 1.49 \\
\hline Coal w/ CCS & 310 & 1239 & 1549 & 2.82 \\
\hline IGCC & 310 & 369 & 679 & 1.24 \\
\hline IGCC w/ CCS & 310 & 502 & 812 & 1.48 \\
\hline Natural Gas & 256 & 161 & 417 & 0.76 \\
\hline N.G. w/ CCS & 256 & 502 & 758 & 1.38 \\
\hline Nuclear & 209 & 577 & 786 & 1.43 \\
\hline Geothermal & 0 & 515 & 515 & 0.94 \\
\hline CST Tower & 0 & 625 & 625 & 1.14 \\
\hline CST Trough & 0 & 800 & 800 & 1.46 \\
\hline CST Fresnel & 0 & 1000 & 1000 & 1.82 \\
\hline Solar PV & 0 & 2 & 2 & 0.00 \\
\hline Wind & 0 & 0.5 & 0.5 & 0.00 \\
\hline Biomass & 0 & 553 & 553 & 1.01 \\
\hline
\end{tabular}

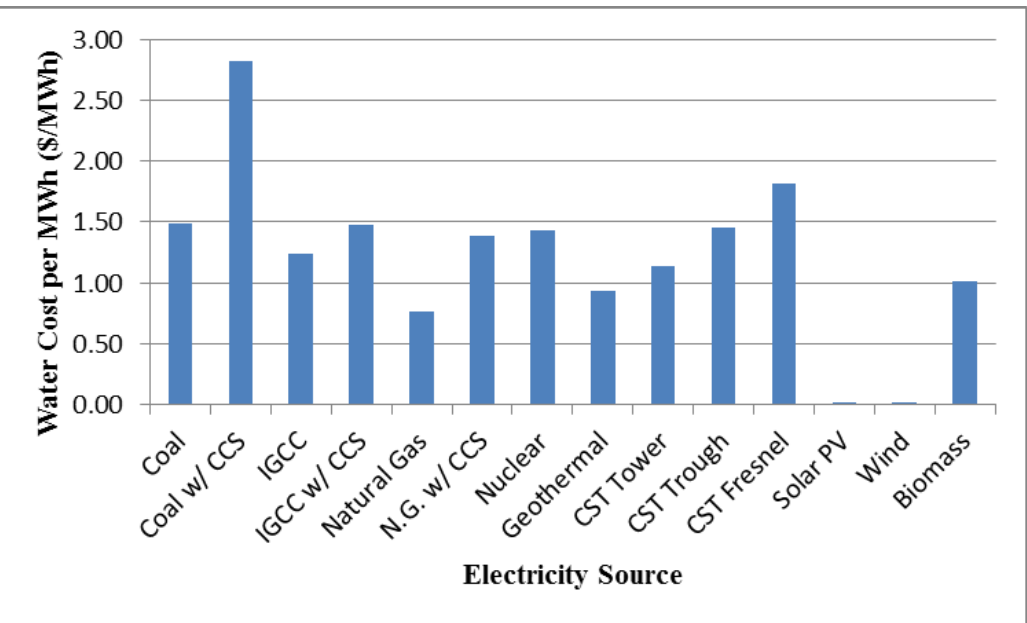

Figure 4.5 Freshwater Marginal Cost for Electricity Generation 
Table 4.22 and Figure 4.5 compare the cost per unit electricity for a number of electricity sources. They demonstrate the avoided water cost of renewable energy technologies such as solar PV and wind. Since solar PV and wind technologies do not require the extraction of a fuel source, the use of thermoelectric cooling, nor atmospheric controls, they avoid the three largest culprits of water use for power production. This is why they have marginal water consumption costs of $\$ 0.00 / \mathrm{MWh}$. Compared to conventional energy sources of previous generations (such as coal and nuclear) solar PV and wind can save between $\$ 1$ and \$2 per MWh in water consumption. Electrical production with natural gas consumes less water than coal and even some forms of CST with a marginal water cost below $\$ 1 / \mathrm{MWh}$ but solar PV and wind still save $\$ 0.76 / \mathrm{MWh}$ worth of freshwater compared to NGCC power plants.

With respect to reducing greenhouse gas emissions while conserving water, switching to solar PV and wind offer greater benefits than carbon capture and sequestration. Retrofitting existing plants with CCS will reduce atmospheric emissions, but also increase water costs substantially. Coal with CCS for instance, raises the freshwater consumption cost from $\$ 1.49 / \mathrm{MWh}$ to $\$ 2.82 / \mathrm{MWh}$, making the relative water savings potential of renewable energy technologies even greater. Natural gas with CCS raises the consumption cost from $\$ 0.76 / \mathrm{MWh}$ to $\$ 1.38 / \mathrm{MWh}$.

Concentrated solar thermal technologies that use the Rankine cycle for thermoelectric cooling do not offer the water savings potential that solar PV and wind do. CST systems have water costs comparable to conventional power generation even though 
they do not require fuel extraction. This is because their operational water consumption is relatively high compared to other thermoelectric technologies.

Geothermal power plants have wide ranges in water cost and important caveats so they need to be evaluated on a case by case basis. In the geothermal scenarios evaluated (Clark et al, 2010), the flash system had a much lower water cost than EGS and binary systems because geofluid was assumed to be used for cooling in the flash scenario and was not replaced. Studies that consider minimal makeup water replacement report water consumption to be as low as $5 \mathrm{gal} / \mathrm{MWh}$ (Kagel et al, 2007). On the contrary, as was demonstrated by the Calpine Corporation case study, the make-up water requirements to maintain the reservoir can be very substantial. Therefore the rate of geothermal water consumption ranges from 5 gal/MWh reported by Kagel et al (2007) to $1217.5 \mathrm{gal} / \mathrm{MWh}$ in the case of Calpine, which replaces $80 \%$ of the consumed water. The associated water costs can thus range from $\$ 0.01 / \mathrm{MWh}$ to $\$ 2.22 / \mathrm{MWh}$ for geothermal operations in Southern California that use MET water, either through direct purchases from MET or through the use of groundwater that results in equivalent purchases from MET. The water cost depends immensely on how the situation is defined.

Since $\$ / M W h$ rates of water cost per unit energy tend to seem small, total water costs are developed here to demonstrate the economies of scale. A table could be created to show what the total costs would be for a representative size power plant of each technology, however, this could be misleading since large capacity power plants such as nuclear would have much greater total water costs partly because they create much more 
electricity per power plant than the average size power plant of each other technology. To remedy this potential qualm, the total water costs for each technology have been normalized to the electrical generation capability of a $540 \mathrm{MW}$ natural gas combinedcycle power plant, operating with a capacity factor of 0.465 for forty years. Natural gas was chosen as the basis for electricity generation because it is the predominant source of electricity generation in California and policy decisions are more likely to compare solar PV and wind against a natural gas combined-cycle power plant alternative, rather than a coal or nuclear plant. The total expected output of such a $540 \mathrm{MW}$ natural gas combinedcycle power plant is calculated according to the equation below:

$(540 M W) \times\left(24 \frac{\text { hours }}{\text { day }}\right) \times\left(365.25 \frac{\text { day }}{\text { year }}\right) \times(40$ years $) \times(0.465) \approx 88,000,000 M W h$

Table 4.23 Freshwater Costs Normalized to NGCC Plant Electricity Production

\begin{tabular}{|cccc|}
\hline Power Plant Type & $\begin{array}{c}\text { Freshwater Cost } \\
(\$ \mathbf{M W h})\end{array}$ & $\begin{array}{c}\text { Total Water Cost } \\
(\$ / 40 \text { years })\end{array}$ & $\begin{array}{c}\text { Annual Water } \\
\text { Cost } \mathbf{( \$ / y e a r )}\end{array}$ \\
\hline Coal & 1.49 & $131,000,000$ & $3,280,000$ \\
\hline Coal w/ CCS & 2.82 & $248,000,000$ & $6,210,000$ \\
\hline IGCC & 1.24 & $109,000,000$ & $2,730,000$ \\
\hline IGCC w/ CCS & 1.48 & $130,000,000$ & $3,260,000$ \\
\hline NGCC & 0.76 & $67,000,000$ & $1,670,000$ \\
\hline NGCC w/ CCS & 1.38 & $122,000,000$ & $3,040,000$ \\
\hline Nuclear & 1.43 & $126,000,000$ & $3,150,000$ \\
\hline Geothermal & 0.94 & $83,000,000$ & $2,070,000$ \\
\hline CST Tower & 1.14 & $100,000,000$ & $2,510,000$ \\
\hline CST Trough & 1.46 & $129,000,000$ & $3,210,000$ \\
\hline CST Fresnel & 1.82 & $160,000,000$ & $4,010,000$ \\
\hline Solar PV & 0.004 & 320,000 & 8,000 \\
\hline Wind & 0.001 & 80,000 & 2,000 \\
\hline Biomass & 1.01 & $89,000,000$ & $2,220,000$ \\
\hline
\end{tabular}


Table 4.23 shows the total water costs for each technology to produce 88 million MWh, equivalent to what a 540 MW NGCC power plant would produce in forty years. It also shows the total value of freshwater a power plant of each technology would consume per year to produce as much electricity. The $\$ / \mathrm{MWh}$ values include water consumption data for energy production as well as electricity generation.

The results indicate that a NGCC power plant that uses freshwater in Southern California will consume $\$ 67$ million worth of water in its forty year lifespan. Carbon Capture and Sequestration could raise this water cost to $\$ 122$ million. To produce as much electricity, a coal power plant would use \$131 million, though the implementation of CCS could raise the water cost to $\$ 248$ million. A typical nuclear power plant would consume $\$ 126$ million worth of water to produce as much electricity as a NGCC power plant, though a typical nuclear power plant would produce almost 8 times as much electricity and therefore consume almost $\$ 1$ billion worth of water in its lifespan. To match the electricity demand of a typical natural gas plant, solar PV would consume an estimated $\$ 320,000$ worth of water for cleaning purposes. Wind farms would consume even less, estimated at $\$ 80,000$ in total to offset the electricity demand of a NGCC power plant. Compared to thermoelectric power plants, the solar PV and wind plants use negligible water (less than $1 \%$ as much), potentially saving millions of dollars of water per year. 


\subsection{Renewables Portfolio Standard Water Savings}

California's Renewables Portfolio Standard (RPS)-program, promulgated by CA SB2, requires investor-owned utilities, electric service providers and community choice aggregates to increase procurement from eligible renewable electricity resources to $33 \%$ of the total procurement by 2020 . While this commitment to increasing the use of renewable energy was made to reduce greenhouse gas emissions, it also has the potential to conserve water. This section estimates the annual value of water that would be conserved in California by meeting the RPS standards. To do so, two energy mix scenarios were developed - one representing the expected energy mix without the RPS and the second representing the energy mix after compliance with the RPS. Water costs of these two scenarios are then compared using the Southern California water price used elsewhere in this thesis. Both scenarios meet the California electricity demand in 2020, which is expected to be $316.28 \mathrm{GWh}$ based on forecasts by the California Energy Commission (Kavelec and Gorin, 2009).

Table 4.24 shows the total electricity generation of California in 2011 before the implementation of RPS. Electricity generation data for Table 4.24 come from Quarterly Fuel and Energy Reports (QFER) and SB 1305 reporting requirements for generation units 1 MW or larger in capacity. Approximately 201 million MWh of electricity were generated in California in 2011. 
Table 4.24 California In-State Electricity Generation by Source in 2011

\begin{tabular}{|ccc|}
\hline Electricity Source & California Generation (MWh) & Relative Percentage \\
\hline Coal & $3,120,000$ & 1.6 \\
\hline Natural Gas & $91,233,000$ & 45.4 \\
\hline Nuclear & $36,666,000$ & 18.2 \\
\hline Hydroelectric & $42,731,000$ & 21.3 \\
\hline Biomass & $5,807,000$ & 2.9 \\
\hline Geothermal & $12,685,000$ & 6.3 \\
\hline Solar PV & $1,097,000$ & 0.5 \\
\hline Wind & $7,598,000$ & 3.8 \\
\hline Total & $200,937,000$ & 100 \\
\hline
\end{tabular}

The water costs associated with electricity generation are calculated for both scenarios in Table 4.25 based on the marginal water cost for each electricity source (presented in Table 4.22). Solar PV and wind have been merged into one category since they both have negligible water consumption. Both scenarios assume that no new energy is commissioned or decommissioned for nuclear, hydroelectric, biomass, and geothermal sources since 2011. Therefore, the annual MWh production for all of these technologies is the same as listed in Table 4.24. The non-RPS scenario also assumes that solar PV, wind, and coal sources produce the same amount of electricity as they did in 2011. All new electricity to meet the additional 115.34 million MWh demand is assumed to come from natural gas combined-cycle power plants in this scenario. In the RPS scenario, however, enough electricity to meet the $33 \%$ renewables goal is assumed to come from solar PV and wind sources. This accounts for 34.45 million newly created megawatthours from solar PV and wind technologies. All coal-fired electricity is assumed to be displaced. Any remaining electricity demand is met by new NGCC power plants. 
Table 4.25 Total Water Costs for Electricity Production for the Year of 2020 Using the Non-RPS and RPS Scenario

\begin{tabular}{|crrccccc|}
\hline Source & \multicolumn{3}{c}{ Non-RPS Scenario } & \multicolumn{3}{c|}{ RPS Scenario } \\
& $\boldsymbol{\%}$ & $\mathbf{M W h}$ & $\begin{array}{c}\text { Water Cost } \\
\mathbf{( \$ )}\end{array}$ & $\mathbf{\%}$ & $\mathbf{M W h}$ & $\begin{array}{c}\text { Water Cost } \\
\mathbf{( \$ )}\end{array}$ \\
\hline Coal & 1.0 & $3,120,000$ & $4,649,000$ & 0.0 & 0 & 0 \\
\hline Natural Gas & 65.3 & $206,576,000$ & $156,998,000$ & 55.4 & $175,242,000$ & $133,184,000$ \\
\hline Nuclear & 11.6 & $36,666,000$ & $54,432,000$ & 11.6 & $36,666,000$ & $52,432,000$ \\
\hline Hydroelectric & 13.5 & $42,731,000$ & & 13.5 & $42,731,000$ & \\
\hline Biomass & 1.8 & $5,807,000$ & $5,865,000$ & 1.8 & $5,807,000$ & $5,865,000$ \\
\hline Geothermal & 4.0 & $12,685,000$ & $11,924,000$ & 4.0 & $12,685,000$ & $11,924,000$ \\
\hline Solar PV/Wind & 2.7 & $8,695,000$ & 0 & 13.6 & $43,149,000$ & 0 \\
\hline Total & 100 & $316,280,000$ & $231,868,000$ & 100 & $316,280,000$ & $203,405,000$ \\
\hline
\end{tabular}

To calculate the water costs for each scenario, the electricity generation in MWh (Table 4.25) for each source is multiplied by its respective $\$ / M W h$ water cost (calculated in Table 4.22). The water cost for all electricity sources are then summed to calculate the total water cost for each scenario. The total water cost of California electricity generation in 2020 under the RPS scenario is $\$ 28.5$ million less than for the non-RPS scenario (Table 4.25), indicating that the RPS will be responsible for conserving $\$ 28.5$ million worth of water in 2020 and presumably each year after that. This represents water savings of $12.3 \%$ relative to the expected water cost under the non-RPS scenario.

There are several caveats worth mentioning here. All new renewable electricity is considered solar PV or wind in the RPS scenario. While much of the renewables brought online are likely to be solar PV, other technologies such as concentrated solar thermal are also eligible to meet RPS standards and use considerably more water. If the other renewable energy technologies contribute substantially to meeting the RPS standard, the yearly water savings will have been overestimated here. On the contrary, natural gas 
electricity is monetized based on combined-cycle power plants. While this is appropriate for newly commissioned natural gas power plants, older facilities are less efficient. Thus, natural gas power plant water requirements are underestimated. Therefore, the yearly water savings are underestimated with respect to the longevity of older natural gas power plants that will still contribute to the total water cost for electricity generation in 2020. Lastly, it's important to note that water prices are not constant over time. MET water rates increased $70 \%$ from 2008 to 2014. Assuming water rates increase at the same rate over the next six years, the water savings of the Renewable Portfolio Standard would be $70 \%$ higher in 2020 dollars, equating to water savings of $\$ 48.4$ million per year. 


\section{Chapter 5: Conclusions}

The results of this study indicate that solar PV and wind harnessing can greatly reduce the cost of water consumption compared to conventional power generation. These technologies can conserve $\$ 1.49$ worth of water per MWh generated compared to coal power plants. They can conserve $\$ 0.76$ per MWh compared to natural gas combinedcycle power plants and $\$ 1.43$ per MWh compared to nuclear power plants that use or displace freshwater.

The water savings of solar PV and wind systems are even more pronounced if the playing field is leveled for atmospheric greenhouse gas emissions. Since the operational use of solar PV and wind systems create no atmospheric gas emissions, it is logical to compare them to thermoelectric power plants with carbon capture and sequestration which would be needed to minimize their atmospheric impact. With this scenario solar PV and wind technologies can conserve $\$ 2.82 / \mathrm{MWh}$ compared to coal power plants that utilize CCS and \$1.38/MWh compared to natural gas CCS power plants.

Not all renewable energy technologies conserve water; solar PV and wind have negligible water consumption relative to thermoelectric power plants but the water consumption of concentrated solar thermal is comparable to conventional power generation, using between $\$ 1.14 / \mathrm{MWh}$ and $\$ 1.82 / \mathrm{MWh}$ for cooling purposes, depending on the design of the concentrator. Biomass power plants, like CST power plants, predominantly use water for thermoelectric cooling. Those that use freshwater for cooling have water costs of $\$ 1.01$ per MWh generated. Solar PV and wind are thus the two 
technologies that offer the most potential for water conservation for the energy industry. They do use some water for cleaning but their estimated water consumption costs are only $\$ 0.004 / \mathrm{MWh}$ and $\$ 0.001 / \mathrm{MWh}$ for solar PV and wind respectively.

The largest water related expenses of electricity generation are for environmental compliance. Remediation of massive oil spills such as the BP oil spill in 2010 can be orders of magnitude higher than the cost of freshwater consumption. The largest cost per unit electricity generation evaluated in this study was the $\$ 10.66 / \mathrm{MWh}$ incurred by LADWP to convert to closed-loop cooling. The unforeseen cost of environmental compliance is one that is not evaluated in preliminary economic analyses of power plant commissioning, yet is a real expense that gets passed on to electricity rate payers.

Water use by many early power plants was subject to riparian rights in California, which allowed them to make use of nearby water sources without formally purchasing the water. For some of them, water consumption may not be monetized in their costs of production at all. Their water consumption is valued in this report using the MET tier 1 rate as a proxy to estimate the societal value of the water these power plants consume. Since water prices are reflective of infrastructure costs of production, however, they are not necessarily indicative of the societal value and essentialness of the resource. Recycled wastewater for example is more expensive than freshwater since it requires more energy to produce, yet freshwater is eligible to be used for more purposes making its societal value greater. 
This study is limited in scope to Southern California in 2014 since water prices vary spatially and temporally. Monetization of water consumption for electricity generation is regionally dependent since a national water market does not exist in the United States. Water rates change over time, meaning that these water costs may be outdated in the near to distant future. The MET tier 1 water rate has increased $80 \%$ in the past 7 years. If water rates continue to increase, power plants to be commissioned for 30 years can expect lifetime water costs to be double the consumption costs presented in this report. Different conclusions are expected for different locations and years.

It is important to note that additional use of solar PV and wind energy technologies do not necessarily guarantee that the estimated value of water will be saved from the alternative. If a policy decision retires the use of a power plant that consumes water from a nearby river or lake and decides to compensate by constructing a solar PV plant of comparable size (or support equivalent DG solar PV), then all of the water that the power plant was using will be saved. However, if the Calpine geothermal operation were to be retired, for example, the wastewater treatment facilities that supply it may not be able to sell the vast quantities of treated wastewater elsewhere, thus not guaranteeing that the full water cost will be conserved. They likely would be able to sell the water nearby for irrigation purposes, especially in this drought-stricken time, but additional expenses would be incurred by the infrastructure requirements to move such quantities of water. Be that is it may, increased adoption of solar PV reduces demand on waterburdening power plants corresponding to lesser electricity generation and water 
consumption from such sources, even if it does not result in the decommissioning of thermoelectric power plants.

Another important consideration is that the water consumption unit costs are only taking into account water consumed. There are other negative consequences of water used for conventional power generation that are not included in the unit costs, such as accidental oil spills, groundwater and surface water contamination from coal and uranium mining, potential water contamination from hydraulic fracturing, biological impacts to aquatic species from impingement and entrainment caused by OTC and associated water withdrawals. Though much of the water withdrawn is returned, its quality may be degraded making it no longer suitable for other intended purposes. Mitigation costs can be on the order of tens of millions of dollars as in the case of Diablo Canyon, whose compensatory cost of mitigation was estimated to be $\$ 67,875,000$. This equated to under \$0.10/MWh because Diablo Canyon produces much more electricity than the average power plant, however the total cost of mitigation is very close to the total expected water consumption cost of a 540 MW natural gas combined-cycle plant, estimated to be $\$ 67,000,000$ (Table 4.23). For OTC power plants using freshwater, the expense for environmental mitigation represents an additional water-related cost on top of the consumption cost. The negative effect that conventional power production has on nearby ecosystems represents an added benefit of solar PV and wind.

The results of this study underscore a societal and economic issue alleviated by increased adoption of solar PV and wind energy. For distributed generation solar PV 
owners, these benefits are not reflected in their system costs (since they are not the ones who see economic savings from the water minimization they cause) though they have real economic consequences. The results of this study substantiate desires held by renewable energy advocates for greater government subsidies to reward DG customers for the societal and economic benefits they procure.

\subsection{Further Research}

Data gaps made attempts to monetize the lifecycle water cost less thorough in this thesis. If all power plants, of all size, report precise water usage data regularly then monetization and other analyses will be more accurate. Inconsistencies in data reporting particularly with respect to nonoperational water consumption such as device manufacturing, power plant construction, power plant decommissioning, etc. - between technologies make drawing comparisons more difficult. Harmonizing the data for all the technologies allows for better extrapolations and analyses. Meldrum et al (2013) has begun that process in a 2013 study of water usage but further research is needed as more data becomes available.

This report used water rates for Southern California to estimate the water cost for electricity production, making the scope rather limited. Power plants across the United States obtain water from a variety of different sources where water is valued differently. Thus, further research can be extended to other regions. Future studies can use the methods presented here to estimate water costs for power plants in other regions. The methods in this report can also be used by policy makers for specific energy decisions. To 
compensate for the rising electricity demand associated with the rising populations, each individual energy decision - such as whether to build a natural gas power plant or wind power plant or whether to extend the renewable energy tax incentive - is more informed by accounting for the value of water associated with each decision. Policy analysts may extend the work of this report to any applicable decision process provided that sitespecific data is available.

Another way to expand this study would be to organize water consumption information for each technology into a database or lifecycle analysis software program. The program would make use of water consumption data for all parts of the lifecycle including fuel extraction, processing steps, transportation, cooling tower use, decommissioning, fuel disposal and any other relevant segment of the electricity cycle that uses water. An interface can then be designed for ease of use by policy makers to evaluate site-specific cases. Ideally the program would prompt the following questions: What fuel source is being used? Where is the fuel source coming from? How is it being transported? What kind of power plant is being used? Where is the power plant located? What type of cooling method is being employed? What is the lifespan of the power plant? What kind of water is being used? Each prompt could have a subset of options to choose from. For instance, options for the first question include: coal, natural gas, nuclear, hydropower, concentrating solar thermal, solar PV, wind, biomass. The user will be able to select the appropriate type from a dropdown menu for each question and a final water cost estimate will be calculated and displayed. This report gives a solid foundation for developing such a program but much additional data will be needed. Additionally, 
another program could be created to calculate mitigation costs associated with water withdrawals by power plants. 


\section{REFERENCES}

Atwater, R. (2014). Bay Delta Conservation Plan and Importance to So Calif. Sources of Water for Southern California. Retrieved from http://www.southbaycities.org/sites/default/files/general_assembly/speakers/Richa rd Atwater Presentation _0.pdf

Anderson, Shea. Reuters. (2006). Idaho Committee Adopts Moratorium on Coal Power, March 14, 2006

Averyt, K., J. Fisher, A. Huber-Lee, A. Lewis, J. Macknick, N. Madden, J. Rogers, and S. Tellinghuisen. (2011). Freshwater use by U.S. power plants: Electricity's thirst for a precious resource. A report of the Energy and Water in a Warming World initiative. Cambridge, MA: Union of Concerned Scientists. November.

Bakken, T. H., Killingtveit, Å., Engeland, K., Alfredsen, K., \& Harby, a. (2013). Water consumption from hydropower plants - review of published estimates and an assessment of the concept. Hydrology and Earth System Sciences, 17(10), 3983 4000. doi:10.5194/hess-17-3983-2013

Bergin, T. (2010). BP ups spill cost to $\$ 40$ billion, profits beat forecast. Reuters. Retrieved July 18, 2014, from http://www.reuters.com/article/2010/11/02/us-bpidUSTRE6A111820101102

Burkhardt, J., Heath, G., \& Cohen, E. (2012). Life Cycle Greenhouse Gas Emissions of Trough and Tower Concentrating Solar Power Electricity Generation. Journal of Industrial Ecology, 16, S93-S109. doi:10.1111/j.1530-9290.2012.00474.x

Burkhardt, J. III, et al. (2011). Life Cycle Assessment of a Parabolic Trough Concentrating Solar Power Plant and the Impacts of Key Design Alternatives. Environmental Science and Technology, 45, 2457-2464.

California Biomass Collaborative. (2012). Energy Crop Assessment in California Using Economic Optimization. Draft project Report. CEC Contract No: 500-2011-XXX

California Energy Commission. (2005). Blythe Energy Project Phase II Application for Certification (02-AFC-1) Riverside County. CEC-800-2005-005-CMF

California Energy Commission. (2011). Renewable Power in California: Status and Issues. CEC Staff Report. CEC-150-2011-002. August 2011.

Calpine Corporation. (2012). The Water Story. Retrieved July 30, 2014, from http://www.geysers.com/water.aspx 
Calpine Corporation. (2014). The Geysers Geothermal Operation, (February), 2014.

Retrieved from http://www.calpine.com/media/Geysers_Factsheet.pdf

Clark, C., C. Harto, J. Sullivan, and M. Wang, (2010). Water use in the development and operation of geothermal power plants. Argonne National Laboratory Report (ANL/EVS/R-10/5)

Cooley, H., Fulton, J., \& Gleick, P. (2011). Water for Energy: Future Water Needs for Electricity in the Intermountain West. Oakland, CA. 1-893790-36-3; ISBN 13: 978-1-893790-36-0

Dauphine, N., \& Cooper, R. (2009). Impacts of Free-Ranging Domestic Cats (Felis Catus) on Birds in the United States: a Review of Recent Research with Conservation and Management Recommendations, 205-219. Retrieved from www.abcbirds.org/abcprograms/policy/cats/pdf/impacts_of_free_ranging_domest ic_cats.pdf

De Wild-Scholten MJ, Alsema EA. (2005). Environmental life cycle inventory of crystalline silicon photovoltaic system production: status 2005/2006; 2007. http://www.ecn.nl/publicaties/default.aspx?au=44649.

DOE. (1983) Energy Technology Characterizations Handbook: Environmental Pollution and Control Factors (Washington, DC: US Department of Energy (DOE))

DOE. (2006). "Energy Demand on Water Resources - Report to Congress on the Interdependency of Energy and Water." U.S. Department of Energy

DOE/NETL. (2010). Estimating Freshwater Needs to Meet Future Thermoelectric Generation Requirements 2010 Update. DOE/NETL-400/2010/1339

Douglas, K., Boyd, J. D., Byron, J. D., Eggert, A., \& Weisenmiller, R. (2010). ABENGOA MOJAVE SOLAR PROJECT Commission Decision. CEC-800-2010008-CMF

EIA, (2003) Energy Information Administration. Annual Coal Report, DOE/EIA-0584.

EIA. (2011) “Domestic Uranium Production Report.” U.S. Energy Information Administration (2011)

EIA. (2012). Coal Transportation Rates to the Electric Power Sector. Retrieved May 06, 2014, from http://www.eia.gov/coal/transportationrates/trend-coal.cfm\#fig3

EIA. (2013a). Annual Coal Distribution Report 2012, (December). Retrieved from http://www.eia.gov/coal/distribution/annual/pdf/acdr_fullreport2012.pdf 
EIA. (2013b). Electric Power Annual 2012, (December).

EIA. (2014). Planned coal-fired power plant retirements continue to increase. Retrieved July 10, 2014, from http://www.eia.gov/todayinenergy/detail.cfm?id=15491\#

EIA (2014b). Electric Power Monthly, (June).

Energy and Environmental Analysis Inc., \& Eastern Research Group Inc. (2007). Biomass Combined Heat and Power Catalog of Technologies - U.S. Environmental Protection Agency Combined Heat and Power Partnership. Retrieved from http://www.epa.gov/chp/documents/biomass_chp_catalog.pdf

Engelder, T., Howarth, R., \& Ingraffea, A. (2011). Should fracking stop? Nature, (September), 271-275.

EPRI. (2002) Water \& Sustainability (Volume 3): U.S. Water Consumption for Power Production-The Next Half Century, Palo Alto, CA. 1006786.

Fthenakis, V., Kim, H.C. (2010). Life-Cycle Uses of Water in U.S. Electricity Generation. Renewable and Sustainable Energy Reviews 14, 2039-2048. 10.1016/j.rser.2010.03.008

Foster, M., Cailliet, G., Callaway, J., Mead-Vetter, K., Raimondi, P., Roberts, P., (2013). Desalination Plant Entrainment Impacts and Mitigation - Report to the State Water Board.

Jennejohn, D., Blodgett, L and Gawell, K. (2009). "Geothermal energy and water consumption," Geothermal Energy Association, Washington, D.C., accessed 08/22/2014 at http://www.geoenergy.org/pdf/Geothermal_Energy_and_Water_Consumption_Issue_Brief.pdf

Galbraith, K. (2011). Drought Could Pose Problems for Texas Power Plants | The Texas Tribune. Retrieved May 15, 2014, from http://www.texastribune.org/2011/09/16/drought-could-post-problems-texaspower-plants/

GAO (2009). ENERGY-WATER NEXUS Improvements to Federal Water Use Data Would Increase Understanding of Trends in Power Plant Water Use ENERGYWATER NEXUS Highlights, (October).

GCEP. (2005). An assessment of carbon capture technology and research opportunities. Global Climate \& Energy Project. Stanford University. http://gcep.stanford.edu

Gerbens-Leenes, W., Hoekstra, A. Y., \& van der Meer, T. H. (2009). The water footprint of bioenergy. Proceedings of the National Academy of Sciences of the United States of America, 106(25), 10219-23. doi:10.1073/pnas.0812619106 
Gleick, P.H. (1992). Environmental Consequences of Hydroelectric Development: The Role of Facility Size and Type. Energy, Vol. 7(8): 735-747.

Gleick PH, (1993). Water in crisis: a guide to the world's fresh water resources. New York: Oxford Univ. Press.

Gleick, P.H. (1994). "Water and Energy." Annual Review of Energy and the Environment, 19: 267-99.

Groman, S., \& Reuters. (2014). California Drought Crisis: A \$5B Hit to the Economy. The Fiscal Times. Retrieved March 05, 2014, from http://www.thefiscaltimes.com/Articles/2014/02/06/California-Drought-PushesFarmers-Curtail-Crops

Grubert, E., Beach, F., \& Webber, M. (2012). Can switching fuels save water? A life cycle quantification of freshwater consumption for Texas coal- and natural gasfired electricity. Environmental Research Letters 7. 7045801 Retrieved May 07, 2014, from http://iopscience.iop.org/1748-9326/7/4/045801/pdf/17489326_7_4_045801.pdf

Grunwald, M., \& Eilperin, J. (2005). Energy Bill Raises Fears About Pollution, Fraud. Washington Post. Retrieved May 19, 2014, from http://www.washingtonpost.com/wpdyn/content/article/2005/07/29/AR2005072901128.html

Hanemann, W. (2006). The economic conception of water. Water Crisis: Myth or Reality. Retrieved from http://books.google.com/books?hl=en\&lr=\&id=zXThrKaavjcC\&oi=fnd\&pg=PA6 $1 \& d q=$ The+economic+conception+of +water\&ots=1sMqm7K5ow\&sig=94rp51Y_ mCrRqnqFICy7YmJDIxo

Healthgate Resources. (1998). Beverly Uranium Mine Environmental Impact Statement.

Hinrichs, R., \& Kleinbach, M. (2013). Energy Its Use and the Environment. (E. Dodd \& B. Kirksey, Eds.) (5th ed.).

Hoekstra, A.Y., Aldaya, M.M. and Avril, B. (eds.) (2011). Proceedings of the ESF Strategic Workshop on accounting for water scarcity and pollution in the rules of international trade, Amsterdam, 25-26 November 2010, Value of Water Research Report Series No. 54, UNESCO-IHE, Delft, the Netherlands.

Hsu, D. D., O’Donoughue, P., Fthenakis, V., Heath, G. a., Kim, H. C., Sawyer, P., ... Turney, D. E. (2012). Life Cycle Greenhouse Gas Emissions of Crystalline Silicon Photovoltaic Electricity Generation. Journal of Industrial Ecology, 16, S122-S135. doi:10.1111/j.1530-9290.2011.00439.x 
IEA. (2012). World Energy Outlook 2012. 978-92-64-18084-0

IEA \& OECD. (2014). Energy Policy Highlights.10.1787/9789264200630-en

IPCC. (2005). IPCC special report on Carbon dioxide Capture and Storage. Prepared by Working Group III of the Intergovernmental Panel on Climate Change [Metz, B., O. Davidson, H.C. de Coninck, M. Loos and L.A. Meyer (eds.)], Cambridge University Press, Cambridge, United kingdom and New York, NY, USA, 442 pp.

Jennejohn, D., Gawell, K., McCaull, J., Glassley, B., \& Brown, E. (2011). Energizing Southern California's Economy: The Economic Benefits and Potential for Geothermal Energy in Southern California (pp. 1-13).

Kagel, B. A., Bates, D., \& Gawell, K. (2007). A Guide to Geothermal Energy and the Environment, (April).

Kavalec, Chris and Tom Gorin, (2009). California Energy Demand 2010-2020, Adopted Forecast. California Energy Commission. CEC-200-2009-012-CMF

Keith, G., Jackson, S., Napoleon, A., Comings, T., \& Ramey, J. A. (2012). The Hidden Costs of Electricity

Kenny, J.F., Barber, N.L., Hutson, S.S., Linsey, K.S., Lovelace, J.K., and Maupin, M.A., (2009). Estimated use of water in the United States in 2005: U.S. Geological Survey Circular 1344, 52 p.

Kim, H. C., Fthenakis, V., Choi, J.-K., \& Turney, D. E. (2012). Life Cycle Greenhouse Gas Emissions of Thin-film Photovoltaic Electricity Generation. Journal of Industrial Ecology, 16, S110-S121. doi:10.1111/j.1530-9290.2011.00423.x

Klein, G., Krebs, M., Hall, V., O'Brien, T., \& Blevins, B. B. (2005). California 's WaterEnergy Relationship. doi:CEC-700-2005-011-SF

Komanoff Energy Associates, Greenpeace. (1992). "Fiscal Fission: The Economic Failure of Nuclear Power"

Kumar, A., T. Schei, A. Ahenkorah, R. Caceres Rodriguez, J.-M. Devernay, M. Freitas, D. Hall, Å. Killingtveit, Z. Liu. (2011). Hydropower. An IPCC Special Report on Renewable Energy Sources and Climate Change Mitigation [O. Edenhofer, R. Pichs-Madruga, Y. Sokona, K. Seyboth, P. Matschoss, S. Kadner, T. Zwickel, P. Eickemeier, G. Hansen, S. Schlömer, C. von Stechow (eds)], Cambridge University Press, Cambridge, United Kingdom and New York, NY, USA. 
LADWP. (2010). Urban Water Management Plan. Retrieved from https://www.ladwp.com/ladwp/faces/ladwp/aboutus/a-water/a-wsourcesofsupply?_afrLoop $=1118135795892709 \& \_a f r W i n d o w M o d e=0 \& \_a f r W i n$ dowId=b0zc2mn81_1\#\%40\%3F_afrWindowId\%3Db0zc2mn81_1\%26_afrLoop \%3D1118135795892709\%26_afrWindowMode\%3D0\%26_adf.ctrlstate\%3D4qvo0c4ni_4

LADWP. (2013). Power Integrated Resource Plan, (December).

LADWP (2013b). Appendix B: LADWP's Implementation Plan. Retrieved from http://www.waterboards.ca.gov/water_issues/programs/ocean/cwa316/docs/otc_ju ly2011/otc_a2sr_apxb.pdf

LADWP. (2013c). Haynes Generating Station Repowering Project. Retrieved May 19, 2014, from http://www.ladwpnews.com/external/content/document/1475/1346383/1/Haynes Fact Sheet.pdf

LADWP. (2013d). LOS ANGELES DEPARTMENT OF WATER AND POWER Financial Statements and Required Supplementary Information June 30, 2013 and 2012 ( With Independent Auditors ' Report Thereon ), 2012.

Land Letter. (2004). Western Power Plants Come Under Scrutiny as Demand and Drought Besiege Supplies; March 4, 2004; http://www.eenews.net/Landletter.htm

Laws, Edward A. (2000). Aquatic Pollution: An Introductory Text. New York: John Wiley and Sons. 978-0-471-34875-7

Macknick, J., R. Newmark, G. Heath, and K. Hallett, (2011). A Review of Operational Water Consumption and Withdrawal Factors for Electricity Generating Technologies. NREL Technical Report, NREL/TP-6A20-50900

Macknick, J., S. Sattler, K. Averyt, S. Clemmer, and J. Rogers. (2012). The water implications of generating electricity: Water use across the United States based on different electricity pathways through 2050. Environmental Research Letters 7; doi:10.1088/1748-9326/7/4/045803.

Maulbetsch, J. S., \& DiFilippo, M. N. (2006). Cost and value of water use at combinedcycle power plants. doi:CEC-500-2006-034

Mayeda, P., Riener, K., \& Pacific Gas \& Electric Company. (2013). Economic Benefits of Diablo Canyon Power Plant - An Economic Impact Study. Retrieved from http://www.pge.com/includes/docs/pdfs/shared/edusafety/systemworks/dcpp/PGE _Economic_Impact_Report_Final.pdf 
Mays, L. W. (2011). Water Resources Engineering (2nd Edition.). Wiley India Pvt. Limited. ISBN: 9788126531646

McAuley, S.D., and Kozar, M.D., (2006). Ground-water quality in unmined areas and near reclaimed surface coal mines in the northern and central Appalachian coal regions, Pennsylvania and West Virginia: U.S. Geological Survey Scientific Investigations Report 2006-5059, $57 \mathrm{p}$. http://pubs.usgs.gov/sir/2006/5059/pdf/sir2006-5059.pdf

Mekonnen, M.M. and Hoekstra, A.Y. (2011). The water footprint of electricity from hydropower, Value of Water Research Report Series No. 51, UNESCO-IHE, Delft, the Netherlands

Meldrum, J., Nettles-Anderson, S., Heath, G., \& Macknick, J. (2013). Life cycle water use for electricity generation: a review and harmonization of literature estimates. Environmental Research Letters, 8(1), 015031. doi:10.1088/1748$9326 / 8 / 1 / 015031$

Mielke, Erik, Diaz Anadon, Laura, and Narayanamurti, Venkatesth. (2010). "Water Consumption of Energy Resource Extraction, Processing, and Conversion, A review of the literature for estimates of water intensity of energy-resource extraction, processing to fuels, and conversion to electricity," Energy Technology Innovation Policy Discussion Paper No. 2010- 15, Belfer Center for Science and International Affairs, Harvard Kennedy School, Harvard University, October.

Morris, Gregg. (2014). Director of Green Power Institute. Personal Communication. July $7^{\text {th }}$.

Mudd, G. M., \& Diesendorf, M. (2008). Sustainability of uranium mining and milling: toward quantifying resources and eco-efficiency. Environmental Science \& Technology, 42(7), 2624-30. Retrieved from http://www.ncbi.nlm.nih.gov/pubmed/18505007

NETL. (2009). Estimating Freshwater Needs to Meet Future Thermoelectric Generation Requirements. National Energy Technology Laboratory; 2009, DOE/NETL$400 / 2009 / 1139$

NETL. (2010). Estimating Freshwater Needs to Meet Future Thermoelectric Generation Requirements 2010 update. National Energy Technology Laboratory 2010; DOE/NETL-400/2010/1339

NETL. (2010b) Life Cycle Analysis: Supercritical Pulverized Coal (SCPC) Power Plant DOE/NETL-403-110609 (Pittsburgh, PA: US Department of Energy, National Energy Technology Laboratory (NETL)) 
NETL. (2010c). NETL Life Cycle Inventory Data-Unit Process: Natural Gas Sweetening (Pittsburgh, PA: US Department of Energy, National Energy Technology

Laboratory (NETL))

NRDC. (2007). Coal in a Changing Climate, (February).

NREL. (2002). Fuel from the Sky, Solar Power's Potential for Western Energy Supply. National Renewable Energy Laboratory; NREL/SR-550-32160

Oak Ridge National Laboratory-U.S. Department of Energy (ORNL). (2011). U.S. billion-ton update: Biomass supply for a bioenergy and bioproducts industry. ORNL/TM-2011/224. Oak Ridge, TN.

Palmer, M. A. et al. (2010). Mountaintop Mining Consequences. Science. Vol. 327, January 2010, 148-149.

Patel, S. (2011). IEA: Global Power Demand to Surge 2.2\% Annually Through 2035 | POWER Magazine. Retrieved March 07, 2014, from http://www.powermag.com/iea-global-power-demand-to-surge-2-2-annuallythrough-2035/

Pfund, N. E., \& Walker, N. W. (2013). Ask Saint Onofrio : Finding What Has Been Lost in a Tale of Two Energy Sources, (August).

Pickert, K. (2014). Turning off the Tap - Even the governor can't convince Californians to take their drought seriously. Time Magazine. August $4^{\text {th }}$.

Raimondi, Peter. (2013) Desalination Plant Entrainment Impacts and Mitigation - Report to the State Water Board. Appendix 4. Review and Responses to Questions Concerning APF and Mitigation Fees

Reuters. (2009). Water Scarcity and Agriculture in California | West | United States | Epoch Times. The Epoch Times. Retrieved February 22, 2014, from http://www.theepochtimes.com/n2/united-states/water-scarcity-agriculturecalifornia-13633.html

Reyes, J. (2014). Production Engineer Supervisor, Calpine. Personal Communication. July $30^{\text {th }}$.

Richter, C., S. Teske, and R. Short, (2009). Concentrating Solar Power: Global Outlook 2009 - Why Renewable Energy is Hot. Greenpeace International, SolarPACES and ESTELA, 88 pp. Reprinted with permission from Greenpeace International. 
Rogers, J., K. Averyt, S. Clemmer, M. Davis, F. Flores-Lopez, P. Frumhoff, D. Kenney, J. Macknick, N. Madden, J. Meldrum, J. Overpeck, S. Sattler, E. SpangerSiegfried, and D. Yates. (2013).Water-smart power: Strengthening the U.S. electricity system in a warming world. Cambridge, MA: Union of Concerned Scientists. July.

Rogers, P. (2014). California Shuts Major Water Supply as Drought Worsens. Mercury News. January $31^{\text {st }}$.

Santa Rosa. (2014). Rate Table. City of Santa Rosa. Retrieved from http://ci.santarosa.ca.us/doclib/Documents/Rate Sheet Public.pdf

Schneider, K. (2008). U.S. Faces Era of Water Scarcity. Circle of Blue WaterNews. Retrieved April 02, 2014, from

http://www.circleofblue.org/waternews/2008/world/us-faces-era-of-waterscarcity/

Seyboth, K., Matschoss, P., Kadner, S., Zwickel, T., Eickemeir, P., Hansen, G., ... Von Stechow, C. (2012). Renewable energy sources and climate change mitigation: special report of the Intergovernmental Panel on Climate Change. Choice Reviews Online (Vol. 49, pp. 49-6309-49-6309). doi:10.5860/CHOICE.49-6309

Solley, W.B., R.R. Pierce, and H.A. Perlman. (1998). Estimated Use of Water in the United States in 1995. U.S. Geological Survey Circular 1200. Reston, Va.: U. S. Geological Survey.

Sovacool, B. (2008). "Valuing the Greenhouse Gas Emissions From Nuclear Power: A Critical Survey." Energy Policy, 36: 2940-2953.

Sovacool, B. and K. Sovacool. (2009). "Identifying Future Electricity-Water Tradeoffs in the United States.” Energy Policy, 37 (7): 2763-2773

Sovacool, B. K. (2013). The avian benefits of wind energy: A 2009 update. Renewable Energy, 49, 19-24. doi:10.1016/j.renene.2012.01.074

Stevens, P. (2012). briefing paper " Shale Gas Revolution ": Developments and Changes. Energy, Environment and Resources, EERG BP 2O(August).

Strzepek, K., Baker, J., Farmer, W., \& Schlosser, C. (2012). Modeling Water Withdrawal and Consumption for Electricity Generation in the United States, (222). Retrieved from http://dspace.mit.edu/handle/1721.1/71168

Thomsen, F., Lüdemann, K., Kafemann, R. and Piper, W. (2006). Effects of offshore wind farm noise on marine mammals and fish, biola, Hamburg, Germany on behalf of COWRIE Ltd. 
Tolba, M.K. (1985). The Environmental Impacts of Production and Use of Energy. Part IV - the Comparative Assessment of the Environmental Impacts of Energy Sources, Phase 1 - Comparative Data on the Emissions, Residuals and Health Hazards of Energy Sources. Energy Report Series ERS 14-85 (Nairobi: United Nations Environment Programme)

Torcellini, P., Long, N., \& Judkoff, R. (2003). Consumptive Water Use for U.S. Power Production, (December). Retrieved from http://www.nrel.gov/docs/fy04osti/33905.pdf

Tracy, B. (2014). Lake Mead is shrinking - and with it Las Vegas' water supply. CBS News. Retrieved June 04, 2014, from http://www.cbsnews.com/news/lake-meadis-shrinking-and-with-it-las-vegas-water-supply/

TWDB. (2003) Power Generation Water Use in Texas for the Years 2000 Through 2060: Final Report (Austin, TX: TexasWater Development Board (TWDB))

U.S. Army Corps of Engineers Detroit District. (2013). Great Lakes Update. Great Lakes Update. Volume 198

U.S. Census Bureau. World Population Clock. http://www.census.gov/popclock/

Union of Concerned Scientists. (2012). Biomass Resource Assessment. Union of Concerned Scientists. Retrieved April 03, 2014, from http://www.ucsusa.org/assets/documents/clean_vehicles/Biomass-ResourceAssessment.pdf

U.S. Department of the Interior, Bureau of Reclamation. (2012). Colorado River Basin Water Supply and Demand Study.

Vattenfall. (2010). Vattenfall Wind Power Certified Environmental Product Declaration EPD® of Electricity from Vattenfall's Wind Farms. 02-01-2010. http://www.vattenfall.com/en/file/Certified_Environmental_Product_Declaration_ of_Electricty_from_Vattenfall_s_Windfarms_2010_12180312.pdf

Water in the West. (2013). Water and Energy Nexus : A Literature Review. Retrieved from http://waterinthewest.stanford.edu/sites/default/files/WaterEnergy_Lit_Review.pdf

Weaver, E. (2013). Energy Could Be Twice as Thirsty by 2035 - EBN: 22:4. buildinggreen.com. Retrieved March 05, 2014, from http://www.buildinggreen.com/auth/article.cfm/2013/3/15/Energy-Could-BeTwice-as-Thirsty-by-2035/ 
West, L. (2014). Water - Is Water Now More Valuable Than Oil? Retrieved April 22, 2014, from http://environment.about.com/od/globalwarming/a/waterinvesting.htm

Wilson, W., Leipzig, T., \& Griffiths-Sattenspiel, B. (2012). Burning Our Rivers The Water Footprint of Electricity. A River Network Report. Portland, Oregon.

World Business Academy, (N.D). Diablo Canyon Threatens to Gut California's "Once Through Cooling" Policy, Background PG\&E efforts to undermine State Marine Environment Protection Policy. http://worldbusiness.org/wpcontent/uploads/2014/08/Diablo-Canyon-CA-Once-Through-CoolingOverview.pdf

World Wildlife Federation, First Solar, 3TIER, \& Fresh Generation. (2012). Solar PV Atlas: Solar Power in Harmony with Nature.

York, R., Foster, M., Davis, N., Schoonmaker, J., Unsworth, R., Holmes, C., ... McKinney, J. (2005). Issues and Environmental Impacts Associated with OnceThrough Cooling at California's Coastal Power Plants. CEC-700-2005-013 